\title{
Catalog of scaled verbal material
}

\author{
ALAN S. BROWN \\ Southern Methodist University, Dallas, Texas 75275
}

\begin{abstract}
A total of 172 studies presenting information on scaled verbal material (letters, CVCs, words, etc.) were summarized and indexed. For each study, the following information was abstracted: kind of materials, type and number of subjects, task, and data presentation format. These studies were indexed according to the type of materials scaled and, within material type, by type of scale information (objective information, subjective rating, or subject production). All studies were from a readily accessible English language source.
\end{abstract}

The following is designed to be a reference manual for researchers in all areas involving verbal processes, including learning, memory, linguistics, psycholinguistics, mental assessment, etc. It contains a summary collection of publications where verbal materials have been classified along either objective (e.g. frequency of written occurrence) or subjective (e.g. . rating of "goodness") dimensions.

\section{Criteria for Inclusion}

This collection includes only those studies which met all of the following criteria: (1) A differentiation of materials was made along some dimension. (2) A partial or complete listing of the materials (along with scale values) was presented. (3) The published form is in a readily accessible English language source (excluding technical reports, mimeos, etc.). (4) The study used English speaking subjects (or researchers, where objective information was compiled).

Those studies in which different levels of previously differentiated items were used in some task (such as high meaningfulness CVC stimuli in paired-associate learning) were not included. In studies where words were used, only those using English were included. Finally, an attempt was made to survey all major English language journals and publications through 1974, in a search for the scaling studies.

\section{Organization of Catalog}

The first section consists of a classification of the studies according to the type of material examined (trigrams, words, letters, etc.) and, under each material type, the procedure used. The procedures fall into three general classes:

Objective information. This usually involved an objective measurement, or count, of some aspect of the material (e.g., frequency of written occurrence).

I would like to express my sincere appreciation to Benton J. Underwood for his invaluable assistance at all stages of this project. I am also grateful to Arthur W. Melton. Gregory A. Kimble. Clifford T. Morgan. and Rudolph W. Schulz for their assistance in finding an appropriate outlet for this publication.
Subjective rating. This included tasks where the subjects placed material along points on a psychological scale (e.g., ease of pronunciation).

Subject production. This covered situations where the material served as a stimulus for the subject to respond to directly, producing an original response (e.g., single-word free association).

The second section includes an alphabetical listing of all studies, with the following information on each:

Stimulus materials. The general class of items scaled.

Subjects. The number and location (university) of the subjects; unless otherwise noted, subjects were college undergraduate students.

Task. The procedure followed by the subjects (rating or production) or the researchers (collecting objective information). NOTE: In cases where objective information was gathered, sections Subjects and Task were sometimes omitted.

Data. The type of information presented on the stimulus materials, as well as other types of relevant descriptive and comparative statistics (actual data not given); an attempt was made to list the data in the order in which it was presented in the article, as well as include notations and abbreviations used, to facilitate direct reference to the original article

\section{Use of Catalog}

Each study was given a number, according to its position in the alphabetical compilation. This number was used to classify it in the first section under the appropriate topic.

To illustrate, if one wanted to find a list of CVCs rated on pronounceability, that person would look first under "Trigrams-CVC," then under "Subjective rating," and finally locate "Pronounceability." The outline index shows six studies where such ratings have been made: numbers $10,55,117,149,150$, and 165. The researcher would then turn to these studies listed in the second section to find out more information about type of stimuli, procedures, etc.

Many of the studies were multiply listed in the index in order to provide a complete categorization of 
all studies. For example, Tulving, McNulty, and Ozier (1965), study number 163 , used two-syllable nouns as stimuli. Therefore, it was listed under Dissyllables-Words, Words-General, and Words
-Nouns. Whenever another article is cited in the summary of a study, the reference may be located either (a) as another catalogued study or (b) in the reference section at the end.

\section{OUTLINE INDEX}

\section{Objective Information}

\section{SOUNDS}

Distinctive feature difference: 140

Frequency of occurrence (oral): 45

Frequency of occurrence (written): 19, 157, 168

Frequency of occurrence (oral and written): 31

\section{Objective Information}

\section{PUNCTUATIONS}

Frequency of occurrence (written): 31

\section{Subjective Rating}

\section{NUMBERS}

Number of associations: 12

\section{LETTERS}

\section{Objective Information}

Frequency of occurrence (proper names only): 13

Frequency of occurrence (technical terms only): 13

Frequency of occurrence (written): 8, 99, 165

Frequency of occurrence (written and oral): 31,32

Generated meaningfulness (averaging meaningfulness values for all CVCs with that letter in it): 121

\section{Subjective Rating}

Frequency of occurrence (written): 8

Imagery (visual): 16

Preference: 60,104

Whether it came from pleasant or unpleasant word: 5

\section{Subject Production}

Continued-word free association: 4

Frequency of occurrence at each position of CVCs generated by subjects: 116

Guesses of letters in a set of unknown cards: 8

Single-letter free association: 3, 84

Single letter most likely to follow in language: 84 , 165

Single letter most likely to follow when at beginning of word: 165

Single-word free association: 4

\section{Objective Information}

\section{BIGRAMS}

Frequency of occurrence (oral): 9

Frequency of occurrence (proper names only): 13

Frequency of occurrence (technical terms only): 13

Frequency of occurrence (written): 7, 9, 99, 111, 165

Subjective Rating

Imagery (visual): 16
Subject Production

Single-letter free association: 3

Single letter most likely to follow in language: 165

\section{Objective Information}

TRIGRAMS-CVC

Frequency of occurrence (written): 100, 165

Subjective Rating

Goodness: 73

Imagery (visual): 16

Number of associations: 115, 119, 120

Physical effort to silently pronounce: 150

Pronounceability: 10, 55, 117, 149, 150, 165

Whether a word or not: 6,143

\section{Subject Production}

Associative latency: 71

Continued-word free association: 96, 146, 147

Pronunciation latency: 122

Single association (one or more words): 50, 59, 64, $82,159,165$

Single coding cue (for learning): 141

\section{Objective Information}

\section{TRIGRAMS-CCC}

Acoustic confusability: 142

Frequency of occurrence (written): 100, 165

Subjective Rating

Imagery (visual): 16

Number of associations: 26

Pronounceability: 165

Subject Production

Single free association (one or more words): 59, 165,170

\section{TETRAGRAMS}

\section{Objective Information}

Frequency of occurrence (written): 101

\section{Subjective Rating}

Imagery (visual): 16

\section{Subjective Rating}

\section{PENTAGRAMS-CVCVC}

Number of associations: 91

Pronounceability: 88

Subject Production

Associative latency: 88, 156

Continued-word free assocation: 88

Single-word free association: 156 


\section{PENTAGRAMS-NONWORDS (PARALOGS)}

Objective Information

All letter combinations which can be made into word(s): 124

Frequency of occurrence (written): 102

Subjective Rating

Number of associations: 91

Pronounceability: 88

Subject Production

Associative latency: 88

Continued-word free association: 88

\section{PENTAGRAMS-WORDS \\ Objective Information}

All words which can be made into other five-letter words: 124

All words which cannot be made into other fiveletter words: 124

Frequency of occurrence (written): 102

Subjective Rating

Number of associations: 91

Orthographic distinctiveness: 172

Pronounceability: 88,172

Subject Production

Associative latency: 88,156

Continued-word free association: 88

Single-word free association: 156

\section{Objective Information}

\section{OCTAGRAMS}

Computer-generated letter sequences (based on actual frequency of occurrence): 57

Generated letter sequences based on text search: 103,107

\section{Objective Information}

\section{DECAGRAMS}

Computer-generated letter sequences (based on actual frequency of occurrence): $\mathbf{5 7}$

\section{Objective Information}

\section{MONOSYLLABLES-NONWORDS}

Frequency of occurrence (written and oral): 31

\section{Objective Information}

\section{MONOSYLLABIES-WORDS}

Frequency of occurrence (written and oral): 31

Subjective Rating

Number of associations: 24

Subject Production

Single-word free association: 49

\section{Subjective Rating}

\section{DISSYLLABLES-NONWORDS}

Emotionality: 114

Familiarity: 113

Subject Production

Continued-word free association: 112, 118, 165

\section{Subjective Rating}

\section{DISSYLLABLES-WORDS}

Emotionality: 114

Familiarity: 113

Imagery (visual): 163

Number of associations: $24,148,163$

Pleasantness: 148

Subject Production

Continued-word free association: 112, 118, 133, 165

Single-word free association: 133

\section{Subjective Rating}

TRISYLLABLES-WORDS

Number of associations: 24

\section{Subjective Rating}

\section{PSEUDOWORDS}

Pronounceability: 48

\section{WORDS-CONCEPTUAL CATEGORIES \\ Subjective Rating \\ Familiarity with instances: 14}

Number of associations to category name: 11, 66

Subject Production

Continued-word instance production: $11,58,66$, 92,145

Single-word associative latency: 93

Single-word free association to response(s) given to category name: $28,47,98$

\section{Objective Information}

\section{WORDS-NOUNS}

Frequency of occurrence (oral): 45

\section{Subjective Rating}

Age of acquisition: 21

Concreteness: $51,129,153$

Evaluation (positive-negative): 53

Frequency of personal use: 162

Frequency of public use: 162

Imagery (visual): 127, 129, 163

Number of associations: 148,163

Pleasantness: 148

Pronounceability: 153

Quantification: 77

Specificity: 153

Subject Production

Associative latency: 156

Category to which it belongs: 94

Continued-word free association: 105, 127, 129, $133,139,153$

Dominant single sensory impression: 164

Single-word adjective association: 33

Single-word free association: 125, 133, 156

\section{Objective Information}

WORDS_VERBS

Frequency of occurrence (oral); 45 


\section{Subjective Rating}

Evaluation (positive-negative): 53

Frequency of occurrence: 90

Imagery (enactive): 90

Impression value (good-bad): 35

Quantification: 1, 77

\section{Objective Information}

\section{WORDS-ADJECTIVES}

Frequency of occurrence (oral): 45

\section{Subjective Rating}

Favorableness: 25,89

Goodness: 42

Pleasantness: 61

Potency: 42

Surprisingness: 42

Subject Production

Continued-word free association: 23

Single-word free association: 29

\section{Objective Information}

WORDS-ADVERBS

Frequency of occurrence (oral): 45

Subjective Rating

Favorableness: 25,89

Quantification: 61

\section{Subject Production}

WORDS-HOMOGRAPHS

Single-word free association: 27

\section{Subject Production}

WORDS-HOMOPHONES

Single-word free association: 44

\section{Subjective Rating \\ Imagery (visual): 128}

WORDS-NOMINALEATIONS

\section{Subjective Rating}

\section{WORDS_COLOR}

Number of associations: 152

Semantic differential: 169

\section{Subject Production}

Continued-word free association: 152

\section{Objective Information}

\section{WORDS-GENERAL}

Date of first recorded written use: 126

Five-letter words which can and cannot be made into other five-letter words: 124

Frequency of occurrence (oral): 45, 63, 76

Frequency of occurrence (written): 45, 83, 95, 97 , $102,108,156,167$

Frequency of occurrence (written and oral): 31,45

\section{Subjective Rating}

Age of acquisition: 21, 155

Concreteness: 17, 34, 51, 129, 153

Emotionality: 17, 34, 87, 114
Evaluation (positive-negative): 53

Familiarity: 14, 113, 134, 155

Favorableness: 25,89

Frequency of occurrence: 20,90

Frequency of personal use: 162

Frequency of public use: 162

Goodness: $17,35,42,73,74,154$

Hostility: 18

Imagery (auditory): 15

Imagery (enactive): 90

Imagery (visual): $15,34,127,128,129,155,162$, 163

Liking (in reference to food): 75

Number of associations: $11,17,24,66,91,148$, $152,162,163$

Orthographic distinctiveness: 172

Pleasantness: $17,61,148$

Potency: 42

Preference: 86

Pronounceability: 88, 153, 172

Quantification: 1, 61, 77

Semantic differential: $34,56,67,69,169$

Specificity: 153

Surprisingness: 42

Which of two words goes best: 39

Which of two words is the most likely free associate: 54

\section{Subject Production}

Associative latency: 87, 88, 93, 156, 166

Category to which word belongs: 94

Continued-word free association: $23,36,46,70,72$, $74,88,105,112,118,127,129,133,139,146$, $147,152,153,155,165$

Continued-word restricted association: $11,33,58$, $66,92,145$

Dominant single sensory impression: 164

Emotionality (inferred from response patterns): 65

Galvanic skin response: 87

Give opposite: 22

Produce sentence to fit word: 40,41

Produce words which could substitute in a sentence: 40,41

Single-word free association: $22,27,28,29,30,37$, $38,39,40,41,44,46,47,49,54,62,68,78,79$, $81,85,87,98,109,123,125,130,131,132,133$, $136,137,138,144,156,160,161,171$

Tapping out activity dimension: 151

\section{Subjective Rating}

\section{PAIRS-CVC}

Ease of learning: 135

Similarity: 135

\section{Subject Production}

Associative connection: 110

\section{Subjective Rating}

\section{PAIRS-CCC}

Ease of learning: 135

Similarity: 135 
Subjective Rating

\section{PAIRS-WORDS}

Closeness of association: 29, 52

Ease of learning: 135

Familiarity: 52

Favorableness: 25

Pleasantness: 61

Probability of co-occurrence: 43

Similarity of meaning: $43,52,59,135$

Vividness of connotation: 52

\section{Subject Production}

Classing opposites: 53

Single-word free association: 2

\section{Subject Production}

\section{WORD STRINGS}

Order of approximation of English text: 106
Subjective Rating

\section{SENTENCES}

Concreteness: 80

\author{
Subjective Rating \\ PHRASES \\ Liking (adjective phrases): 75
}

\section{SPECIAL SUBJECT TYPES}

Children and adolescents: 2, 3, 22, 23, 33, 34, 37, $39,81,105,130,131,132,146,147,171$

Mental patients: $74,97,136$

Prisoners: 143

\section{CATALOG}

1

Abelson, R. P.. \& Kanouse. D. E. Subjective acceptance of verbal generalization. In S. Feldman (Ed.), Cognitive consistency. New York: Academic Press. 1966.

Stimulus Materials

\section{Study I}

36 generic assertions, formed from various combinations of 6 subjects, 6 verbs, and 6 objects (i.e., "Artists avoid magazines"). Subject:

32 (Yale University).

Task

Each subject rated both the subject and object of each assertion on a 6-point implicit quantifier scale (one or two, a few, some many, most, or all)

Data

(1) Listing of all 18 critical words (6 subjects. verbs, and objects) with the mean rating for both subject and object across all sentences using that word.

(2) Scatter plots of agreement proportions vs. mean scale rating, separately for subject, object, and verb words.

\section{Stimulus $M$}

\section{Study III}

Subjects

Task

25 (Yale University).

Each subject rated each of 126 items on a questionnaire consisting of 6 presentations of each of 21 verbs: 3 times in inductive and 3 times in deductive forms (using the same 3 subject-object pairs for both inductive and deductive forms); the rating scale was the same one used in Study II (implicit quantifier). Data

(1) Listing of all 21 verbs, with the following for each: (a) mean object quantifier rating: (b) agreement proportions for occurrences in the inductive form; and (c) agreement proportions for occurrences in the deductive form.

(2) Scatter plot of agreement proportions vs. mean scale rating for verbs from Studies II and III.

(3) Scatter plot of agreement proportions based on evidence from instances vs. agreement proportions based on evidence from qualities.
Amster, H. Convergent association norms for 10-year-old children and college age adults. Psychonomic Monograph Supplements, 1967, 2(Whole No. 17), 1-32.

\section{Children's Norms}

\section{Stimulus Material}

112 word pairs; the two words in each pair contained one or more common responses in the Palermo and Jenkins (1964) norms for children.

Subjects

252 10-to-11-year-old children from 5th and 6th grades in Berkeley and San Lorenzo schools.

Task

One-word written response to each of 112 pairs; self-paced, but encouraged to work rapidly; pairs were presented in each order (e.g., black-white, white-black) an equal number of times, but each subject received only one order.

Date

Separate listing of all 112 pairs; after each pair was an alphabetical listing of all single-word responses which were (a) common to both words in Palermo and Jenkins and (b) occurred in the present study with a frequency of greater than one. For each of these single-word responses, the following information was given:

(1) Frequency when the first-listed stimulus was presented first in the pair.

(2) Frequency when the second-listed stimulus was presented first in the pair.

(3) Total frequency of response.

(4) Frequency of that response to first stimulus of the pair in the Palermo and Jenkins norms.

(5) Frequency of that response to second stimulus of the pair in the Palermo and Jenkins norms.

\section{Stimulus Materials}

\section{Adult Norms}

67 word pairs; the two words in each pair contained one or more common responses in the Palermo and Jenkins norms for adults. Subjects

252 (University of California at Berkeley).

Task

Same as for children.

\section{Data}

Same presentation format as for children. 


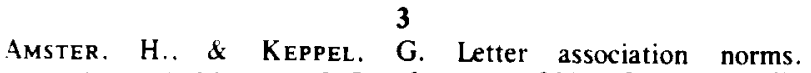
Psychonomic Monograph Supplements, 1966, 1(Whole No. 9). 211-238.

\section{Stimulus Materiab}

(1) All letters of the alphabet (26).

(2) All possible two-letter combinations (676)

Subjects

408 2nd grade children; 2045 th grade children Tank

Give a single-letter response to each stimulus, whether it is a single or double letter stimulus; all fifth graders responded to every stimulus (702), but the second graders each responded to only half of the stimuli (resulting in 204 subjects responding to each stimulus from each grade level).

Data

The following information was given separately for each grade level:

(1) Alphabetical listing of all single letters, with the frequency with which each of the letters (including itself) was given as a response to it. as well as the frequency of no response ("blank").

(2) Alphabetical listing of all two-letter combinations. with the frequency with which each of the letters was given as a response to it, plus no response frequency.

\section{4}

ANDERSON. N. S. Word associations to individual letters. Journa! of Verbal Learning and Verbal Behavior, 1965, 4. $541-545$.

\section{Stimulus Material}

26 letters of the alphabet, in both upper and lower case.

Subjects

218 (University of Maryland).

Task

Continued association. 75 subjects responded to each lowercase letter for $60 \mathrm{sec}$ each; 73 subjects responded to each uppercase letter for 60 sec each.

Single association. 70 subjects responded twice to each letter of the alphabet. once as upper- and once as lowercase, with a singleword free association response.

Data

(1) Alphabetical listing of all letters with the following for each: (a) average number of continued associations $(m)$, and standard deviations for upper case; and (b) same information for lower case.

(2) Analysis of rating changes across thirds of the rating order.

(3) Correlation between $m$ for upper and lower case.

(4) Intercorrelations among the following measures: (a) $m$ for upper case; (b) $m$ for lower case; (c) number of words beginning with that first letter, from Thorndike and Lorge (1944); (d) vocal reaction time, from Fitts and Switzer (1962); (e) letter preferences, from Horton and Mecherikoff (1960); (f) frequency of the letter in the initial position in names, from Bourne and Ford (1961); (g) frequency of the letter in names (all positions), from Bourne and Ford; (h) frequency of the letter in the initial position of words, from Bourne and Ford; and (i) frequency of the letter in words (all positions), from Boume and Ford.

(4) Alphabetical listing of all letters, with the most common response, and $\mathbf{N}$ for each of the following classes: (a) single association-upper case, (b) single association-lower case, (c) first response for continued association (most common)-upper case, and (d) first response for continued association (most common)-lower case.

\section{5}

ANisfeld, M. Subjective approximation of relative letter incidence in pleasant and unpleasant English words. Journal of Verbal Learning and Verbal Behavior, 1968, 7, 33-40.

\section{Word Rating}

\section{Stimulus Materiab}

1,490 words, from published sources as well as generated by authors.

Subjects

20 (Cornell University).
Task

Subjects rated either a set of 1.150 words $(N=10)$ or a set of 340 words $(\mathbf{N}=10)$ on a 3-point pleasantness scale (pleasant, neutral, unpleasant)

\section{Stimulus Materials}

\section{Letter Rating}

All 26 letters of the alphabet.

Subjects

Students at Cornell University (number unspecified). Taik

Guessing task. Each subject was told that ". . . two equally large groups of words had been chosen from a dictionary. One group contained 'pleasant words-words which have pleasant connotations, which bring pleasant thoughts, associations, and memories to mind'.... The other group contained 'Unpleasant words'.... The instructions further explained that one letter was picked randomly from each word and S's task was to guess whether the letter belonged to a P or to a U word."

Frequency estimation task. After the guessing task, the same subjects were ".... asked to estimate, on a 5-point scale, for each letter of the alphabet whether it occurred with greater or lesser frequency in $\mathrm{P}$ or $\mathrm{U}$ words."

Data

(1) Alphabetical listing of 26 letters of the alphabet, with the following for each from the word rating task: (a) proportion of time it was the initial letter in a $P$ word; (b) proportion of time it was the initial letter in a $U$ word; (c) $Z$ value for the difference between " $a$ " and " $b$ "; (d) proportion of time it was in any position in a $P$ word; (e) proportion of time it was in any position in a $U$ word; (f) $\mathrm{Z}$ value for the difference between " $\mathrm{d}$ " and "e."

(2) Alphabetical listing of 26 letters of the alphabet, with the following for each from the letter rating task: (a) proportion of time it was judged as from a $\mathbf{P}$ word when in the initial position on the card; (b) proportion of time it was judged as from a $U$ word when in the initial position; (c) proportion of time it was judged as from a $\mathbf{P}$ word, overall; (d) proportion of time it was judged as from a $\mathbf{U}$ word, overall.

- (3) Statistical comparisons of proportions judged $P$ and $U$, for letter rating.

(4) Examination of effects of P-U variable with frequency of occurrence separated out.

(5) Correlations: (a) number of letters in the word and pleasantness rating; and (b) number of letters in the word and frequency of the word.

(6) Partial correlation between pleasantness and word length, with frequency of the word held constant.

(7) Alphabetical listing of all 26 letters of the alphabet, with the following for each: (a) mean guessing score-number of times a letter was guessed as coming from a $\mathbf{P}$ word (out of $\mathbf{3}$ presentations): and (b) mean estimation score-rating of whether the letter occurred more often in a $\mathbf{P}$ or $\mathbf{U}$ word.

(8) Rank-order correlation between guessing and estimation scores.

(9) Examination of whether the subjects had any overall bias toward $U$ or $P$ ratings.

(10) Relationship between performance on the guessing task and performance on the word rating task.

Archer, E. J. A re-evaluation of the meaningfulness of all possible CVC trigrams. Psychological Monographs, 1960, 74(Whole No. 497).

Stimulus Materials

“. . . all possible three-letter combinations of the Roman alphabet of the form consonant-vowel-consonant, with the restrictions that the two consonants are different and neither is a $y$ when $y$ is the vowel"; 2,480 total trigrams.

Subjects

335 (University of Wisconsin).

\section{Task}

Subjects made "yes-no" judgments for each of approximately 2,670 CVCs, indicating for each item whether it was meaningful 
subjects responded "yes" if an item (a) was thought to be a word. (b) reminded them of a word, (c) sounded like a word, or (d) could be used in a sentence; otherwise, they responded "no." Data

(1) Alphabetical listing of all CVCs with association value (AV) for each, determined by percent of subjects responding "yes."

(2) Comparable data from Glaze (1928) and Krueger (1934),

(3) Items for which AV differed as a function of subject's sex.

(4) Test-retest reliability of AV for repeated CVCs.

(5) Correlations between present study. Glaze, and Krueger on the range of $\mathrm{AV}$.

7

AtKins, R. E. An analysis of the phonetic elements in a basal reading vocabulary. Elementany School Journal, 1926. 26. 5\%-606.

Stimulos Materials

38 common bigrams. plus "final e" and "final y" (which occur at the end of a word).

Tank

A tally of the occurrence of these 40 letters and bigrams in 2,500 most frequently occurring words. as compiled by Thorndike (1921). Data

(1) Listing of 40 letters and bigrams, with the following for each: (a) number of phonetic occurrences (phonetic $=$ most common pronunciation); (b) number of unphonetic occurrences (unphonetic $=$ noncommon pronunciations); and (c) total number of occurrences.

(2) Graphical representation of information in (1), separately for each letter and bigram.

(3) Listing of $\mathbf{4 0}$ letters and bigrams, in decreasing order of "final score." with the following for each: (a) key word example of a word with the most common pronunciation of that stimulus; (b) "final score" -weighting of the phonetic occurrences with a positive value and weighting of the unphonetic occurrences with a negative value, to obtain an overall weighted sum; and (c) rank among the bigrams and letters, according to the weighted. or final. score.

8

Attwenve, F. Psychological probability as a function of experienced frequency. Journal of Experimental Psychology. 1953. 46. $81-86$.

Stimulus Material

All 26 letters of the alphabet.

Subject:

204 airmen basic trainees at Lackland Air Force Base.

Taak

Frequency judgment $(\mathrm{N}=90)$. Each subject judged "... how often. on the average. you think each letter would appear in a sample of reading matter ... with a total of a thousand letters in it."

Guessing group $A(\mathbf{N}=38)$. Each subject guessed what letter each of 100 cards had on it; "Here on the table is a sealed package with 100 small cards in it. Each one of these has some letter ... printed on it.... You are to try to guess, one by one, what these letters are-without every seeing the cards."

Guessing group $B(\mathbf{N}=38)$. Same as the above instructions, plus the statement that the letters occur with about uniform frequencies in the deck.

Guessing group $C(\mathrm{~N}=38)$. Same as instructions for $\mathrm{A}$, plus the statement that "... on the average any particular letter will come up just about as often ... as it does in ordinary reading matter."

Letter frequency count (by authors). Count of written frequency of each letter in 10,341 letters sampled from magazines and newspapers.

Data

(1) Alphabetical listing of all 26 letters with the following for each: (a) frequency in English text count. (b) mean judged frequency; (c) mean group A value; (d) mean group $B$ value, and (c) mean group $\mathrm{C}$ value.

(2) Overall sum. standard deviation. and (1.000 X standard deviation) sum for each of the 5 measures mentioned above.
(3) Correlation between magazine and newspaper frequencies for the letters.

(4) Intercorrelations among 6 measures: 5 listed under 1 plus alphabetical order ranking.

(5) Reliability correlations for 6 measures in 4

(6) Graphical comparison of mean judged frequency and English text frequency. plus a statistical test.

(7) Generation of linear regression function for information in 6 above after a $\log$ transformation.

Baddelay, A. D., Conrad, R., \& Thompson, W. E. Letter structure of the English language. Nature, 1960, 186, 414-416.

\section{Stimnlm Material}

Written material. All words in the editorial columns of The London Times newspaper for $S$ successive days.

Spoken material. Text of British Broadcasting Corp. radin serial "Mrs. Dale's Diary" over 5 successive days. Data

(1) Alphabetical listing of all 26 letters of the alphabet, plus "space," in a matrix form, with the frequency with which every letter or a blank space followed it for written material.

(2) Same analysis as above, except for oral material.

\section{0}

Badia. P.. Rosenherg, B. G., \& Langer, J. Representational value, meaningfulness, and pronounciability in serial learning. Psychological Reports. 1965. 16. 997-1000.

\section{Stimulun Material}

100 CVCs taken from Nobel (1961) and varying in $m^{\prime}$ values. Sabject

75 (Bowling Green State University)

Taek

Rate each of the $100 \mathrm{CVCs}$ on a 9-point pronounceability scale, using Underwood and Schulz (1960) technique.

Data

Mean and stand ard deviation of pronounceability $\left(p^{\prime}\right)$ ratings for 36 of the 100 CVCs.

11

Battig. W. F. \& Montague, W. E. Category norms for verbal items in 56 categories: A replication and extension of the Connecticut category norms. Joumal of Experimental Psychologv Monograph, 1969. 804No. 3, Pt. 2), 1-46.

Stimulus Materials

43 conceptual categories from the Connecticut norms (Cohen, Bousfield. \& Whitmarsh. 1957) plus 13 added categories (56 total). Subjects

Production task. 270 (University of Maryland), and 172 (University of Illinois).

Rating task. $20^{-}$(University of Maryland).

Task

Production. Experimenter spoke each category name twice (in person or on tape) in a row to the groups of subjects. following which the subjects were allowed $30 \mathrm{sec}$ to write down all the instances of that category which they could think of; all subjects were presented with all 56 categories.

Rating. Subjects rated, on a 1-to-7 scale $(1=$ none, $4=$ average, $7=$ very many), the number of category members they thought they could identify. without actually trying to mentally count the members.

Data

(1) Listing of each category (56) with all the responses listed below it. in order of decreasing total frequency (alphabetically listed within frequency level). The following information was given for each response: (a) total frequency. combining both samples $(\mathbf{N}=$ 442): (b) frequency with which the response was a primary (tirst-given) one; (c) frequency in the Illinois sample $(N=172)$; (d) frequency in the Maryland sample $(\mathbf{N}=270)$; (e) mean rank position of listing of the response in the response sequence of each subiect in the Maryland sample who gave that particular response. (NOTE: Respinses with a total frequency of 9 or less are listed as a group. with no specitic information given on items $c$. $d$, or e above.) 
(2) Listing of all 56 categories, in order of decreasing correlation between Maryland and Illinois responses, with the following information on each: (a) correlation of the Maryland and Illinois frequencies for all responses given at least $S$ times in one of the two samples; (b) correlation of frequency and output rank for the Maryland sample, including all responses with a frequency of 5 or more; (c) mean total number of responses (summed across samples); and (d) mean rated frequency.

\section{2}

Battig, W. F., \& Spera, A. J. Rated association values of numbers from 0-100. Journal of Verbal Learning and Verbal Behavior. 1\%2, 1. 200-202.

Stimulus Materials

Numbers 0 through 100.

\section{Subjects}

Task

5 (University of Virginia).

"Rate numbers as to how many different things or ideas are associated with the number, and how difficult it is to think of these associations $s^{\circ}$ by circling one of five letters (A.E) on a line to the right of each number."

Data

(1) Listing of all numbers, in order, with mean and SD of ratings for each.

(2) Correlation with Anderson (1961). who obtained mean frequencies of continued associations $(60 \mathrm{sec})$ to each single-digit number. .

(3) Correlation with Battig (1962), who had subjects write down single word association to each number.

(4) Correlation with PA performance where 2-digit numbers were responses (excluding doubles and ones ending in zero) from Battig (1962) and Battig and Brackett (1961).

\section{3}

Bourne, C. P., \& Ford, D. F. A study of the statistics of letters in English words. Information and Control. 1961. 4, 48-67.

Stimulus Materials

(1) 2,082 subject names: single-word descriptors which were used to index a collection of technical documents at the Stanford Research Institute (i.e., magnetic, optical, etc.)

(2) 8,207 proper names: names of students from 1959 student registration lists at Stanford University (considering up to a maximum of 22 letters).

Data

(1) The following rankings of single letters, in decreasing order of frequericy (no specific values given): (a) frequency as initial letter in text material, separately for 5 studies (including the present one); (b) frequency as initial letter in proper names, separately for 3 studies (including the present one); and (c) overall frequency in text. separately for 5 studies (including present one), as well as in proper names.

(2) Alphabetical listing of all 26 letters of the alphabet along with the following for each: (a) percent occurrence in subject words (summed over positions) presented graphically, plus rank among letters; and (b) same analysis as above, except for proper names.

(3) Alphabetical listing of all 26 letters of the alphabet along with the following for each: (a) percent occurrence at each of the first 10 positions (plus rank among letters) of subject words; and (b) same analysis as above, except for proper names.

(4) Listing of the 30 most common bigrams, in decreasing order of frequency (summed across all positions), separately for 6 studies on textual material (including the present study) plus proper names.

(5) Listing of all possible bigrams, in matrix form (all 26 letters across the top and down the side) with the frequency per 10,000 bigrams (summed over all positions) for each combination, plus frequency with which it was followed by a space, for subject words.

(6) Same as (5), except for proper names.
(7) Listing of all possible bigrams, in matrix form, with the rankirg of each combination (1 through 440) on the basis of frequency lincluding the letter-space combination) for subject words.

181 Same as (7), except for proper names.

(9) Frequency distribution of subject word lengths.

(10) Frequency distribution of proper name lengths.

\section{4}

Bowen, J. H. Familiarity scale values for 420 nouns in twelve combinations of frequency of occurrence and conceptual categorization. Psychological Reports, 1969, 25, 899-910.

\section{Stimulus Materials}

420 words, 35 in each of 12 groups formed by the combination of 4 conceptual categories (animals, occupations, articles of dress. persons' names) and 3 Thorndike and Lorge (1944) frequency levels (less than 1 per million but more than 1 per 18 million, 1 to 4 per million. and 5 to 100 per million).

Subjects

192 (State University of New York at Albany).

\section{Task}

Task $I(\mathrm{~N}=96)$. Each subject rated their familiarity (in terms of prior exposure frequency), with all words within a given frequency level, on a 5-point scale; each subject was given words from only one of the 3 frequency levels, or a total of 140 words; the subject was given a sheet containing all the words within a given concept-frequency class grouped together and instructed to select one "reference" word from the 35 which best represented each of the 5 familiarity levels and put it at the top of the sheet under the appropriate heading, after which the remaining words were to be listed under the appropriate column.

Task $2(\mathrm{~N}=96)$. Same procedure as above, except each subject rated words from all frequency levels: 12 words from each of the 3 frequency levels of given concept were listed on each page; 144 total words were rated.

Data

(1) Listing of all 420 words, with mean scale value, standard deviation of scale value, and rank within its conceptual-frequency class, for Task 1 only.

(2) Correlations between the two rating procedures. plus internal consistency correlations.

15

Bowers. H. The constancy of imaginal content. Journal of Educational Psychology, 1929, 20, 295-298.

\section{Visual Imagery Study}

\section{Stimulus Materials}

63 words (no mention of selection process).

\section{Subjects}

Task

61 high school students from Ontario, Canada.

Each subject copied the entire set of 63 words onto a piece of paper (from the blackboard), and then rated each on a 4-point scale (0-3) on the distinctness of mental image which the word aroused: subjects were retested 1 week later on the same list with the same procedure.

\section{Data}

(1) Listing of 59 of the 63 words (4 very abstract words were not listed-their function was to catch cheaters) with mean imagery ratings separately listed for males $(N=36)$ and females $(N=25)$. NOTE: If a subject's rating of a given word differed by more than 1 point on the two tests. then his score for that word was not included: if a subject gave an imagery rating of other than " 0 " to the very abstract words mentioned above (such as "alas" and " $\rightarrow, 15{ }^{\prime \prime}$, on either test, then his entire protocol was excluded from consideration.

(2) Correlations between (a) the two rating sessions and $\{b \mid$ the sexes.

\section{Stimulus Materials}

\section{Auditory Imagery Study}

60 words. mostly onomonopoetic. 
Sublects

40 high school students from Ontario. Canada. Tauk

Each subject copied the entire set of 60 words onto a sheet of paper (from the blackboard) and then rated each on a 4-point scale $(0-3)$ on the clarity of the internal auditory impression on the mind's ear.

Data

(1) Listing of all 60 words with mean imagery rating separately for males $(\mathbf{N}=20)$ and females $(N=20)$.

(2) Correlation comparing male and female ratings.

16

Bowers. H. Factors influencing visual imagery for letter groups. American Journal of Psychology. 1932. 44. 775-779.

Stimules Materials

(1) 26 single letters of the alphabet. (2) 40 bigrams, (3) 80 trigrams, and (4) 80 tetragrams.

The trigrams were formed by adding a given letter (such as " $r$ ") to the beginning of one of the bigrams (such as "ab") to form "rab": in addition, another trigram was formed by adding that same letter to the end of the same bigram, to form "abr": the tetragrams were formed in a like manner. with a single letter being added to the front of a trigram which was itself formed by a frontal addition, and the same letter added to the end of the trigram formed by adding to the end of a bigram.

The following is an example of such a generated set of stimuli (40 such sets in all):

Subjects

ab abr rab abrt trab

Subjects were from a Canadian high school; the total number used was not made clear; the $\mathbf{N}$ varied among the various stimulus classes. with 182. 183. 125. and 92 for singles. bigrams. trigrams. and tetragrams. respectively (with no indication of subject overlap among stimulus classes).

Task

Each subject rated the stimulus on the "clarity of the mental picture" formed by the letter or letter combination, using a 6-point scale (from "clear and distinct as original" to "could not form a mental picture"); practice was given on numbers.

Data

(1) Listing of all 226 letters and letter combinations (ordered by sets. as illustrated above), with mean rating for each.

(2) Correlation between 2 subgroups rating single letters

(3) Probable error of the mean for 14 selected stimuli ( 4 singles. 2 digrams. 4 trigrams. and 4 tetragrams). most of which were of median imaginal content.

(4) Split-half reliability correlations for each stimulus type.

(5) Mean ratings for each of the 4 stimulus types.

(6) Correlations between meap ratings for bigrams, trigrams. and tetragrams with ratings of the individual constituant letters.

(7) Correlations between mean ratings for trigrams and those for the initial and terminal constituant bigrams.

(8) Correlations between mean ratings for tetragrams and those for first 2. first 3. last 2. and last 3 letters.

(9) Correlations between mean ratings for bigrams. trigrams. and tetragrams with the mean of the mean ratings of all its potential constituant groups.

17

Brown. W. P.. \& URE, D. M. J. Five rated characteristics of 650 word association stimuli. British Joumal of Psychology. 1969. 60. 233-249.

\section{Stimulm Material}

650 words. representing all stimuli used by Kent and Rosanof (1910). Hull and Lugoff (1921). Smith (1922), Rapaport. Gill, and Schafer (1946). Laffal (1955). Levinger and Clark (1961). Brown (195). Wallenhorst (1965), Brown and Ogle (1966). Smith and Harleston (1966), and Brown (unpublished)

Subjects

353 (Aberdeen University).

\section{Tauk}

Each subject rated each of $\mathbf{3 7 5}$ words, comprised of one of 2 halves of the total set (325). plus 25 repeated items from that set. plus 25 items from the other half of the items, on each of the following 7-point scales: (1) goodness (G); (2) pleasantness (P); (3) intensity of emotion (E); (4) concreteness (C), or how directly can the meaning be experienced by the senses; and (S) associative difficulty (AD), or how readily the word leads you to hink of other words or ideas.

Date

(1) Alphabetical listing of all 650 words, with the mean ratings on each of the five scales mentioned above.

(2) Reliability of ratings both within and between sets of words (halves).

(3) Intercorrelations among the five scales.

(4) Comparisons of the present study with previous studies: G: Jenkins. Russell. and Suci (1958). Heise (1965); P: Brown (1965). Silverstein and Dienstbier (1968). Heise (195); E: Levinger and Clark (1961). Brown (1965). Smith and Harieston (1966); C: Paivio. Yuille. and Madigan (1968). Spreen and Schulz (1966); AD: Laffal (1955). Brown (195). Noble (1961), Cieutat (1963), Paivio et al. (1968). Silverstein and Dienstbier (1968).

\section{8}

Buss. A. H. The psychology of aggression. New York: Wiley, 1961. Pp. 120-123.

\section{Stimulos Material}

185 words of "hostile" meaning (from various sources).

Sabject:

138 (University of Pittsburgh).

Taak

Each subject was presented each word (in alphabetical order) and asked to rate each on a 9-point scale of intensity of hostility associated with the word.

Data

Listing of 146 of the original 185 (39 were eliminated due to excessive rating variability) in increasing order of male-rated hostility value. with the following for each:

(1) Median male rating.

(2) Median female rating

(3) Thorndike and Lorge (1944) frequency.

\section{9}

CARroll. J. B. The assessment of phoneme cluster frequencies. Language. 1958, 34. 267-278.

\section{Stimulu Material}

837 consonant clusters, consisting of 2 phonemes. Date

(1) Listing of 19 basic consonant sounds, with the following for each (based on the above pool of 2-phoneme clusters): (a) frequency of initial occurrence. (b) probability of initial occurrence. (c) frequency of terminal occurrence, and (d) probability of terminal occurrence.

(2) Extensive comparisons with similar data from Keller and Saporta (1957) on Chontal language.

(3) Comparisons of the theoretical and observed phoneme distributions.

\section{0}

Carroll. J. B. Measurement properties of subjective magnitude estimates of word frequency. Joumal of Verbal Leaming and Verbal Behavior. 1971. 10. 722.729.

\section{Stinales Matertal}

60 words, selected by Shapiro (1969) to represent a wide range of frequency according to Thorndike and Lorge (1944) and Kučera and Francis (1967).

Subjects

Lexicographer sample. 15 people from editorial staff of American Heritage Dictionary of the English Language.

Other adult sample. 13 people with college education, but who were not necessarily attending college at the time. Task

Following Shapiro's (1\%9) instructions, subjects rated each of 
the 60 words according to how frequently it appears in written English: they started with any word. assigned it a number. and then rated the rest in comparison to the first one (using whole numbers. decimals. or fractions): 4 practice words given.

Data

(1) Listing of all 60 words in decreasing order of their standard frequency index (SFI) a log conversion of objective frequency, with the following for each: (a) SFI: (b) mean log frequency rating by lexicographers: (c) mean $z$ frequency rating by lexicographers (d) standard deviation of $z$ frequency rating by lexicographers: (e) items b. c. and d (above) for other adult sample; and (f) items b. c. and d (above) for combined samples.

12) Reliability of estimates for each sample separately. and the combined sample. with the following for all 3: (a) reliability, (b) mean square error. (c) standard error of measurement ( $z$ scores). (d) standard error of measurement (SFI units). and (e) $95^{\circ}$. confidence limits (SFI ünits).

(3) Mean standard deviations of $z$ scores (for both samples). mean SFI for words in 8 ranges of SFI. plus statistical significance tests.

(4) Correlations: (a) log of the first number chosen with mean $\log$ response to all words. (b) log of first number chosen with subject's accuracy in judging objective frequency, (c) mean log response to all words with subject's accuracy in judging objective frequency. and (d) standard deviation of $\log$ values of responses with subject's accuracy in judging objective frequency.

\section{1}

CARRoll. J. B.. \& WhITE, M. N. Age-nf-acquisition norms for 220 picturable nouns. Journal of Verbal Learning and Verbal Behavior. 1973. 12. 563-576.

\section{Stimula Material}

220 picturable nouns. selected from the following sources Carroll and White (1973); Mérriam-Webster Third International Dictionary: Paivio. Yuille, and Madigan (1968); and Peabody Picture Vocabulary Test.

Subjects Tack

62 (Rutgers University).

Each subject rated half of the words (110). according to the followingd instructions: ". . we need your estimate of when in your life you probably first learned each of a series of words. that is. first learned the word and its meaning either in spoken or written form": subjects used 9 age categories. from 2 to 13 plus.

Data

(1) Alphabetical listing of all 220 nouns with the following for each: (a) mean and standard deviation of male ratings; (b) mean and standard deviation of female ratings: (c) mean and standard deviation of combined ratings; (d) Thorndike and Lorge (1944) ( $T$-L) frequency ( $G$ count); (e) Kucera and Francis (1967) (K-F) frequency; and $(f)$ frequency from American Heritage Word Frequency Book (A-H) (see Carrol, Davies, \& Richman, 1971). (NOTE: Some words were missing from one or more of the above 3 frequency counts; for these words, a supplementary objective rating judgment was performed by 20 additional subjects and the results converted to each frequency scale).

(2) Mean. standard deviation, standard error of measurement, and reliability correlation separately for each of two forms of the word set. and for males, females, and combined within each form.

(3) Intercorrelations among the following 9 measures: (a) mean male rating; (b) mean female rating; (c) mean combined rating; (d) T-L frequency; (e) K-F frequency; (f) A-H frequency, adjusted for dispersion of word in different subject matter categories; (g) A-H total frequency; (h) A-H early grade frequency (grades 3 through 6): and (i) A-H late grade frequency (grades 7 through 9 . plus ungradeu sample).

(4) Intercorrelations among 16 measures. 4 involving age of acquisition ratings of Carroll and White 11973), 3 involving age of acquisition ratings of the present study. 3 involving latency of picture naming. and 6 involving word frequency, for 93 uords common to Carroll and White and the present study.

(5) Beta coefficients and multiple correlations in prediction of latency data for 93 pictures based on 6 combinations of variables (for males. females. and combined ratings and latencies).

\section{2}

Carroll. J. B., Kueldergand, P. M., \& Carton. A. S. Number of opposites versus number of primaries as a response measure in free-association tests. Joumal of Verbal Learning and Verbal Behavior. 1962, 1, 22-30.

\section{Strody 1}

\section{Stimulus Material}

100 words. from Kent and Rosanoff (1910).

\section{Subjects}

5 staff members of Harvard. including the authors; 42 (Simmons College).

Each person classed each word into one of the following: (1) adjectives having opposites. (2) nouns or verbs having opposites. and (3) words not having opposites. For words classed into the first two categories. the subjects gave opposite responses.

Data

(1) Listing of 34 Kent and Rosanoff (K-R) stimuli where opposite responses were given. along with: (a) stimulus number from $K \cdot R$ study. (b) opposite response(s), (c) percent of Harvard staff giving each opposite. and (d) percent of Simmons subjects giving each opposite.

(2) Means. medians. and standard deviations of frequencies for opposite and nonopposite primary and secondary responses as tabled in Russell and Jenkins (1954).

(3) Means, medians. and standard deviations of response frequencies adjusted for 100 cases. to $K-R$ primaries. from Russell and Jenkins (1953) supplementary norms.

\section{Study 2}

\section{Stimulas Material}

100 words. from $K \cdot R$ study.

\section{Subjects}

46 (Simmons College)

\section{Task}

Each subject gave a single-word free association to each of the 100 words.

Data

(1) Means and standard deviations of (a) opposites given to the opposite-evoking stimuli (OES), (b) the number of primary responses to non-OES (NOES), and (c) the total of primaries given to OES and NOES. combined.

(2) Reliability correlations for both OES and NOES. comparing first and second half of list in each case.

(3) Correlation of number of opposites given to OES with number of primaries given to NOES.

\section{Stimulus Materials \\ Study 3 \\ 50 words. the first half listed by K-R.}

\section{Sabjects}

344 high school students from Boston.

\section{Takk}

Each subject gave a single-word free association to each of the 50 stimuli: 211 of the subjects were retested in the same manner on the same set of words 16 months later.

\section{Data}

(1) Means and standard deviations of the entire group of subjects on the first test. and the retested group for the first and second tests. separately, for each of the following response classes: (a) opposite primaries. (b) nonopposite primaries. and (c) all primaries. 
(2) Reliability correlations for each of the above 3 response classes.

(3) Detailed comparison of response patterns of those subjects who tended to give opposite responses with those who tended to give nonopposite responses.

\section{3}

Castaneda. A.. Farel. L. S., \& Odom, R. Associative characteristics of sixty-three adjectives and their relation to verbal paired-associate learning in children. Child Development. 1961. 32. 297-304.

Stimulus Materials

69 common adjectives. jud ged (by authors) to be within the range of reading ability of $4 \mathrm{th}$. 5th. and 6th grade child ren.

Subjects

82 children (presumably from 4 th. 5th. and 6 th grades. although not stated).

Task

Each subject "... was required to call out any words that the adjective made him think of after first having read it aloud"; the subjects were allowed $8 \mathrm{sec}$ per word: 10 practice words were given. Data

(1) Alphabetical listing of 63 of the original 69 adjectives 16 were consistently misunderstood), with all responses given to each (excluding id iosmcratic and proper noun responses) listed after the adjective in decreasing order of frequency. with the percent frequency listed beside each response; associations also appearing as stimuli were capitalized and those also appearing as responses to other stimuli were asterisked.

(2) Comparisons of high and low association value pairs in paired-associate learning with children.

\section{4}

Cieltat. V. J. Association indices for 446 randomly selected English monosyllables. bisyllables. and trisyllables. Journal of Verbal Learning and Verbal Behavior. 1963. 2. 176-185.

Stimulus Materials

(1) 148 monosvllables. (2) 150 disyllables, and (3) 148 trisyllables. Syllables were selected in the following manner: 150 pages of Webster's New Intemational Dictionan (1957) were randomly selected: the first monosyllable. the first disyllable. and the first trisyllable occurring on the page were selected (if none was found. successive pages were searched until the first occurred).

Subjects

120 (Lou isiana State University)

Task

Each subject rated each of the $\mathbf{4 4 6}$ words on "... the number of things or ideas it reminds you of.." on a 7 -point scale from "none" to "extremely many."

Data

Alphabetical listing of all syllables. by class. with the following for each:

(1) Association value (a): proportion of subjects rating a word in any category, other than "none."

(2) Mean of rated association $\left(a^{\prime}\right)$ : arithmetic mean of ratings (none $=1$, extremely many $=7$ ).

(3) Standard deviation of rated association ( $\mathrm{SDa} a^{*}$ ).

(4) Transformed $a^{\prime}$ values $\left(\mathrm{Z} a^{\prime}\right)$ : $a^{\prime}$ was converted separately for each word class, into standard scores with mean $=500$ and stand ard deviation $=100$.

\section{5}

CLIfF, N. Adverbs as multipliers. Psychological Review, 1959, 66, $27-44$.

\section{Stlmulos Materiah}

9 adverbs and 15 adjectives. paired in all possible adverb-adjective combinations. resulting in 150 stimuli (including each adjective singly presented).

Sobjects

218 (Wayne State University). 186 (Princeton University), and 133 (Dartmouth University).

Task

Each subject rated every stimulus word or word pair (150 critical stimuli, plus 15 repeats and 39 fillers) on an 11-point scale of favorableness: ". . the stimuli were all to be rated in terms of how the subject would interpret them on reading and that they were all to be applied to people."

Data

(1) Extensive comparisons of the 3 subject samples.

(2) Listing of all adverb-adjective combinations (including "no adverb" -adjective) in a matrix along with the successive interval scale values for each; this was repeated 3 times, once for each subject sample.

(3) Extensive checks on the fit of a model to the obtained ratings (separately for each subject sample).

\section{6}

Canstantini, A. F.. \& Blackwood, R. O. CCC trigrams of low association value: A re-evaluation. Psychonomic Science, $1968.12,67-68$.

Stimulus Material

343 CCC trigrams. taken from lowest association value class $(0 \%-17 \%)$ from Witmer (1935).

Subjects

80 (University of Bridgeport)

Task

Each subject was presented each trigram for $5 \mathrm{sec}$ (slide presentation) and had to rate it on a 5-point scale on how many associations. ideas, or things it made them think of; 50 of the trigrams were repeated.

Data

(1) Listing of all 343 trigrams in one of 5 new classes based on association values generated in the present study $(0-20,21-40$ $41-60,61-80$, and $81-100$ ), in alphabetical order within class.

(2) Reliability correlation of repeated items.

27

Cramer. P. A study of homographs. In L. Postman \& G. Keppel (Eds.). Norms of word association. New York: Academic Press. 1970 .

Stimulus Materials

100 homographic words. selected from Fallows (1898).

\section{Sabjects}

Task

109 (University of California at Berkeley).

Each subject was given each of the 100 words to give a single-word free association response to (procedure from Palermo and Jenkins. 1964).

Data

(1) Alphabetical listing of all homographs, along with the following for each: (a) Thorndike and Lorge (1944) frequency (T-L). (b) primary (most frequent) response, (c) percent frequency of primary response. (d) number of different responses (D) (e) mean number of responses referring to the first meaning of the word (as judged by raters), and (f) mean number of responses referring to the second meaning of the word (as judged by raters).

(2) Summary of (a) mean strength of primary response, (b) mean number of different responses. (c) mean number of responses for meaning one, and (d) mean number of responses for meaning two: all the above information presented separately for each of $5 \mathrm{~T}$ - $\mathrm{L}$ frequency classes.

(3) Alphabetical listing of all 100 homographs, along with the following for each: (a) listing of all responses. in decending order of frequency; (b) total frequency of occurrence for each response; and (c) percent frequency of each response.

\section{8}

DeEse. J. On the structure of associative meaning. Psychological Revien: 1962, 69, 161-175.

Stimulas Materials

42 most frequent single-word responses to the stimulus "butterfly." from Russell and Jenkins (1954).

Subjects

$\$ 0$ (Johns Hopkins University).

Task

Each subject gave a single-word free association to each stimulus 
Data

(1) Listing of all 42 words, in decreasing order of frequency (by Russell \& Jenkins), with the frequency with which it was a response to each of the first 19 words when they were used as stimuli.

(2) Listing of the first 19 words, in decreasing order of frequency, with overlap coefficients (number of responses common to the two stimuli) between it and each of the other 18 words.

(3) Rotated centroid factor loadings of stimulus overlap for the first 19 words on each of 6 factors.

(4) Rotated centroid factor loadings of stimulus overlap on 6 factors. for (a) 17 words derived from "music" category, (b) 16 words derived from "slow" category, and (c) 15 words derived from "religious value" category.

29

DEEsE. J. The associative stiucture of some common English adjectives. Joumal of Verbal Learning and Verbal Behavior, $1964,3,347.357$.

\section{Stimalas Material}

278 adjectives from 2 sources: (a) high-frequency words from the Thorndike and Lorge (1944) G count (50 per million or more) or (b) the standard form of the semantic differential.

Subjects

100 (Johns Hopkins University)

Task

Each subject gave a single-word free association response to each word.

Date

(1) Listing of $\mathbf{4 0}$ pairs of adjectives which elicit each other as primaries (principal responses), along with the actual frequency with which each word evokes the other (regardless of whether it is the primary).

(2) Correlations between factor loadings for 11 of the $\mathbf{4 0}$ pairs mentioned above, contrasting it with every other pair in the subset (10).

\section{0}

DEEsE, J. The structure of associations in language and thought. Baltimore: Johns Hopkins University Press, 1965.

\section{Study 1}

\section{Stimulas Material}

182 words from 3 different classes: (a) aggressive responses taken from a study of scoring of the Rorschach Test (50 words), (b) affectively neutral words $(90)$, and (c) words of "metaphorical psychosexual content" (42).

Subjectu

100 (Johns Hopkins University).

Tack

Each subject gave a single-word free association to each word.

(1) Alphabetical listing of all 50 aggressive words, with the percent of times each was a response to the stimulus words "ambition" and "fight."

(2) Alphabetical listing os 46 words which occur as responses to more than 2 of the 50 aggressive word stimuli; following each word is an alphabetical listing of all the stimuli it was given as a response to, along with the frequency for each.

(3) Factor loadings, after verimax rotation, for 43 aggressive words.

(4) A plot of factors I and II (after $45^{\circ}$ rotation) of 26 aggressive words.

(5) A plot of factors III and IV (after $45^{\circ}$ rotation) for 28 aggressive words.

\section{Stody 2}

(From Jones \& Filenbanm, 1964)

\section{Stimules Matedal}

"... examples of all main form classes and structure groups in English"; specific number not given.

Subjects

466 (University of North Carolina).
Task

Each subject gave a single-word free association to each word. Dat

(1) Listing of 14 verbal auxiliaries (i.e., be, are, can, will, etc.) with the following for each: (a) intersection coefficients (proportion of common responses evoked by the two stimuli) of each word with each of the remaining 13 words; and (b) plots of rotated factors $I$ II, III, and IV of the intersections of verbal auxiliaries.

(2) Listing of 14 personal pronouns, with the same two analyses as done for the verbal auxiliaries.

(3) Listing of 14 prepositions, with the same two analyses as done for the verbal auxiliaries, plus percent of paradigmatic associations to each.

\section{1}

DEwEY, G. Relativ frequency of English speech sounds. Cambridge, Mass: Harvard University Press, 1923.

Stimulus Materish

“. . . 100,000 words of connected matter adequately representativ of good English as used-written, spoken, and printed-today"; following sources were used: newspapers, magazines, novels, speeches, personal correspondence, religious publications.

(NOTE: In all the following analyses, the frequency is always out of the entire 100,000-word sample.)

Data

Wonds:

(1) Listing of all words occurring more than 10 times, presented in decreasing order of frequency, with all "variant" forms of a word listed separately; actual frequency of the word listed beside it.

(2) Listing of "root" words occurring more than 10 times, with the following data for each root word: (a) frequency of occurrence (all variants were summed for this tally), and (b) number of variants of each root.

(3) Relisting of (1) in alphabetical onder.

(4) Relisting of (2) in alphabetical order.

(5) Various analyses of percent of the language which each of the general frequency classes comprise.

Syllables (for all syllabic analyses, the "Revised Scientific Alfabet" was used):

(1) Listing of the 220 commonest syllables occurring oftener than 100 times, in decreasing order of frequency, with actual frequency value beside each.

(2) Relisting of (1) with each syllable put into its appropriate vowel class ( 19 vowels considered $)$, in decreasing order of frequency with in each class.

(3) Listing of the 1,370 commonest syllables occurring oftener than 10 times, by vowel class [see (2) above] in decreasing frequency order within each class; actual frequency value listed beside each syllable.

(4) Relisting of the 1,370 syllables in (3) according to phonetics of the initial sound; each syllable was placed in one of 988 celk, formed by the crossing of 19 vowels with 51 possible initial consonant sounds plus an additional class if the syllable was the initial one; actual frequencies were placed next to each syllable.

(5) Summarization of the information in listing (4) by the 70 possible initial sounds (total frequencies for each).

(6) Relisting of 1,370 syllables in listing (3) according to phonetics of the terminal sound; each syllable was placed in one of 1,843 cells, formed by the crossing of 19 vowels with 96 possible terminal consonant sounds plus an additional class if the syllable was the terminal one; actual frequencies were placed next to each syllable.

(7) Summarization of the information in (6) by the 115 possible terminal sounds (total frequencies for each).

(8) Relisting of 1,370 syllables in (3) with 10 different frequencies for each; both (a) the number of times the syllable occurred and (b) the number of different words in which it occurred were tabulated under each of the following classifications: syllable occurring as the initial, medial, and terminal syllable of the word, or as the entire word, plus an overall total.

(9) Summary statistics of the percent of the overall language structure contributed by the various classes of syllables. 
Sounds:

(1) Listing of $\mathbf{4 8}$ sounds based on the Revised Scientific Alfabet along with the following for each: (a) percent of all sounds accounted for, (b) total number of occurrences, and (c) total number of different words in which it occurred

(2) Listing of " 41 plus 1" sounds based on the Simplified Spelling Board along with the same 3 pieces of information on each as presented in (1) above.

(3) Listing of " 41 plus 1" sounds, in order of decreasing frequency of occurrence, with the following for each: (a) same 3 pieces of information as presented in (1) above, (b) total frequency divided by number of different words which it occurred in, (c) frequency of occurrence as initial syllabic sound. (d) frequency of occurrence as medial syllabic sound, (e) frequency of occurrence as terminal syllabic sound, (f) frequency of occurrence as entire syllable sound, (g) frequency of occurrence as initial word sound, (h) frequency of occurrence as medial word sound, (i) frequency of occurrence as terminal word sound, and (j) frequency of occurrence as entire word.

(4) Listing of 40 sounds based on the Standard Pitmanic Shorthand, arranged in decreasing order of frequency, with the same 3 pieces of information on each as were presented in (1) above.

(5) General summary of sound frequencies.

Letters:

(1) Alphabetical listing of all 26 letters, with the following for each: (a) percent of all letter occurrences which it accounts for, (b) total number of occurrences, and (c) total number of different words in which it occurred.

(2) Listing of all 26 letters, in decreasing order of frequency, with the following for each: (a) same 3 items as in (1) above, (b) frequency in the initial position of the word, (c) frequency in the medial position of the word. (d) frequency in the terminal position of the word, and (e) frequency with which it was the entire word.

Miscellaneous. Listing of certain "incidental" characteristics of the count which were not listed under any of the above classifications, and the frequency of each: proper names, numerals, titles and salutations (itemized), abbreviations (itemized), foreign words. punctuation marks (itemized), plus the total number of sentences used.

\section{2}

DiMascio. A. Learning characteristics of nonsense syllables: A function of letter frequency. Psychological Reports. 1959. 5. $585-591$.

Data

(1) Alphabetical listing of all letters of the alphabet with the following for each: (a) frequency of occurrence per 1.000 words, from Pratt (1939); and (b) log of this frequency value.

(2) Examination of the relationship between: (a) CCC association value (Witmer. 1935) and summed log frequency value for the CCC, and (b) CVC association value (Glaze, 1928) and summed log frequency value for the CVC.

(3) Relationship of $\log$ frequency value to learning with association value held constant.

(4) Relationship of association value to learning with $\log$ frequency value held constant.

\section{3}

DiVesta, F. J. Developmental patterns in the use of modifiers as modes of conceptualization. Child Development, 1965, 36. 185-213.

\section{Stimulus Materials}

100 "familiar nouns," from a list compiled by Osgood, Archer. and Miron (1\%2).

Subject

100 children in each of 5 grades ( 2 through 6 ), for 500 subjects total; the children were from 2 different schools in a middle-class district, and were run both as individuals and in groups. Task

Each noun was read aloud in a sentence [i.e., "The

(noun)"], and the subject was to fill in an adjective which seemed to fit. either orally (if individual) or on paper (if group).

\section{Data}

(1) Listing of the 100 most frequent adjectives, by decreasing $\mathrm{H}$ values, separately for each grade level, with the following for each: (a) frequency: overall number of occurrences; (b) diversity: number of different nouns it modified; and (c) H:an entropy index which combined the frequency and diversity measures.

(2) Comparisons among the various grade levels.

(3) Listing of all 100 nouns, separately for each grade level, in decreasing order of number of different adjectives elicited by it

(4) Listing of all 100 nouns, in decreasing order of homogeneity of $\mathrm{H}$ rank across all grades, with $\mathrm{H}$ rank for each grade also listed [from (3)]. (NOTE: For this comparison, the noun listed first is the one whose rank position varied least across all grade levels.)

\section{4}

DiVESTA, F. J., \& Walls, R. T. Factor analysis of the semantic attributes of 487 words and some relationships to the conceptual behavior of fifth-grade children. Joumal of Educational Psychology Monograph, 1970, 61(6, Pt. 2), 1-40.

\section{Stlmulus Materials}

\section{Study 1}

487 words from several grammatical classes (including 172 stimulus words and their primary associates from Palermo and Jenkins, 1964).

Subjects

Fifth grade children from 7 schools in 2 states (New York and Pennsylvania); no specific number given.

Tauk

Each subject rated 20 to 25 words on each of 87 -point scales of the semantic differential (friendly-unfriendly, good-bad, niceawful, brave-not brave, big-little, strong-weak, moving-still, and fast-slow).

\section{Data}

(1) Alphabetical listing of all 487 words, with the following for each: (a) Thorndike and Lorge (1944) frequency, and (b) average rating on each if the 8 scales.

(2) Overall mean and standard deviation of ratings on each of the 8 scales.

(3) Factor loading for each scale on the 3 main factors of evaluation, potency, and activity.

(4) Frequency distributions of factor scores for each of the 3 semantic dimensions.

Stimulus Materiab

Study 2

487 words from Study 1.

Subjects

15 undergraduate college students (school unspecified).

Task

Imagery group (I) $(\mathrm{N}=5)$. Each subject rated each word on a 7-point scale of imagery ("low imagery" to "high imagery").

Concreteness group (C) $(\mathrm{N}=5)$. Each subject rated each word on a 7-point scale of concreteness ("highly abstract" to "highly concrete").

Emotionality group $(\mathrm{E})(\mathrm{N}=5)$. Each slibject rated each word on a 4-point scale of emotionality ("neutral," "pleasant," "unpleasant." and "mixed").

NOTE: Instructions for groups $I$ and $C$ were patterned after Paivio, Yuille, and Madigan (1968), and group E was patterned after Noble (1958).

Data

(1) Alphabetical listing of all 487 words with average ratings for each on I. C, and $E$.

(2) Alphabetical listing of all $\mathbf{4 8 7}$ words with factor scores on the evaluation, potency, and activity scales.

(3) Intercorrelations of ratings on I, C, E, and the 3 semantic differential scales mentioned above.

(4) Correlation between I and probability of association with its primary associate for 172 stimulus words from Palermo and Jenkins.

(5) Correlations between I and C at each of 4 levels of E.

(6) Correlation between stimulus and primary response scores 
(from Palermo and Jenkins) on each of the 3 semantic differential scales.

(7) A study examining the salience of each of the 3 semantic differential scales in a simple concept identification task among 3- to 4-year-olds.

(8) A study examining the effect of category separation on the semantic differential on a concept identification task among 5th grade and adult subjects.

\section{5}

Dxon. T. R.. \& Dxon, J. F. The impression value of verbs. Journal of Verbal Learning and Verbal Behavior, 1964, 3. $161 \cdot 165$.

\section{Stimules Material}

200 verbs in the simple past tense; list was constructed on the basis of an earlier rating by 4 judges to insure that 60 verbs were "good." 60 "bad," and 80 neutral.

Subjects

120 (University of Kentucky).

Tent

Each subject rated each verb on an 11-point impression value scale (from "very good impression" to "very bad impression"); the subjects were instructed to "... imagine themselves using the verbs in sentences while talking to a psychologist..." and rate each .... in terms of the kind of impression $S$ thought a psychologist would get of him when he used each verb in a sentence."

Data

(1) Alphabetical listing of each verb, along with mean impression values separately for males $(N=60)$ and females $(N=60)$.

(2) Statistical comparisons of male and female ratings.

(3) Effectiveness of scaled impression value in several verbal conditioning studies.

\section{6}

Duncan, C. P.. \& Wood, G. Norms for successive word associations. Psychonomic Monograph Supplements, 1966, 1. 203-206.

Stimulus Materials

20 words [the first 20 from the Kent and Rosanoff (1910) norms].

Sabjects

500 (Northwestern University).

Tack

Each subject produced 5 single-word responses to each stimulus word (each stimulus was listed 5 times in a row with a blank space beside each).

Data

Listing of each of the 20 stimulus words with the following for each:

(1) The 10 most frequent responses, listed in decreasing order of frequency.

(2) Frequency of each response in each of the 5 possible positions of listing.

(3) Total frequency of each response.

\section{7}

ENTwISLE, D. R. Word associations of young children. Baltimore: Johns Hopkins University Press, 1966.

\section{Stimulus Material}

96 words from all frequency levels of Thorndike and Lorge (1944) ( $J$ count) and all form classes (nouns, adjectives, verbs, etc.), designed to overlap as much as possible with previous word-association studies.

\section{Sebjects}

20 prekindergarten children from Baltimore County, Maryland 200 kindergarten children from Baltimore County, Maryland; 340 1st graders from Baltimore County schools; 340 3rd graders from Baltimore County schools; 340 5th graders from Baltimore County schools; 200 (Johns Hopkins University); 100 Amish children, 20 in each of grades 1. 2, 3. 5, and 6 (Baltimore County schools).
Taak

Each subject responded (orally) to each stimulus word (after the experimenter read it to him) with a single-word free association response.

Data

(1) 5 separate alphabetical listings of all 96 words (once each for kindergarten. 1st grade. 3rd grade. 5th grade, and college), with the following for each word in each listing: (a) 3 most common male responses. with percent occurrence; and (b) 3 most common female responses, with percent occurrence.

(2) Alphabetical listing of $\mathbf{3 0}$ selected words from the Kent and Rosanoff (1910) norms. with the 3 most common responses (and percentages for each) from each of the following sources: (a) Woodrow and Lowell (1916); (b) grades 4, 5, and 6 from Palermo and Jenkins; (c) and grades $1,3,5$, and kindergarten of the present study.

(3) Alphabetical listing of the 30 selected words in (2), with the 3 most common responses (and percentages for each) for adult subjects in each of the following studies: (a) Kent and Rosanoff. (b) Russell and Jenkins. (c) Palermo and Jenkins, and (d) present study.

(4) Alphabetical listing of 16 selected words from Fillenbaum and Jones (1\%5) with comparison of percent of responses in each of 8 form classes (separately for Fillenbaum and Jones and the present study).

(5) Alphabetical listing of all 96 stimulus words for a summary of the kindergarten responses; after each stimulus is listed all responses (alphabetically) with the following for each response: (a) male frequency, (b) female frequency, and (c) total frequency.

(6) Alphabetical listing of all 96 stimulus words for urban children in grades 1. 3. and 5 ( $N=280$ in each case): after each stimulus are listed all responses (aiphabetically) with 9 frequencies for each-male, female, and total frequencies at each of 3 grades.

(7) Extensive examinations of each of the following: (a) response changes with age; (b) effects of intelligence and sex; (c) socioeconomic, rural-urban. and subcultural differences in response; and (d) relationship of findings to other similar studies.

\section{8}

Epsten, W. Backward association as a function of meaningfulness. Journal of General Psychology, 1962, 67, 11-20.

Stimulus Material

24 pairs of words; 8 pairs of each of the following types: (a) 2 concrete nouns (CN); (b) 2 abstract nouns (AN); and (c) a preposition and a conjunction, or function words (FW).

Subjects

15 (University of Kansas).

Tack

Each subject free-associated for $60 \mathrm{sec}$ to each of the $\mathbf{4 8}$ single words (not pairs) using Noble's (1952) technique.

Data

(1) Listing of all 24 pairs, by type, along with the $m$ value for each member of the pair.

(2) Mean $m$ values for stimulus and response members within each class.

(3) Comparison of backward stimulus recall after regular paired-associate learning. as a function of pair type.

\section{9}

ERvin. S. M. Changes with age in the verbal determinants of word-association. American Journal of Psychology, 1961, 74. 361-372.

\section{Free-Ascociation Study}

\section{Stimulus Material}

46 words from a variety of grammatical classes, all within the vocabulary of kindergarten children.

\section{Sabjects}

23 kindergarten children; 10 1st grade children; 52 3rd grade children: 996 th grade children. 
Task

Each subject responded to each word with a single-word free-association response; the experimenter spoke the stimulus word, and the kindergarten and 1st grade children responded orally while the 3rd and 6th graders responded in writing. Data

(1) Listing of the 30 stimulus words which evoked paradigmatic responses, along with the following for each: (a) part(s) of speech of the evoked paradigmatic responses; and (b) frequency of the paradigmatic response at each of 3 grade levels (kindergarten and 1,3 , and 6).

(2) Probability of words from 4 grammatical classes (noun, pronoun, intransitive verb, transitive verb, and adjective) following a stimulus word of any of 5 classes (4 mentioned earlier, plus adverb) when the stimuli are (a) word association stimuli and (b) words preceding it in text.

\section{Stimulus Materiah}

\section{Clowed Alternative Study}

35 3-word sets, from each of 3 classes: (1) grammatically alike. but containing an antonym (i.e., snow, winter, summer); (2) antonyms contrasted with syntagmatic associate (i.e., pillow, soft, hard); (3) syntagmatic and paradigmatic associates contrasted (i.e., fire, hot, warm).

Subjects

Same as for first study.

\section{Task}

Each subject was presented each 3-word set in written form, and asked to say (kindergarten and 1st grade) or circle (3rd and 6th grades) the word with which the middle word of the 3 seemed to go best.

Data

Listing of 20 of the 35 sets, along with the number of subjects choosing the correct alternative for kindergarten and 1,3 , and 6 , separately.

\section{0}

Ervin, S. M. Correlates of associative frequency. Journal of Verbal Learning and Verbal Behavior, 1963, 1. 422-431.

\section{Stimulus Material}

List 1. Set of high-frequency words (number unspecified) from Thorndike and Lorge (1944), with the following 2 subdivisions (1) 12 lexical words, plus 9 buffers of low communality; and (2) words from a variety of grammatical classes of low communality, alternating with high-communality buffer words

List 2. A short list of high-communality lexical words (number unspecified).

Subjects

385 high school students from California; 166 (University of California at Berkeley).

Task

College group. Each subject performed 3 separate operations on the words in List 2 (in the following order):

(1) A single-word free association to each word.

(2) A sheet was presented with each stimulus word written in the middle of a long blank; the subject created a sentence around the word, incorporating it.

(3) On the above sheet, a space was provided to the side of the "sentence creation" blank on which the subject was to write 4 other words which could be substituted for the stimulus word, in the sentence.

High school group. Each subject performed the same operations as the college group, except with the words in List. 1. Data

(1) Alphabetical listing of all words in List 2 and the second part (see above) of List 1 ( 50 words total) with the following for each: (a) number of different response words given; (b) correlations of objective frequency of associative response with (i) frequency of the substituted words (Task 3), (ii) frequency of the prestimulus-word words in the constructed sentence (Task 2), and (iii) frequency of the poststimulus-word words in the constructed sentence (Task 2); (c) beta coefficients for the above 3 frequencies; and (d) multiple correlations among the measures.

(2) Listing of each of 10 types of lexical words and 9 types of function words with the following for each: (a) frequency of occurrence (per 1,000 words) in single-word utterances (including both written and oral); and (b) frequency of occurrence in association to (i) function word stimuli and (ii) lexical word stimuli.

\section{1}

Ervin-Tripp, S. M. Substitution, context, and association. In L. Postman \& G. Keppel (Eds.), Norms of wond association. New York: Academic Press, 1970.

\section{Stimulus Materials}

High-communality (HC) list. 12 nouns, verbs, and adjectives known to have very high-frequency primary associates, plus 9 buffer words.

Grammatical $(G)$ list. 38 grammatically heterogeneous words (question words, nouns, verbs, adjectives, adverbs, pronouns, gerunds, and function words) with high-communality words between each pair of stimuli.

\section{Subjects}

\section{Task}

$G$ list. The following 3 operations were performed on the words by each subject, with 1 week separating each task

(1) Write the first single-word free association for each word in the list.

(2) Write a sentence for each of half the words from the list, with the stipulation that it not start with the "key" word (stimulus word).

(3) Write 4 other single words which could be substituted for the key word in the sentence generated.

HC List. Same 3 operations, except in one class period. Data

(1) Alphabetical listing of the 50 critical words (fillers excluded) from both lists with a listing of all responses (in alphabetical order) to each word plus the following for each response: (a) number of times it was given as an associative response to the key word (Task 1); (b) number of times it replaced the key word in the sentence (Task 3); (c) number of times it preceded the key word in the sentence (Task 2); and (d) number of times it followed the key word in the sentence (Task 2).

(2) Listing of 10 classes of content words and 9 classes of function words, with the following for each: (a) percentage of the time words from that class occur as single-word utterances in the language; and (b) frequency of response words from each of the classes.

(3) Listing of all 50 key words, with the following totals for each: (a) associative responses given; (b) sentences generated; (c) subjects giving substitute words; (d) number of times a function word preceded the key word; (e) number of times a function word followed the key word; ( $f$ ) number of times the key word was the first in the generated sentence; and $(g)$ number of times the key word was the last in the generated sentence.

(4) Alphabetical listing of all 50 key words. with the following for each: (a) number of different word responses; (b) simple correlations of associative frequency of response words with each of the following (separately): (i) frequency of use as a substitute word, (ii) frequency of use in the generated sentences prior to the key words, and (iii) frequency of use in the generated sentences following the key words; (c) beta coefficients for the immediately preceding comparisons; and (d) multiple correlation values.

(5) Relation of slope of predictor variables ( 9 total) to (a) correlation with associative frequency for substitutions. preceding responses, and following responses, and (b) number of paradigmatic and syntagmatic associates for the 5 most frequent responses (including, again, substitutions, preceding responses, and following responses). 
42

Feldman. S. Motivational aspects of attitudinal elements and their place in cognitive interaction. In S. Feldman (Ed.), Cognitive consistency. New York: Academic Press. 1966.

\section{Stimales Material}

25 adjectives.

Subject:

93 (school unspecified).

Task

Goodness rating (evaluation) $(\mathrm{N}=75)$. Each subject rated each adjective singly and in combination with every other adjective on a 9-point goodness (evaluation) scale.

Surprisingness rating $(\mathbf{N}=18$ ). Each subject rated each single adjective on an 11-point surprisingness scale. Data

(1) Alphabetical listing of all 25 adjectives. with the following for each: (a) mean goodness rating (evaluation); (b) mean potency rating (on hard-soft dimension) (NOTE: source of rating not clear); (c) modifying capacity: "... extent to which the given adjective pulled the rating of pairs in which it appeared toward itself': (d) $\log$ frequency: from Thorndike and Lorge (1944) G count; and (e) mean surprisingness rating.

(2) Intercorrelations among 6 measures: 5 listed in (1) plus evaluative polarity.

\section{3}

Flavell. J. H. Meaning and meaning similarity: II. The semantic differential and co-occurrence as predictors of judged similarity in meaning. Joumal of General Psychology. 1961. 64. 321-335.

\section{Stimulos Materials}

120 pairs of words. formed from 240 words selected from Jenkins. Russell, and Suci (1958), with 30 in each of the following classes: (1) 2 concrete nouns (CN-CN). (2) 2 abstract nouns (AN-AN), (3) 2 adjectives (A-A), and (4) a concrete noun and an adjective (A-CN) Within each pair class. an attempt was made to have a wide variety of meaning-similarity types (i.e.. synonyms, antonyms, unrelated words. etc.).

Sabjects

74 (University of Rochester). Tank

C test $(\mathrm{N}=37)$. "For each pair, you will consider an occurrence. taken at random. of the object, event. or quality which the left hand word in the pair refers to. Then you will estimate the probability that the right hand object. event, or quality will co-occur in the same spatial setting": a 7-point scale was used, with the following probabilities assigned: $1=0 \%-5 \%, 2$ and $3=5 \%-50 \%, 4=$ $50 \% .5$ and $6=50 \%-95 \%$, and $7=95 \%-100 \%$; every subject in the $\mathrm{C}$ group rated 90 pairs (excluding the AN-AN pairs) twice, once in the forward and once in the backward direction.

$S$ test $(\mathrm{N}=37)$. Each subject rated each of the 120 pairs, once, on a 7-point scale of "similarity-dissimilarity of meaning": 2 forms of the presentation order were used-one with $\mathrm{CN}$-A and the other with A.CN ordering.

Data

(1) Listing of all pairs separately by the 4 classes, with ranking scores for each pair on S, C, and D (from Jenkins et al.); the ranking referred to position among the other pairs within the class with reference to the particular dimension (range $=1-30$ ); for class AN-AN. only $S$ and $D$ rankings were given.

(2) Intercorrelations among $S, C$, and D for pair classes $\mathrm{CN}-\mathrm{CN}$, $A \cdot A$, and A-CN. separately, with the following for each class: (a) $S$ with $C_{\text {; }}$ (b) $S$ with $D_{\text {; }}$ (c) $C$ with $D_{\text {; }}$ (d) multiple correlations predicting $S$ from $C$ and $D$; (e) partial correlation of $S$ and $C$, holding $D$ constant: and $(f)$ partial correlation of $S$ and $D$, holding C constant.

(3) Correlations between S and C for the "forward" presentation of test $C$ as well as the "backward" presentation of test $C$, separately for CN-CN. A-A, and A-CN.
44

Foley, J. P.. \& MacMillan, Z. L. Mediated generalization and the interpretation of verbal behavior: $V$. 'Free association' as related to differences in professional training. Jourmal of Experimental Psychology. 1943, 33, 299-310.

\section{Stimulos Materials}

20 critical words. Homophones which have legal, medical, and neutral (nonprofessional) meanings (i.e.. confinement. binding. etc.). with the restriction that the word have the same pronunciation in each meaning.

20 neutral words. Selected from the Kent and Rosanoff (1910) norms. with the following restrictions: (a) the word had no legal or medical connotation. and (b) the word had a high communality of verbal responses to it in a free-association test (large percentage of subjects gave the same response).

\section{Subjects}

40 Ist year law students: 23 2nd year law students: 37 1st year medical students; 43 2nd year medical students: 75 nonprofessionals (liberal arts students in psychology classes).

Task

Each subject wrote down the first free association to each word after the experimenter read it aloud.

Data

(NOTE: The subjects' responses were put into legal, medical, or neutral classes by 3 professional psychologist judges.)

(1) Listing of each critical word (20), accompanied by the percent of legal. medical. and neutral responses given by each of the 5 classes of subjects.

(2) Listing of each neutral word (20), with the same information for each as mentioned in (1).

(3) Overall mean percent of legal. medical. and neutral responses for the critical, neutral, and combined lists for each subject class. separately.

(4) Comparison of the combined legal and combined medical subject groups on the percent of legal and medical responses given to the critical words.

\section{5}

.French. N. R., Carter. C. W., \& Koentg. W. The words and sounds of telephone conversations. Bell System Technical Journal. 1930. 9. 290-324.

\section{Stimulns Materials}

Words taken from conversations on the telephone "... over typical toll circuits terminating in the city of New York"; one observer collected information over 6 weeks. with the following data gathered during each of the successive weeks (along with number of calls monitored): nouns $(500)$, verbs $(500)$, adjectives and adverbs $(500)$, prepositions and conjunctions $(150)$, pronouns $(150)$, and articles (150).

\section{Data}

(1) Listing of the classes of items excluded, along with the percentage of exclusions which each class comprised.

(2) Plot of the increase in the number of different words as the total number of words increased from 100 to 100,000 , separately for both nouns and verbs.

(3) Listing of 7 word classes $(6$ mentioned above plus auxilliary verbs) with the following for each: (a) total frequency of words. (b) number of different words, and (c) ratio of (a) to (b).

(4) Listing of all words used in $1 \%$ or more of the total conversations, in decreasing order of frequency, with the following for each: (a) total number of times the word was used, and (b) number of different conversations in which it occurred.

(5) Relisting of the information in (4) above, with the words listed in alphabetical order

(6) Listing of the 50 most frequent words in conversational English (present study) along with the 50 most frequent words in written English (from Dewey, 1923), each listed in decreasing order of frequency; words common to both lists were indicated.

(7) Listing. in decreasing order of frequency, of the 25 
most common words from the combined oral and written data for each of the following classes: (a) nouns, (b) verbs, and (c) adjectives and adverbs.

(8) Listing of 5 classes of words (nouns, verbs, adjectives and adverbs, "minor" words, and "all words") with the percent of the words in each class which have $1,2,3,4,5$, and 6 syllables, plus the average number of syllables for words in that class.

(9) Extensive analysis of frequency of occurrence of various speech sounds in terms of: (a) vowels, (b) initial consonants, (c) tinal consonants, (d) unaccented vowels, and (e) initial consonant compounds (i.e., st, pr, etc.). (10) Comparison of written and oral data on relative frequency of occurrence of each of the following: (a) vowels, (b) initial consonants, and (c) final consonants.

(11) Frequency of occurrence of the 24 consonant sounds (compounds included) both before and after each of 18 vowel sounds, presented in matrix form.

\section{6}

GaRSKOF. B. E. Relation between single word association and continued association response hierarchies. Psychological Reports. 1965. 16. 307-309.

Stimulus Materials

20 words (selection process not detailed)

Subjects

Task

120 (Rutgers University).

Single association task $(\mathrm{N}=100)$. Each subject gave a singleword free association response to each of 20 words.

Continued association task ( $\mathrm{N}=20$ ). Each subject responded to each stimulus word for $60 \mathrm{sec}$ with as many associations as she could think of.

Data

Listing of 20 stimuli with the following for each:

(1) Correlation between response frequencies under the two methods

(2) Correlation between associative frequency of the response under the single method with the rank order of emission frequency under the continued method.

\section{7}

Garskof, B. E., Houston, J. P.. \& Mednick, S. A. Overlap and direct associative strength norms for 480 word pairs. Psichonomic Monograph Supplements, 1967. 2(Whole No. 18). 33-38.

Stimulus Materials

32 words chosen from hierarchies of the stimulus words "mutton" and "sheep" in the Russell and Jenkins (1954) norms.

Subjects

Task

58 (University of Michigan).

Each subject gave a single-word written free association response to each of 75 words ( 32 critical plus 43 filler).

Data

Alphabetical listing of all 32 critical words across the top and down the side of a matrix with each of the following cross comparisons of every word with each of the others:

(1) Overlap value of the 2 words, based on the ". . ratio of the sum of the cross products of the ranks of the common associates to the sum of the squares of the ranks of the larger hierarchy."

(2) Standard deviation of the overlap value.

(3) Percent of subjects who gave the row word as a response to the colunin word.

(4) Percent of subjects who gave the column word as a response to the row word.

\section{8}

Gibson, E. J.. Pick, A., Osser, H., \& Hammond, M. The role of grapheme-phoneme correspondence in the perception of words. American Journal of Psychology. 1962. 75. 554-570.

\section{Stimulus Materials}

50 "pseudowords." varying from 4 to 7 letters long.

Subjects

165 (Cornell University).

Task

Each subject rated each pseudoword on a 9-point pronounceability scale, collowing the procedure used by Underwood and Schulz (1960).

Data

(1) Listing of all 50 pseudowords, along with mean pronunciation rating for each.

(2) Comparisons of scaled pronunciation with actual pronunciation latency, pronunciation variation, recall performance (at varying exposure durations). and recognition performance.

\section{9}

GLANZER, M. Grammatical category: A rote learning and word association analysis. Journal of Verbal Learming and Verbal Behavior. 1962, 1, 31-41.

\section{Stimulus Materials}

28 words. 4 from each of 7 grammatical classes (noun adjective. adverb, verb, pronoun, preposition, and conjunction), each of which was (a) a monosyllable. (b) of AA frequency, according to Thorndike and Lorge (1944), and (c) unambiguously assignable to a grammatical category.

Subjects

25 Army enlisted men.

Task

Each subject made an oral free association response to each stimulus word (also presented orally) 4 times (the entire list of 28 words $w$ as presented 4 times in a row, in a different order each time).

Data

(1) Comparisons and analysis of the response latencies for stimulus words in each of the grammatical classes, separately for each trial.

(2) Rank order correlations between response latencies and paired-associate learning with that response serving as both stimuli and responses.

(3) Average number of different responses given to each stimulus across the 4 trials. separately for each grammatical class (plus analvsis).

(4) Rank order between variety [see (3) above] and latency.

(5) Rank order correlation among the following measures (combining granmatical classes): (a) number correct in anticipation procedure when the word was used as a response in paired-associate learning (with nonsense stimuli); (b) number of correct anticipations when the word was used as a stimulus (nonsense responses); (c) word association latency: (d) word association variety (average number across the 4 trials); and (e) number of correct anticipations when the word was used in triplets of the form "nonsense-critical word-nonsense."

(6) Alphabetical listing of all 28 words, by grammatical class. with the following for each word: (a) the 2 most frequent word associations (except in 3 cases where ties occurred. and all responses were listed); and (b) mean proportion of subjects giving that response (considering all 4 trials).

\section{0}

Glaze. J. A. The association value of non-sense syllables. Journal of Genetic Psychology, 1928, 35, 255-269.

Stimulus Materials

2,019 CVCs; $_{3}$ all possible CVC combinations with (a) " $Y$ ". considered as a vowel and a consonant. (b) exclusion of consonant repetitions within a syllable, and (c) exclusions of words.

Subjects

15 (Colorado College).

\section{Task}

\section{Procedure 1}

Each subject was presented with 252 CVCs, one at a time, via 
tachistoscope for a duration of $3 \mathrm{sec}$ each; within that 3-sec interval. the experimenter first pronounced the letters of the CVC and the subject then did one of the following: (1) gave an oral association of 1 or 2 words: (2) said "yes" if the particular association was longer than 2 words (but did not give the association): (3) did not say anything if the CVC meant nothing. A practice list of $\mathbf{5 0} 3$-letter words was given prior to the CVCs. Data

(1) Listing of all 2.019 CVCs. alphabetically arranged within one of 16 different association categories. where association value $=$ percent of subjects giving a specitic response to the CVC (specific association values not given for each CVC).

(2) Number of CVCs classed as true nonsense (no response) for each subject separately.

\section{Procedure 2}

Task

The subjects went back over their responses and classed each CVC into one of 18 categories based on what that CVC meaning (as inferred from the response) referred to (i.e.. chemistry. morality. sounds. etc.).

Data

Listing of all 18 categories with the number of different CVCs classed under it.

51

Gorman. A. M. Recognition memory for nouns as a function of abstractness and frequency. Journal of Experimental Psychology. 1961. 61. 23-29.

Stimulus Materials

1.791 nouns from the Thorndike and Lorge (1944) norms that (1) had G-count frequencies higher than 6; (2) were not capitalized. abbreviated. contracted. or hyphenated: (3) were not expressly indeterminant as to frequencr: (4) were not plural of an entry that accurred in the singular: and (5) did not have substantial non-noun use.

Subjects

2 university professors (including the author). Task

Each subject classed each noun as being either concrete (reference to objects. to material. to sources of sensation is relatively direct) or abstract (reference is relativelv indirect): $" \mathrm{~m}$ " subscript was used for those words which had some meaning in both abstract and concrete categories.

Data

(1) Percent classification agreement between the two judges

(2) Alphabetical listing of 120 concrete nouns. and an alphabetical listing of 120 abstract nouns. both randomly chosen (with restrictions on initial and terminal letters) from a subset of 1.061 on which there was complete agreement by both judges; Thorndike and Lorge frequencies ( $G$ count) were listed beside each word.

(3) Analyses of the effect of abstractness and concreteness on short-term recognition memory.

\section{2}

HaAgen. C. H. Synonymity, vividness. familiarity. and association value ratings of $\mathbf{4 0 0}$ pairs of common adjectives. Journal of Psychologr. 1949. 27. 453-463.

\section{Stimulos Material}

480 adjectives. comprised of 80 sets of 6 related words (i.e., agile. nimble. lisels, active. alert. tripping): prior to the experiment. a group of 35 judges selected from each set the word which most completely represented the meaning of the group: this word was used as the standard and paired separately with each of the other 5 words of the set to form a total of 400 pairs to be used as stimuli. Sabjects

Task

Each subject rated all 400 pairs on only one of the following scales: the pairs were presented for 8 sec each. by slide.
(1) Similarity of meaning $(\mathbf{M})$ : degree to which the words denote the same or similar objects. actions. or conditions, on a 1-7 scale $(N$ $=801$.

(2) Closeness of association (A): degree to which words are associated in thought: the immediacy, compellingness, or consistency with which one word calls another to mind. on a 1-7 scale $(\mathbf{N}=80)$.

(3) Vividness of connotation (V): clarity or graphicness of the impressions which the words arouse. on a 1-7 scale $(N=80)$.

(4) Familiarity $(F)$ : degree to which the meaning and use of the words was known to the subject. on a 1.4 scale $(N=40)$.

Data

(1) Median and variability values for the words in 4 of the 80 sets of words. on each of the 4 scales.

(2) Frequency distribution of the number of words represented at each of 12 areas of the scale for each of the 4 scales.

(3) Reliability of scale judgments for each dimension.

(4) Correlations among the 3 main dimensions (M. A. and V).

(5) Sample list of 10 standard words along with examples of high. medium. and low similarity $(M)$ associates of each.

(6) Sample list of 30 standard words. 10 with high. 10 with medium. and 10 with low similarity $(M)$ associates listed for them.

( ) Sample of 10 high. 10 medium, and 10 low $V$ words.

\section{3}

Hamilton. H. W.. \& Deese. J. Does linguistic marking have a psychological correlate? Joumal of Verbal Learming and Verbal Behavior. 1971. 10. 707-714.

\section{Study 1}

Stimulus Material.

86 adjectives. comprised of 43 sets of opposites.

\section{Subjects}

20 (Johns Hopkins University).

Task

Each subject took the entire list of 86 adjectives and sorted them in to opposites: after this. 1 pair of opposites was randomly chosen and the subject placed each member of the remaining 42 pairs with whicherer member of the original pair it seemed to go best.

Data

Listing of all pairs of adjectives in one of 3 categories. depending on whether they met both. one. or neither criteria of "contextual neutralization." with the following for each:

(1) Listing of each member of the pair. one in the "marked" and one in the "unmarked" column.

(2) Thorndike and Lorge (1944) frequency ( $L$ count) of the marked and unmarked adjective.

(3) Year of entry into the language (from Oxford English Dictionary) for marked and unmarked adjective.

(4) Number of subjects sorting the marked and unmarked adjective into the same pile with the marked and unmarked adjective of the original comparison pair.

\section{Study 2}

Stimulus Materials

54 verbs. comprised of 27 sets of opposites.

\section{Sabjects}

Task

6 (Johns Hopkins University).

Task I $(\mathrm{N}=10)$. Each subject was given one opposite set of verbs. randomly chosen. and was to match the members of the remaining pairs with one or the other of the original pair: after this. they picked one member from each pair which had a positive evaluation.

Task $2(\mathrm{~N}=6)$. Each subject was presented the 54 verbs not paired by opposites and was to assign positive and negative evaluation to each verb separately.

Data

Listing of all 27 sets of pairs with the following for each:

(1) Listing of each member. one under column $A$ and one under column B.

(2) Number of other pairs with which the members of a pair were classed significantly often (A with A. B with B). 
(3) Number of subjects judging A member of pair as positive (from Task 1).

(4) Number of subjects judging A member of pair as negative (fronı Task 2).

(5) Number of subjects judging $B$ member of pair as positive (tron Task 2).

\section{Stimulus Materials}

Study 3

(1) 20 nouns, comprised of 10 singular-plural pairs; and (2) 32 verbs. comprised of 16 present-past tense pairs.

Subjects

Task

2 (Johns Hopkins University).

Each subject sorted all nouns and all verbs (separately) into 2 classes. designated as positive and negative in evaluation.

Data

(1) Listing of nouns, with the following for each: (a) number of subjects classifying it as positive in the singular, and (b) number of subjects classifying it as positive in the plural.

(2) Listing of verbs. with the following for each: (a) number of subjects classifying it as positive in the present tense, and (b) number of subjects classifying it as positive in the past tense.

\section{4}

Haun. K. W. Measures of association and verbal learning. Psichological Reports. 1960, 7. 451-460.

\section{Study 1}

\section{Stimulus Materials}

30 words from the Kent and Rosanoff (1910) list. using the following selection criteria:

(1) For half of the stimulus words. the most popular response cccurred about tuice as often as the second most popular response.

(2) For half of the stimulus word. the most frequent response cccurred only slightly more often than the second most frequent response.

(3) Stimulus words with very common opposite responses were not included.

(4) Stimulus words with clang responses were not included. Subjects

183 (Johns Hopkins University).

Task

Each subject gave a single-word free association response to each stimulus word (written).

\section{Study 2}

Stimulus Materials

The 6 most popular responses to each stimulus in Study 1 were combined in all possible pairs ( 15 per stimulus set) to produce a total of $\mathbf{4 5 0}$ different pairs.

Subjects

100 (Johns Hopkins University); about half were from Study 1. Task

Each subject examined each of $\mathbf{4 5 0}$ triads - a stimulus word plus a pair of its responses (MUSIC: piano, note)-and selected the lowercase word which would be most likely as a free association response to the capitalized word.

Data

(1) Alphabetical listing of all 30 stimulus words followed by the 6 most irequent responses to that word (from Study 1) listed in descending order of frequency, with the following information on each response: (a) free association value (FAV): the probability of that response as a free associate to the stimulus; (b) compared associates value. Type V (CAV.V): Thurstone's Case V solution applied to the scaling matrix: and (c) compared associates value. Type III (CAV-III): Thurstone's Case III solution applied to the scaling matrix.

(2) Study examining the effect of CAV and FAV on paired. associate learning.
55

Hayden, B. S., \& Loud, L. Some norms for the pronounciability of nonsense syllables. Psychological Reports, 1969, 25, 415-418.

Stimulus Materials

200 CVCs, constructed by rules suggested by Hilgard (1951): an attempt was made to represent the entire range of association values presented by Glaze (1928)-about $20 \mathrm{CVCs}$ at each of 10 leveis $(0 \%-9 \%, 10 \%-19 \%$, etc. $)$, except for $0 \%-9 \%$, where only $4 \mathrm{CVC}$ were available.

Subjects

201 (Western Maryland College).

Task

Each subject rated each CVC on a 9-point pronounceability scale, using the procedure described in Underwood and Schulz (1960); subjects were self-paced.

\section{Data}

(1) Listing of all $200 \mathrm{CVCs}$, with mean and standard deviation of pronunciation rating for each.

(2) Correlation between present study and Underwood and Schulz, using 13 common CVCs.

(3) Correlation between present study pronunciation values and $m^{\prime}$ values of Noble (1961).

(4) Correlation between present study pronunciation values and association values of Glaze (1928).

(5) Relation between pronunciation and speed of learning (where 50 subjects learned 15 -syllable serial lists).

\section{6}

Heise, D. R. Semantic differential profiles for 1,000 most frequent English words. Psychological Monograph, 1965 79(Whole No. 8)

\section{Stimulus Materials}

1,000 words from the following sources:

(1) 911 from West's (1953) frequency count, each having a frequency of 337 per 5 million, or greater, excluding function words (prepositions, conjunctions, etc.) and others deemed (by the author) not frequent in brief extemporaneous stories.

(2) 85 from a short frequency count, done by the author, of words appearing in a published collection of stories.

(3) 4 having frequent use among sailors (navy, sailor, enlist, and admiral).

\section{Subjects}

342 Navy enlistees. in a training program at Hospital Corps School, Great Lakes Naval Training Center (Illinois); participation was mandatory.

Task

Each subject rated 50 of the words on each of 87 -point scales of the semantic differential; each word was presented in a short sentence, for purposes of definition only: the stimulus word, plus sentence, appeared in the first 36 spaces of a computer card, and the remaining spaces were used for rating the word on each scale. Data

(1) Factor loadings on evaluation (E), potency (P), and activity (A) of each of the 8 scales, using both uncorrected scores and scores corrected for skew and kurtosis.

(2) Estimates of error variance of factor scores (reliability) made by randomly selecting 15 words and having them rerated, then comparing results on $E, P$. and $A$.

(3) Examination of the effects of defining sentence, in terms of verb tense. noun singularity or plurality, and no sentence at all.

(4) Alphabetical listing of all 1,000 words, with the following for each: (a) defining sentence: (b) average ratings on each of $E$. $P$, and $A$ : (c) polarization of the word, or distance from neutrality (scale value of 4 ) in semantic space (by squaring and adding $E, P$, and $A$. and then taking the square root of the sum); (d) a measure of a word's "affiliation" content; and (e) a measure of a word's "achievement" content. 
57

Herata. K.. \& Bryden. M. P. Tables of letter sequences varying in order of approximation to English. Psychonomic Science. 1971. 25. 322-324.

\section{Stimales Material}

Single letters. digrams. trigrams. and tetragrams from the Mavzer and Tresselt (1965) and Mayzner. Tresselt, and Wolin (1955a. b) norms.

\section{Trak}

Each letter series was weighted according to its actual frequency of occurrence and successive letters were randomly drawn (by computer) using these weights. EXAMPLE: In the third order approximation. if $S T_{\text {_ }}$ was the initial digram, all trigrams commencing with ST were weighted and then one letter was randomly drawn to complete this; then if $E$ was chosen, the same procedure would be followed by TE_ in order to further extend this letter series.

Data

(1) 100 10-letter sequences for each of the following orders of approximation to English: zero. first, second. third, and fourth.

(2) 40 8-letter sequences with no repeated letters for each of the above-listed orders of approximation to English.

\section{8}

Herrmann, D. J.. Chaffik R. J. S. \& Corbett. A. T. A factor analusis of six measures extracted from the Battig and Montague (1\%9) category norms: Evidence for three properties of caregories in semantic memon;. Journal of Verbal Learning and Verbal Behavior. 1973. 12. 666-674.

\section{Data}

(1) Reanalysis of the Battig and Montague (1969) norms with the following for each of the 56 categories: (a) number of different responses per category (TAS): (b) number of different responses produced as first responses (NTF); (c) average number of responses per subject in $30 \sec (T / S)$ : (d) average rated frequency for each category (potency measure taken from Battig and Montague. or estimates by the subjects of how many responses they could think of per category) (RF): (e) mean log frequency of the responses. according to Kucera and Francis $(1967)(\log K F)$; (f) intersample correlations between Maryland and Illinois (ISC): and (g) factor scores on each of 3 factors (I. II. and III) derived from factor analysis. where $I$ = category size. $I I=$ category accessibility. and III = category familiarity.

(2) Intercorrelations among the first 6 measures listed above [(a) through (f)].

(3) Rotated principal component structure for the 3 factors considering the 6 response measures. including communality scores for 6 response measures and (a) eigenvalues and (b) cumulative variance accounted for. for each factor.

\section{9}

HiLgARD. E. R. Methods and procedures in the study of learning. In S. S. Stevens (Ed.). Handbook of experimental psychologi. New York: Wiley. 1951.

Date

(1) Listing of the CVCs presented by Glaze (1928) (with deletions of duplications and of syllables where " $Y$ " was used as a vowel) by association value groupings.

(2) Alphabetical listing of 509 low-association value nonsense syllables based on the Glaze (1928). Hull (1933), and Krueger (1934) lists, as compiled by Melton in unpublished form.

(3) 366 CCCs. selected from Witmer (1935) and listed by association value groupings.

(4) Listing of 300 adjective pairs, in order of rated degree of similarity on a 4-point scale. from an unpublished study by Melton and Safier.
60

Horton. D. L.. \& Mecherikoff, M. Letter preferences: Ranking the alphabet. Joumal of Applied Psychology. 1960. 44. 252.253

\section{Stimulus Materials}

26 letters of the alphabet.

\section{Subjects}

100 (University of Minnesota)

Task

Each subject ranked the letters from most to least preferred. Data

(1) Six separate listings of the letters of the alphabet were presented. in each case from the most to the least preferred letter. with each letter accompanied by its mean rank value. for: (a) males $(N=60)$. (b) females $(N=40)$. (c) young subjects $(N=76)$. (d) old subjects $(N=24)$. (e) entire group $(N=100)$. and (f) subjects from a previous study by Mecherikoff and Horton (1959).

(2) Following summary statistics for each of the above 6 listings: (a) N. (b) Kendall's coefficient of concordance (W). (c) mean rank order correlation of all possible pairings of raters $(\boldsymbol{\nabla})$, and (d) reliability coefficient of the rankings $\left(\boldsymbol{F}_{r}\right)$.

(3) Rank order correlations for: (a) male vs. female. (b) young vs. old. and (c) present study males vs. previous study males.

61

Howe. E. S. Probabilistic adverbial quantifications of adjectives. Journal of Verbal Learning and Verbal Behavior, 1963. 1. 225-242.

\section{Stimulus Material}

Study 1

14 adjectives and 10 adverbs. combined into 154 stimuli $(140$ adverb-adjective pairs. plus 14 unmodified adjectives).

Subjects

67 (University of Maryland School of Medicine).

Takk

Each subject rated every stimulus (154) on an 11-point scale of pleasantness.

\section{Data}

(1) Listing of all stimuli in matrix form. with the empirical successive inter al value for each combination.

(2) Listing of all 10 adverbs. in decreasing order of overall multiplicative effects $\left(d_{p}\right)$. with actual $d_{p}$ value for each.

(3) Listing of all 14 adjectives. in increasing scale value of the unqualified form $\left(s_{j}\right)$. with the following for each: (a) $s_{j}$ values. and (b) $K$. representing the difference between the arbitrary zero of the scale values and the psychological zero of the scale.

(4) Comparison of the fit of the data to a generated model.

Study 2

\section{Stimulus Materials}

(1) 7 adjectives from Study 1; and (2) 8 adverbs. 4 probabilistic ones from Study 1 and 4 intensive ones from Cliff (1959).

A total of 287 stimuli were formed by having each adjective presented with: (1) each probabilistic adverb; (2) each intensive adverb; (3) all possible combinations of a probabilistic and an intensive adverb (32 combinations): and (4) no adverb.

Subjects

103 (University of Maryland School of Medicine)

Tack

Each subject rated every stimulus (287) on an 11-point scale of pleasantness.

Data

(1) Listing of each of the 7 adjectives, with the following for each: (a) mean pleasantness value when modified by a probabilistic adverb; (b) mean pleasantness value when modified by an intensive adverb: (c) mean pleasantness value when modified by a 
combination of a probabilistic and an intensive adverb; and

(c) overall mean pleasantness value.

(2) Comparison of the scale values for the 2 studies.

(3) Analyses of order effects for the compound adverbial modifications.

(4) Listing of all 4 intensive adverbs, with the overall multiplicative effect of each.

(5) Listing of all 4 probabilistic adverbs, with the overall multiplicative effect of each.

(6) Listing of 5 adjectives with the following for each: (a) $\mathrm{sj}_{\mathrm{j}}$ value; (b) $\mathrm{K}$ values, when single intensive adverbs were used; and (c) $K$ values. when single probabilistic adverbs were used.

(7) Comparison of the fit of the data to a generated model, through correlations of predicted and obtained values.

\section{2}

Howes. D. On the relation between the probability of a word as an association and in general linguistic use. Journal of Abnormal and Social Psychology, 1957, 54, 75-85.

\section{Stimulns Materials}

100 words from Kent and Rosanoff (1910).

Data

(1) Scatterplot showing relationship between summed Kent and Rosanoff frequency and Thorndike and Lorge (1944) frequency on log coordinates.

(2) Conditional distributions of the summed Kent and Rosanoff frequency for selected frequency ranges from Thorndike and Lorge.

(3) Conditional distribution of the summed Thorndike and Lorge frequencies for selected values of the summed Kent and Rosanoff frequencies.

(4) Regression of the summed Kent and Rosanoff frequencies on the Thorndike and Lorge frequencies.

(5) Regression of the summed Thorndike and Lorge frequencies on the Kent and Rosanoff frequencies.

(6) Listing of the $25 \mathrm{Kent}$ and Rosanoff words with the highest Thorndike and Lorge (magazine count) frequencies. listed in order of decreasing trequency. with the following for each: (a) Thorndike and Lorge frequency, (b) Kent and Rosanoff frequency, and (c) frequency data from an unpublished study by Jenkins.

\section{3}

Howes. D. A word count of spoken English. Joumal of Verbal Learning and Verbal Behavior. 1966, 5, 572-604.

\section{Stimulus Materials}

Spoken English, from 220 interviews of 5,000 words each; 1.100 .000 words, total.

Subjects

20 (Northeastern University and M.I.T.); 20 patients at Boston VA Hospital.

Task

The subjects were told that the purpose was to obtain a speech sample for statistical study of the language and to talk about anything he pleased; college subjects were interviewed once each $(5,000$ words per subject); hospital subjects were interviewed 10 times $(5,000$ words per session and $\mathbf{5 0 , 0 0 0}$ words total per subject). Data

Alphabetical listing of 9,699 words generated by all subjects, with the following information for each word:

(1) Total frequency (over all subjects).

(2) Frequency for college subjects.

(3) Frequency for hospital subjects.

(4) Frequency for one typical hospitalized subject.

\section{4}

Hull. C. L. The meaningfulness of 320 selected nonsense syllables. American Journal of Psychology, 1933. 45. 730-734.

Stimulus Materials

320 CVCs; ". . they (all) appeared to be easy to pronounce and .. 256 of them appeared to be relatively without meaning."

\section{Subjects}

20 (Yale University).
Task

Every subject eventually responded to all $320 \mathrm{CVCs}$, using the follewing system: The CVCs were presented in sets of 16 on a memory drum; each set was gone through 3 times in succession before the next set (there were 20 sets in all); a serial anticipation format was used, with the subject given $2 \mathrm{sec}$ in which to (a) pronounce the next CVC and (b) give an association to the one presently in view; the specitic instructions were as follows: "You are to pronounce this syllable and those that follow it as you see them. After you have seen the list once, you are to endeavor to anticipate the syllables; in other words, as you see one syllable you are to pronounce the syllable that will follow it before it appears. Also, as each syllable appears, if it happens to make you think of anything in particular, tell me as briefly as possible what it is. Please do not try particularly to think of associations for the various syllables, but if you do think of one, be sure to tell me of it."

\section{Data}

(1) Alphabetical listing of all $320 \mathrm{CVCs}$ with the percent meaningfulness values for each (computed by the number of responses given out of a total potential of 60 occasions-20 subjects times 3 exposures each).

(2) Total number of responses given at each of the 3 successive exposures, summed over CVCs and subjects

(3) Frequency distribution of the number of CVCs at various meaningfulness levels for 308 CVCs common to Glaze (1928) and the present study.

(4) Mean and standard deviation of meaningfulness ratings for Glaze and the present study.

(5) Correlation between ratings from Glaze and from the present study

(6) Reliability coefficient of the first vs. the second 10 subjects tested in the present study.

65

Hull. C. L., \& Lugoff, L. S. Complex signs in diagnostic free association. Journal of Experimental Psychology, 1921, 4. 111-136.

Stimulus Materials

100 words used by Jung (1910) in his free association test.

Subjects

100 adults, of various levels of education, from Chicago. Duluth, and Madison.

Task

Each subject gave a single-word free association response to each word; after this, the subject went through the same list again and tried to remember the response he had given the first time through. Data

(1) Listing of all 100 words, with the number of "complex signs of emotionality" given by (a) males, (b) females, and (c) overall, where a complex sign was indicated by any of the following types of response: (a) long associative reaction time; (b) inability to make any response: (c) extremely short associative reaction time; (d) repetition of the stimulus; (e) apparent misunderstanding of the stimulus; $(f)$ inability to remember the first response on the second time through; $(\mathrm{g})$ use of the same response for 2 or more stimuli; (h) strange or apparently senseless reaction; and (i) perseveration.

(2) Frequency distribution of complex signs for words arranged from strongest to weakest emotionality.

(3) Examination of ordering effects of strong on weak words.

(4) Separate listing of the 20 most emotional words, along with the number of complex signs for each.

(5) Separate listing of the 10 weakest emotional words, with the number of complex signs for each.

(6) Frequency of 8 of the complex signs for men, women, and overall.

(7) Examination of diagnostic reliability of the various complex signs.

(8) Diagnostic potency as a function of length of reaction time

(9) Diagnostic potency of 1 indicator vs. 2 indicators. 


\section{6}

Hunt, K. P.. \& Hodge. M. H. Category-item frequency and category-name meaningfulness $\left(m^{\prime}\right)$ : Taxonomic norms for 84 categories. Psichonomic Monograph Supplements. 1971. 4Whole No. 54). 97.121.

Stimulus Materials

84 conceptual categories.

Sobjects

400 (Universitv of Georgia).

Task

Session 1. Each subject rated each category on the number of things or ideas associated with it. on a 7-point scale; the categories were not mentioned as being categories. but as words or phrases.

Session 2. Each subject listed 4 members of each category. Data

(1) Listing of all 84 categories. in decreasing order of category $m^{\prime}$ value, with the following for each: (a) male $m^{\prime}$, female $m^{\prime}$, and overall $m^{\prime}$ (based on results of Session 1); (b) separate listing of all responses with a frequency of 10 or more (for one or both sexes) in decreasing order of total frequency, with male. female. and total frequency listed separately: (c) alphabetical listing of all responses (not segregated by frequency) with frequency of less than 10 for both sexes combined. with male and female totals in parenthes is beside the word: (d) number of illegibles and ommissions for male. female. and total separately.

(2) Correlation between male and female $m^{\prime}$ values.

(3) Correlation between male and total $m^{\prime}$ values.

(4) Correlation between female and total $m^{\prime}$ values.

(5) Reliability correlation of $\boldsymbol{m}$ ' ratings. splitting the subjects into 2 groups.

(6) Listing of 31 categories common to Battig and Montague (1969) and the present study. listed in order of decreasing correlations. with the following for each: (a) rank-order correlation of totai frequency for each category on present study vs. Battig and Montague. considering only responses with frequency of 10 or more from the present study; and (b) number of responses which the correlation was based on.

(7) Rank-order correlation between $\boldsymbol{m}^{\prime}$ of present study and Battig and Montague ratings for number of items in each category (considering the 31 common categories).

67

Jenkins. J. J. Degree of polarization and scores on the principal factors for concepts in the semantic atlas study. American Journal of Psychology. 1960, 73. 274-279.

Stimules Material

360 concepts (words) used in Jenkins, Russell, and Suci (1958). Data

A reanalysis of the earlier information in Jenkins et al. to provide the following additional data; the concepts were alphabetically listed with the following for each:

(1) Degree of polarization $\left(D_{4}\right)$ : ertent to which the profile for a given concept deviates from a completely neutral profile. that is. one which has a score of 4 on each of 20 scales.

(2) Factor scores for each of the factor dimensions of evaluation (I). potency (II). and activity (III).

68

Jenkins. J. J. The 1952 Minnesota word association norms. In L. Postman \& G. Keppel (Eds.), Norms of word association. New York: Academic Press, 1970.

Stimules Materials

100 stimulus words used by Kent and Rosanoff (1910).

Sabject:

1.031 (University of Minnesota)

Task

Each subject was to give a single-word free association to each of 100 words

Date

Alphabetical listing of each of 100 stimulus words. followed by each response (in decreasing order of frequency) along with its frequency of occurrence.
69

Jenkins, J. J.. Russell, W. A.. \& Sucr. G. J. An atlas of semantic profiles for 360 words. American Journal of Psuchology. 1958. 71. 688-699.

\section{Stimalos Material}

(1) 267 words from Kent and Rosanoff (1910): 50 stimulus words plus 3 responses to each $(1$ each of primary, $5 \%$, and $1 \%$ association value). in addition to 67 other words which were "similar" or "opposed" in meaning.

(2) 19 words from Noble (1952): entire range of $m$ values represented, with 1 word for about every $1 / 2 m$ unit.

(3) 18 words generated by authors to sample the extremes of several rating scales.

(4) 25 words from previous studies at the University of Illinois.

(5) 31 miscellaneous words: sampled from social. political clinical, and economic areas.

Subjects

540 (University of Illinois).

Task

Each subject rated only 20 of the words on each of 207 -point bipolar scales. " . . on the basis of what they mean to you"; subjects were asked to rate quickly, on the basis of first impressions; 30 subjects were called back 4 weeks later to do the complete rating again.

Data

(1) Test-retest reliability coefficient (for retested subjects).

(2) Correlation between mean and median scores.

(3) Alphabetical listing of all 360 words. with mean ratings on each of the 20 scales listed as follows: (a) cruel-kind. (b) cured-straight. (c) masculine-feminine. (d) untimely-timely. (e) active-passive. (f) savory-tasteless. (g) unsuccessful-successful. (h) hard-soft. (i) wise-foolish. (j) new-old. (k) good-bad, (l) weak strong. $(m)$ important-unimportant. (n) angular-rounded. (o) calm-excitable. (p) false-true. (q) colorless-colorful. (r) usualunusual. (s) beautiful-ugly, and (t) slow-fast.

\section{0}

Johnson. R. C. Meaningfulness of eighty English words Psychological Reports, 1961. 9. 431

\section{Stimulas Material}

80 words with Thorndike and Lorge (1944) frequency of 34 to 99 (L count).

Sobjects

Task

30 (San Jose State College).

Each subject gave free associations to each of the 80 words, for $60 \mathrm{sec}$ each. using Noble's (1952) procedure.

Data

Listing of all 80 words, from highest to lowest $m$ values. with the $m$ value for each.

\section{1}

Jounson. R. C. Mean associative latencies of $200 \mathrm{CVC}$ trigrams. Journal of Psychology, 1964, 58, 301-305.

Stimulas Materiah

200 CVCs, randomly selected from the Archer (1900) norms.

Subjects

80 (University of Hawaii).

Tadk

Half of the subjects responded to one set of CVCs consisting of 98. while the other half responded to the other set, containing 102; each subject responded to each CVC with a single-word response. of one of the following types: (1) If the CVC is a word. say that word.

(2) If the CVC is not a word, but sounds like a word, say that word

(3) If the CVC is neither a word nor sounds like a word. say the first word which it reminds you of.

\section{Data}

(1) Listing of all $200 \mathrm{CVCs}$ with mean association latencies (L) and Archer association values $(a)$ for each.

(2) Reliability correlation (between subjects) on ratings.

(3) Correlation between $L$ and $a$. 


\section{2}

Johnson, R. C., Frincke. G., \& Martin, L. Meaningfulness. frequency, and affective character of words as related to visual duration threshold. Canadian Journal of Psychology, 1961, 15. 199-204.

\section{Stimulus Materials}

34 words. comprised of the following: (1) 9 "good" and 9 "bad" words selected from Johnson. Thomson, and Frincke (1960); all were between 12 and 14 in frequency of occurrence, according to Thorndike and Lorge (1944) ( $G$ count); and (2) 16 other words presented, but not analyzed.

Subjects

23 (San Jose State University); 79 (University of California at Berkeley).

Task

Each subject gave continuous free associations for $60 \mathrm{sec}$ to each of the 34 words, following Noble's (1952) procedure.

Data

(1) Listing of all 18 good and bad words (grouped separately), with the following for each word: (a) Thorndike and Lorge frequency; (b) $m$ for San Jose group; (c) $m$ for Berkeley group; and (d) visual detection thresholds (VDT), taken from Johnson et al (1960).

(2) Statistical comparisons of good-bad ratings.

(3) Study comparing VDTs for pairs (a) matched on $m$, but varying in frequency; (b) matched on frequency, but varying in $m$ : and $(c)$ matched on frequency and $m$, but varying in goodness.

\section{3}

Johnson, R. C.. Thomson, C. W.. \& Frincke, G. Word values. word frequency, and visual duration thresholds. Psychological Review, 1960, 67, 332-342.

\section{Experiment III}

\section{Stimulus Materials}

$48 \mathrm{CVCs}, 16$ randomly selected from each of 3 association value levels $(100 \%, 47 \%-53 \%$, and $0 \%)$ from Glaze (1928).

Subjects

22 (San Jose State University).

Task

Each subject rated each CVC on a 7-point scale for goodness (from semantic differential), with the ratings occurring in 2 different sessions 1 week apart (half the CVCs were rated on each occasion).

Data

(1) Listing of all $48 \mathrm{CVCs}$ by association value (from Glaze) with the mean goodness rating for each.

(2) Statistical comparisons of the average ratings for the various association levels.

\section{Stimulus Material}

\section{Experiment V}

240 words. from the following sources: (1) 60 from Thorndike and Lorge (1944) G-count frequency pool of 12 through 14 occurrences; (2) 150 from Thorndike and Lorge L count $(6$ randomly selected from each alphabetic category, except " $X$ "); and (3) 30 from Jenkins. Russell, and Suci (1958).

\section{Subjects}

Task

$$
\text { "... various groups of Ss..." }
$$

Each subject rated each word on a 7-point goodness scale.

\section{Data}

(1) Listing of 17 pairs of words which were matched on goodness ratings but varying in frequency, with goodness rating and visual threshold for each member of the pair.

(2) Listing of 17 pairs of words which were matched on frequency but varying in goodness ratings, with frequency and visual threshold for each member of the pair.

(3) Statistical comparisons of members of the pairs within each pair type.

\section{4}

Johnson, R. C.. Weiss, R. L., \& Zelhart, P. F. Similarities and differences between normal and psychotic subjects in responses to verbal stimuli. Journal of Abnormal and Social Psychology, 1964, 68. 221-226.

\section{Stimulus Materials}

Goodness ratings. 50 words from Johnson, Thomson, and Frincke (1960).

Meaningfulness ratings $(m) .34$ words from Johnson, Frincke, and Martin (1961).

Subjects

150 (San Jose State University); 40 psychotic patients (institutionalized male veterans).

Task

Goodness ratings. 28 college and all 40 psychotic subjects rated each of 50 words on a 7 -point goodness scale (good-bad) from the semantic differential.

$m$ ratings. 122 college and all 40 psychotic subjects gave continued free association responses for $60 \mathrm{sec}$ to each of 34 words. using Noble's (1952) procedure.

\section{Data}

(1) Listing of 50 words rated on goodness, with the mean goodness ratings for normal and psychotic subjects, separately (iplus statistical comparisons).

(2) Listing of all 34 words rated on $m$, with the following for each: (a) Thorndike and Lorge (1944) frequency, (b) $m$ ratings by normal subjects. (c) $m$ ratings by psychotic subjects, (d) percent nonidiosyncratic responses (given by 2 or more subjects) by normals. (e) percent nonidiosyncratic responses by psychotics, (t) percent of normals making most common single assiciation, and (g) percent of psychotics making most common single association.

(3) Statistical comparisons of normals and psychotics.

(4) Rank order correlation between normals and psychotics on: (a) mean $m$ value of the word, (b) number of nonidiosyncratic associations, and (c) percent of subjects making most common association.

(5) Intercorrelations of word ranks, separately for normals and psychotics, based on: (a) $m$ vs. percent nonidiosyncratic responses, (b) $m$ vs. percent of subjects making the most common association, and (c) percent nonidiosyncratic responses vs. percent of subjects making the most common response.

(6) Comparison of "good" vs. "bad" words, separately for normals and psychotics. on: (a) $m$, (b) percent idiosyncratic first associations, and (c) percent of subjects making most frequent first association.

\section{5}

Jones. L. V., \& Thurstone, L. L. The psychophysics of semantics: An experimental investigation. Joumal of Applied Psychology, 1955, 39, 31-36.

\section{Stimulus Material.}

51 descriptive words and phrases, having either favorable (i.e., wonderful, highly favorable, etc.) or unfavorable (i.e., mildly dislike, loathe, etc.) connotations.

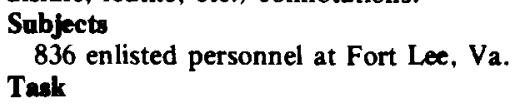

Each subject rated each descriptive word and phrase on a 9-point scale of liking when referred to food (greatest dislike to greatest like).

Data

(1) Listing of all 51 stimuli, in decreasing order of scale values, with the following for each: (a) scale value, expressed as a deviation of that stimulus's modal rated value from the mean of the entire set of 51 stimuli. using a normal deviate score; (b) standard deviation of the scale value; and (c) discrepancy score of the scale value from a normal deviate plot of all the data.

(2) Plots of 9 words and phrases on normal probability axes ( 3 of 
each of the following types: typically distributed rating values. skewed rating values. and bimodal rating values).

\section{6}

JoNes. L. V.. \& Wepman. J. M. A spoken word count. Chicago: Language Research Associates, 1966.

\section{Stimulon Material}

136.450 words spoken by 54 subjects.

\section{Subjects}

54 adults. from 18 to 80 years old.

\section{Tack}

Each subject was presented with 20 cards of the Thematic Apperception Test in a single session. and their verbal responses comprised the word count.

Data

(1) Listing of 1.102 words which (2) were used by at least 2 subjects and (b) occurred at a mean rate of at least 0.4 per 10.000 words. in decreasing order of frequency. with the following for each: (a) whether or not it met both of the following criteria: (i) at least $90 \%$ of its occurrences were as one part of speech and (ii) it occurred at least 2 times per 10.000 words; (b) whether or not it occurred in a previous word tally done by Jones, Goodman, and Wepman (1\%3): (c) part(s) of speech; and (d) frequency of occurrence (a mean of the mean frequencies for each subject).

(2) Listing of all words used by at least 2 of the 54 subjects. presented alphabetically within each grammatical class. with the following for each: (a) number of subjects using it; (b) mean frequency of occurrence per 10.000 words (averaged over all subjects): and (c) standard deviation of the frequency per 10.000 .

(3) Alphabetical listing of all words used by at least 2 of the 54 subjects. with all inflected forms listed separately from their base word and a separate listing of each grammatically different use of the word. with the following for each listing: (a) number of subjects using it: (b) mean trequency of occurrence per 10,000 words; (c) standard deviation of the frequency per 10.000 words; and (d) inflectional code. where appropriate (i.e.. $33=$ past participle. 55 = regular comparative form of the adjective, etc.).

\section{7}

Kanouse. D. E. Verbs as implicit quantifiers. Journal of Verbal Leaming and Verbal Behavior. 1972. 11, 141-147.

\section{Stimulow Material}

(1) 40 noun objects. selected from Thorndike and Lorge's (1944) list of the 1.000 most common English words.

(2) 40 transitive verbs. 10 each from the following 4 categories: manifest positive. manifest negative, subjective positive, and subjective negative.

From this. 160 sentences were created by combining the 40 nouns and 40 verbs into 10 blocks of size 16 (where 4 nouns were combined with 4 verbs. 1 from each type. within each block).

\section{Sabjects}

Task

16 (Yale University).

Probable quantifier group $(\mathrm{N}=8)$. Each subject rated each of the sentences on an implicit quantifier scale. where the subject chose which of the following quantifications best fits the sentence: all, most, many, some, a few, or one or two (this was later converted into a 6-point scale for analysis); in other words. the subject picked one of the modifiers to insert into the sentence "Jimmy bends paper clips" which is closest to the implied number.

Minimum quantifier group $(\mathrm{N}=8)$. Each subject did the same type of rating as above. except using the smallest possible quantifier which applied to the sentence.

Data

(1) Listing of all 40 verbs, in decreasing scale value within each of the 4 classes. with actual mean minimum quantifier value for each (plus overall mean for each class).

(2) Listing of all 40 noun objects, by the 4 classes of verbs (depending on which it had been paired with in the sentence), with mean minimum quantifier values for each (plus overall mean for each class).
(3) Same as (1), except for probable quantifier values.

(4) Same as (2). except for probable quantifier values.

(5) Examination of positive-negative. manifest-subjective. and minimum-probable differences in the ratings.

(6) Study on the effects of implicit quanitification on sentence learning.

Kent. G. H., \& Rosanoff, A. J. A study of association in insanity. American Journal of Insanity. 1910. 56. 37.96. $317-390$.

\section{Stimulus Materials}

100 words. avoiding those "... liable to call up personal experience."

\section{Subjects}

“... over one thousand normal subjects ... of both sexes and of ages ranging from eight years to over eighty years. persons following different occupations. possessing various degrees of mental capacity and education, and living in widely separated localities": more than 200 were professionals or college students, 500 were employed in mental hospitals. and 150 were high school students. Task

Each subject gave a single-word free association response, orally. to each of the 100 words (spoken by the experimenter); when a response was other than a single word, the experimenter did not record the response and represented it again at the end of the list; the same order was used for all subjects. constructed so that no two contiguous words had an obvious relation to each other.

\section{Data}

(1) Listing of all 100 words. in order presented. along with all single-word responses alphabetically listed under each and accompanied by their frequency (out of 1.000 subjects).

(2) Examination of 3 selected groups for further examination: (a) 100 subjects of collegiate or professional education. (b) 100 subjects of common school education. and (c) 75 subjects under 16 years old. For each of these 3 groups, the following percentages were presented (separately for male. female, and total): (a) individual reactions (idiosyncratic responses). (b) doubtful reactions (grammatical variants of usual responses). (c) reactions given by one other person. (d) reactions given by 2 to 5 other persons, (e) reactions given by 6 to 15 other persons. (f) reactions given by 16 to 100 other persons. and (g) reactions given by more than 100 other persons.

(3) Comparisons of 3 types of subjects - contrasting (those giving opposites), defining (those giving synonyms), and specifying (those giving qualifying or specifying terms)- on 58 selected response words from 11 different stimuli. scored in terms of number and percent responding with each given response.

\section{9}

Keppel, G., \& Strand, B. Z. Free-association responses to the primary responses and other responses selected from the Palermo-Jenkins norms. In L. Postman \& G. Keppel (Eds.). Norms of word association. New York: Academic Press. 1970.

\section{Stimules Material}

234 words selected from Palermo and Jenkins (1964) norms. comprised of: (1) all primary responses to the 200 stimulus words; and (2) selected nonprimary responses, with an association strength of $10 \%$ or greater (except 1 case)

\section{Sablects}

182 (University of California at Berkeley).

Tack

Each subject gave a single-word free association response to each stimulus word.

\section{Data}

(1) Alphabetical listing of all 234 words with the following for each: (a) the Palermo and Jenkins stimulus to which it was a response; and (b) all responses to it. listed in decreasing order of frequency. with separate frequency listings for male. female. and total, as well as percentages. 
(2) Statistical comparison of the Palermo and Jenkins with the present norms.

(3) Listing of 201 Palermo and Jenkins stimulus words, with the following for each: (a) primary response (from Palermo and Jenkins); (b) forward association strength (from Palermo and Jenkins): (c) backward association strength (from present study); (d) whether the word pair (stimulus plus response) is a two-way primary (going in both directions): (e) mutual relatedness score (MR). or degree to which the stimulus and its primary tend to elicit common responses (considering only 10 strongest responses to each): and (f) ranking of word pairs in terms of MR score, in entire list of 201 words.

(4) Listing of 118 Palermo and Jenkins stimulus words. along with the following for each: (a) associative strength of the primary associate: (b) primary associate; (c) associative strength of the strongest response to the primary associate (present study); (d) strongest response to primary associate; and (e) associative strength of the original stimulus to the strongest response to its primary associate.

\section{0}

Kiee. H., \& Eysencr. M. W. Comprehension of abstract and concrete sentences. Joumal of Verbal Learming and Verbal Behavior. 1973. 12. 522-529.

\section{Stimulos Materiab}

80 sentences; all were 9 to 13 syllables long. with constant syntactical structure: 40 were "regular" and 40 were "anomalous" (created by substituting in an incongruous final noun).

Subjects

3 judges.

Task

Each judge rated each sentence on a 5-point concreteness scale (1 $=$ very easy to imagine. $S=$ very difficult to imagine).

Data

(1) Listing of 12 sentences. 3 each of the 4 types listed as follows (a) concrete-meaningful. (b) concrete-anomalous. (c) abstractmeaningful. (d) abstract-anomalous.

(2) Relation of sentence structure to (a) types of interference at presentation and (b) comprehension latency.

\section{1}

KofF. R. H. Systematic changes in children's word-association norms 1916-63. Child Development. 1965. 36. 299-305.

\section{Stimulu Materiah}

51 words from Woodrow and Lowell (1916), selected using the following criteria: (1) The children's primary responses had to be significantly different from the adult primary responses of the Russell and Jenkins (1954) norms. (2) The primary responses had to account for a substantial part of the total responses given in each case.

Subjects

147 public school children. ages 8 to 12 , from a "... large midwestern lower-middle class community."

Task

Each subject wrote down a single-word free association response to each word. presented orally by the experimenter Data

(1) Listing of 4 words which evoked the same primary response in both Woodrow and Lowell plus the present study, with the following for each: (a) primary response. (b) percent of subjects making the response from $W_{\text {oodrow }}$ and Lowell, and (c) percent of subjects making the response from the present study.

(2) Listing of 47 words which evoked different primary responses in the two studies. with the following for each: (a) primary response from Woodrow and Lowell. (b) percent of Woodrow and Lowell subjects making that response. (c) primary response from the present study, and (d) percent of present study subjects making that response.

(3) Comparison of the frequency and percentage of primary. secondary, and tertiary responses given in both Woodrow and Lowell and the present study.

(4) Examination of changing response habits over time.

\section{2}

KRUEGER, W. C. F. The relative difficulty of nonsense syllables. Journal of Experimental Psychology, 1934, 17, 145-153.

\section{Stimalus Materials}

2,183 CVCs, with "Y" used as a vowel.

Subjects

586 (College of the City of Detroit)

Tank

Each subject was presented with $1,200 \mathrm{CVCs}, 300$ in each of 4 sessions; 7 sec were allowed for each CVC, during which time the following occurred: (1) The experimenter orally spelled the CVC twice. (2) The subject wrote down the CVC. (3) The subject wrote a response to the CVC, on the basis of the following instructions: "... you are to make a notation of the idea aroused by each respective syllable... This notation may be a word or a phrase.... If no meaning comes to you at once ... make a dash or draw a line in the place of the notation, or write the word 'none'" 100 practice CVCs were given prior to the actual list.

Data

Alphabetical listing of all $2,183 \mathrm{CVCs}$ within each of 160 relative frequency categories ranging from 1.000 down to 0.145 , in increments of 0.005 .

\section{3}

KuĊera, H., \& Francis, W. N. Computational analysis of present-day American English. Providence, R.I: Brown University Press. 1967.

\section{Stimulus Materiah}

500 samples of about 2.000 words each. " .. . distributed among fifteen categories. representing the full range of subject matter and prose styles. from the sports page of the newspaper to the scientific journal and from popular romantic fiction to abstruse philosophical discussion": total sample was $1,014,232$ words.

Data

(1) Listing of 50.406 different words, in decending order of frequency (alphabetically listed within frequency level) with the following for each: (a) total frequency; (b) number of types of sources in which it occurred (out of 15); and (c) number of samples in which it occurred (out of 500 ).

(2) Listing of same 50,406 words in (1), in alphabetical order. with same 3 items of information as in (1).

(3) Listing of 100 most frequent words. in decreasing order of frequency, with the following for each: (a) observed frequency in each of 15 categories: (b) expected frequency in each of 15 categories: (c) percent of total occurrences in each of 15 categories (d) total frequency of occurrence; and (e) chi-square test: observed vs. expected value.

(4) Listing of the word rankings 1 through 50.406 in descending order of frequency (using ranks instead of words) with the following for each: (a) total frequency of oxurrence; (b) number of different words of that same frequency; (c) number of different words at that frequency or higher; (d) percent of total number of different words at that frequency or higher; (e) total number of words at that frequency [(a) times (b)]; (f) cumulative number of words at that frequency or higher; and $(\mathrm{g})$ percent of total words represented by that category plus higher categories.

(5) Same as (4), for a representative subset of 125 samples selected from the 500 .

(6) Same as (4), for a representative subset of 50 samples selected from the 500 .

(7) Relisting of (4). (5), and (6) in ascending order of frequency (rather than descending). plus an examination of a representative subset of 5 samples selected from the 500 .

(8) Separate listings for each of 50 samples (every 10th one chosen). using the format in (4).

(9) Type-token ratios (and log ratios) for the entire corpus. as well as various subsets (type-token ratio is the number of different words compared to the total number of words).

(10) Least squares fit of $a x+b$ to $\log$ rank vs. $\log$ frequency.

(11) Least squares fit of $a x+b$ to $\log$ frequency vs. $\log$ of number of types of that frequency.

(12) Plot of log rank is. log frequency for the entire corpus. 
(13) Plot of log frequency vs. log of number of different words of that frequency.

(14) Plot of $\log$ frequency vs. cumulative percent of different words at that frequency.

(15) Plot of log frequency vs. cumulative percent of total words at that frequency.

(16) Plot of log frequency vs. cumulative percent of total number of words and total number of different words at that frequency.

(17) Listing of all possible word lengths from 1 to 44 , with the following for each: (a) number of different words of that length; (b) number of different words of that length or shorter; (c) percent of different words of that length or shorter; (d) total number of graphic characters represented by that length word; (e) total number of graphic characters represented by that length word or shorter; and ( $f$ ) percent of graphic characters represented by words of that length or shorter.

(18) Same as (17). except for total words. instead of just different words.

(19) Plot of total frequency for each length, both for number of different words as well as total words.

(20) Extensive examinafion of sentence length, considering all 15 categories of subject area separately, and combined.

(21) Examination of the fit of a $\log$ normal model of word frequency distribution to the obtained data.

\section{4}

Lachman, R., \& Laughery, K. R. Letter association and sequence norms. Psychonomic Science, 1965, 2, 103-104.

\section{Stimulus Material}

26 letters of the alphabet.

Subjects

1.611 (State University of New York at Buffalo).

Task

Association group $(\mathrm{N}=812)$. Each subject responded to each letter with the first letter it made them think of.

Sequence group $(\mathrm{N}=799)$. Each subject responded to each letter with another letter "... that you think would most often come next in everyday words."

Data

(1) Alphabetical listing of all 26 letters with the response frequency of every other letter, as well as itself, to it; results for the association and sequence groups were listed separately.

(2) Comparisons of the present results with those of Underwood and Schulz (1960).

\section{5}

LAFFAL, J. Respense faults in word association as a function of response entropy. Journal of A bnormal and Social Psychology, $1955,50,265-270$.

Stimulus Materials

100 words, selected from the frequency range of 10 to 25 per million from Thorndike and Lorge (1944).

Subjects

80 (State University of lowa).

Task

Each subject gave a single-word free association response to each of 100 words; then, the same list was gone through again and the subject tried to give the same response he gave the first time.

Data

(1) Listing of all 100 words, in decreasing order of response entropy $(\mathrm{H})$, with the following for each: (a) $\mathrm{H}$ score (a measure of the number of different responses given to a stimulus, weighted by the number of subjects giving each); (b) number of different responses given (D); and (c) number of different responses on which one or more "faults" (inability to recall the original response) occurred (F).

(2) Intercorrelations of $H, D, F$, reaction time, and total number of faults.

(3) Comparison of fault frequency among 8 different classes of response words (classes based on total associative probability).
86

LEDGERWOOD, R. A comparison of methods in determining the affective value of uords. American Joumal of Psychology, 1932. 44. $796-797$

\section{Stimulus Materials}

20 names of characters and piaces in the novel The Silver Stallion by James B. Cabell; formulations bearing likeness to words were eliminated; the aim was to compile a list with a variety of constituent letters and word lengths; from these 20 words, 380 pairs were formed-each word being paired with every other one twice, once in each order.

Subjects

7 (University of Maine).

Task

Paired comparison. Each subject went through all 380 pairs and underlined the word from each pair that they "preferred."

Order of merit. After the above task, each subject was given all 20 words singly and asked to order them in terms of preference.

Data

(1) Listing of all 20 words in order of increasing frequency of preference on the paired-comparisons method, with the following for each: (a) rank of word on paired-comparison method, and

(b) rank of word on order-of-merit method.

(2) Rank order correlation of the two methods.

(3) Average rank order correlation (rank order correlation of each subject with every other one was computed and then averaged to form a single correlation) for each of the following: (a) paired comparison method. (b) order of merit method, and (c) both methods combined.

\section{7}

Levinger, G. \& C Clark, J. Emotional factors in the forgetting of word associations. Journal of Abnormal and Social Psychology, 1961, 62. 99-105.

\section{Stimulus Materials}

60 words. of which 30 had emotionally disturbing qualities (from Hull and Lugoff, 1921) and 30 had emotionally neutral qualities (10 from Hull and Lugoff and 20 generated by the authors).

Subjects

34 (University of Michigan)

Task

Session 1

(1) Each subject $(\mathrm{N}=34)$ gave a single-word oral free association response to each stimulus, presented orally.

(2) After this, the list was read again and the subject had to recall the response given the first time through.

Session 2 (4 months later):

(1) Each subject ( $N=27$ now, due to dropout) went through the same stimulus list and again gave the first single-word free association they could think of (no mention was made about recalling the previous one).

(2) After this, each subject rated each word on "several" 7-point scales, including emotionality.

Data

(1) Listing of all 60 words with the following for each: (a) whether it was emotional or neutral (as determined ahead of time); (b) frequency from Thorndike and Lorge (1944); (c) frequency of nonrecall of the response in the second part of Session 1; (d) mean galvanic skin response (GSR) to the word; (e) mean reaction time (RT) between the stimulus and the response; (f) mean rated emotionality (ER), $(\mathrm{g})$ population variability, or the number of different responses given from all 34 subjects; and $(h)$ retest variability, or the number of different responses given by the retested subjects $(\mathrm{N}=27)$ in the 2 different tests.

(2) Comparisons of the relationship between: (a) GSR and response recall, (b) recall of emotional and recall of neutral word responses, (c) recall and ER, and (d) recall and Thorndike and Lorge frequency.

(3) Intercorrelations among 7 response measures.

(4) Factor loadings of these 7 response measures on each of 4 dimensions. 
88

LEY, R. \& LoCAscio, D. Associative reaction time and meaningfulness of CVCVC response terms in pairedassociate learning. Journal of Experimental Psychology, 1970, 83. 445-450.

Stimulos Materials

65 CVCVCs (words and paralogs). taken from a list by Taylor (1959).

Subjects

151 (State University of New York at Albany).

Task

Meaningfulness $(\mathrm{Mn})(\mathrm{N}=123)$. Each subject gave continued free association responses to each CVCVC for $30 \mathrm{sec}$ using Noble's (1952) procedure.

Pronounceability ( $P R)(N=28)$. Each subject rated each CVCVC on a 9-point scale of ease of pronunciation, relative to the other CVCVCs in the list. following the Underwood and Schulz $(1960)$ procedure.

Data

(1) Listing of all 65 CVCVCs, in increasing order of Mn with the following for each: (a) mean of $\mathrm{Mn}$, (b) standard deviation of $\mathbf{M n}$. (c) mean of PR. (d) standard deviation of PR. and (e) mean associative reaction time (RT).

(2) Comparison of the effects of RT, Mn, PR, and LF (summed log frequency of the component letters) on paired associate learning.

\section{9}

LiLly, R. S. The qualification of evaluative adjectives by frequency adverbs. Journal of Verbal Learning and Verbal Behavior. 1968. 7. 333-336.

Stimulus Materiat

16 adjectives: 7 positive ("pleasant") and 7 negative ("unpleasant"). plus 2 neutral ("ordinary" and "average").

16 adverbs: 8 of positive frequency ("often") and 8 of negative frequency ("seldom").

Sobject:

317 (Kent State University). Task

Each subject rated a total of 320 items in 2 questionnaires:

Questionnaire 1: 160 items composed of (a) 144 combinations of 8 positive frequency adverbs with the 16 adjectives, (b) 16 unmodified adjectives, and (c) 16 repeated items.

Questionnaire 2: 160 items with the same format as above, except negative frequency adverbs were used.

The ratings were done on a 9-point scale of favorableness; the subjects also made pair comparisons of the stimuli after each questionnaire, with the stimuli arranged into 16 blocks of 4 stimuli each, and the subject ranking them within each block on a favorableness dimension; the questionnaires were done 1 week apart.

Dath

(1) Listing of all 16 adverbs, with the multiplying scale value for each (determined by how much it changed the rating of the adjective it was paired with).

(2) Listing of all 16 adjectives, with the following for each: (a) mean favorableness rating on context of positive frequency adverbs; (b) mean favorableness rating in context of negative frequency adverbs; (c) additive constant (K), reflecting the arbitrary zero point of the empirical scale values (see Cliff, 1959) for positive frequency adverb context: and (d) $\mathbf{K}$ for negative frequency adverb context.

(3) Correlations: (a) repeated items in each questionnaire; (b) unmodified adjectives in both questionnaires; and (c) successive-interval vs. pair-comparison rating methods.

(4) Eigenvalues for negative and positive frequency adverbs (see Gulliksen. 1959).

(5) Average $K$ values for positive and negative frequency adverbs.

\section{0}

LIPPMAN. M. Z. Enactive imagery in paired-associate learning. Memory and Cognition, 1974, 2. 385-390.

Stimalos Materials

226 verbs. selected by a systematic search of the popular literature.

Subjects

115 (Western Washington State College). Task

Enactive imagery ratings $(\mathrm{El})(\mathrm{N}=85)$. Subjects rated each verb .... as to the ease or difficulty with which they arouse the sensation of movement or action" on a-7-point scale.

Frequency ratings $(f)(N=30)$. Subjects rated each verb on the ". . . number of times you have experienced it" on a 7 -point scale; experience refers to how often one has seen, heard, or used the word in speech or writing; procedure was modeled after Noble (1953). Data

(1) Alphabetical listing of all 226 verbs with the following for each: (a) mean EI, (b) standard deviation of EI, (c) mean $f$, and (d) standard deviation of $f$.

(2) Extensive examination of the influence of EI on paired-associate learning.

\section{1}

Locascio, D., \& LEY, R. Scaled-rated meaningfulness of 319 CVCVC words and paralogs previously assessed for associative reaction time. Joumal of Verbal Leaming and Verbal Behavior. 1972, 11, 243-250.

Stimulus Materials

319 CVCVCs (words and paralogs) from Taylor and Kimble (1967).

Subjects

39 (State University of New York at Albany).

Tark

Each subject rated each CVCVC (a third at a time, over 3 successive days) on a 5-point scale of the relative number of associations evoked by the stimulus. using Noble's (1961) procedure.

Data

(1) Listing of all 319 CVCVCs, in increasing order of rated frequency, with the following for each: (a) scaled-rated meaningfulness $\left(m^{\prime}\right)$ : mean scale value; and (b) rated frequency $\left(a^{\prime}\right)$ : this was a conversion of $m^{\prime}$ by assigning ordinal weights of 1 through 5 to the 5 rating categories, and taking a weighted mean.

(2) Correlations between $m^{\prime}$ and reaction time (associative).

(3) Frequency distribution of $m^{\prime}$ values.

\section{2}

Loess, H. Brown. A., \& Campeell. J. Cultural norms for items in 30 taxonomic categories. Psychonomic Monograph Supplements, 1969. 3Whole No. 39), 69-86.

Stimulns Materials

30 taxonomic categories. 26 from Bousfield, Cohen, and Witmarsh (1957) plus 4 new ones.

Subjects

470 (College of Wooster).

Tak

Each subject gave 4 responses to either the 26 Bousfield, Cohen, and Witmarsh categories $(N=214)$ or those 26 plus the 4 new ones $(N=256)$; an illustrative plus a practice category were given prior to the test.

Datn

(1) Listing of all 30 categories, in increasing order of total number of responses; within each category, the responses were listed in decreasing frequency, with the following for each response:

(a) number of 30-category subjects giving the word first;

(b) number of 30-category subjects giving the word second;

(c) number of 30-category subjects giving the word third; 
(d) number of 30-category subjects giving the word fourth; (e) veighted total of 30-category data (WTD TOT): obtained by weighting the positions 1.2 .3 , and 4 by the weights $4,3,2$, and 1 (respectively) and summing the totals; $(f)$ total frequency, summing across all positions. for the 30-category subjects: (g) total frequency. summing across all positions. for the 26-category subjects; and (h) sum of $(f)$ and $(g)$ above. or the total number of subjects giving that response.

(2) Rank-order correlation between all the following. separately for each of the 30 categories (based on the most frequent 36 responses of the 30-category subjects): (a) dominant response vs. unweighted total; (b) dominant response vs. weighted total (c) unweighted vs. weighted total; (d) 26-category vs. 30-category sample of subjects; (e) male vs. female; and (f) present study vs. Bousfield et al.

(3) Listing of all 30 categories with the following for each: (a) total number of different words given; (b) total number of words with a probability of $1 \%$ or greater; and (c) total number of words with a probability of $10 \%$ or greater.

\section{3}

Loftus. E. F., \& Freedman, J. L. Effect of category-name frequency on the speed of naming an instance of the category. Journal of Verbal Learning and Verbal Behavior, 1972, 11. 343-347.

Stimulus Materiak

18 categories with 2 names for each (i.e., tool and implement) for a total of 36 category labels. 1 high and 1 low frequency from Thorndike and Lorge (1944) norms.

Subjects Task

8 (New School for Social Research).

Single free association $(N=24)$. Each subject responded to 66 category names ( 36 critical ones plus 30 fillers) with the first member of that category they could think of.

Question answering $(\mathrm{N}=24)$. Each subject had to answer one of 4 questions with respect to each of the 66 category names: (1) give the last letter of the category name; (2) give the first letter of the category name; (3) give the number of letters in the category name; and (4) give the first member of that category which you can think of.

\section{Date}

(1) Listing of all 36 critical categories, grouped by frequency level (high and low), with the following for each: (a) mean reaction time for the free association task; and (b) mean reaction time for the response to the fourth question of the question group.

(2) Overall means for each class of category for each task.

(3) Statistical test of the reaction time difference between highand low-frequency category names.

\section{4}

Loftus, E. F., \& SChefF, R. W. Categorization norms for fifty representative instances. Joumal of Experimental Psychology Monograph, 1971, No. 2, 355-364.

Stimulus Materials

50 nouns.

Sabjects

200 (New School of Social Research).

Tack

Each subject was given the list of 50 words 3 times in a row, each time giving a different superordinate category in which the response belonged.

Data

Listing of all 50 nouns, with the following for each: the 10 most frequent category responses, in decreasing order of total frequency, with separate frequencies for (a) first occurrence, (b) second occurrence, (c) third occurrence, and (d) overall.

\section{5}

LORGE. I. The semantic count of the 570 commonest English n'ords. New York: Bureau of Publications. Columbia University, 1949.

\section{Stimulus Materiak}

5 million words, based on 2 separate $2 \frac{1}{2}$ million word counts. Data

(1) Alphabetical listing of all words which were not based on the total 5 million word sample, along with its frequency based on $21 / 2$ million $(\mathrm{C})$ or its frequency based on an indeterminant pool (M). (NOTE: These are mainly words from $A$ through $O$ in the alphabet.)

(2) Alphabetical listing of all 570 different words with the following for each: (a) number of the word as listed in the Oxford English Dictionary (1933); (b) frequency (per thousand, or "mille") of each definition of the word, along with the definition listing; and (c) number of different sources in which each definition of each word occurred $(29$ sources total).

\section{6}

MANDler, G. Associative frequency and associative prepotency as measures of response to nonsense syllables. American Journal of Psychology, 1955, 68, 662-665.

\section{Stimolus Material}

100 CVCs from Glaze (1928), with 16, 17, 17, 17, 16, and 17 selected from the $0 \%, 20 \%, 40 \%, 60 \%, 80 \%$, and $100 \%$ association value classes, respectively.

Subjects

34 (Harvard University).

Taak

Each subject wrote down as many different responses to each $\mathrm{CVC}$ in $30 \mathrm{sec}$ as he could (based on looks, sound, or other associations).

\section{Data}

(1) Alphabetical listing of all 100 CVCs with the following for each: (a) associative frequency $(f)$ : mean number of associations elicited by the CVC; (b) associative potency (p): arc sin transformation of the percent of subjects who gave the most frequent associative response; (c) standard deviation of $f$, and (d) most frequent response.

(2) Comparison of $f$ and $p$ with Glaze's data.

(3) Correlations among $f, p$, and Krueger's (1934) values.

(4) Correlation between $f$ and $p$.

\section{7}

ManN, M. B. Studies in language behavior: The quantitative differentiation of samples of written language. Psychological Monograph, 1944, 56(Whole No. 255), 41-74.

\section{Stimulus Material}

Written language samples of 2,800 words taken from each of 48 subjects.

Subjects

24 (State University of Iowa); 24 psychotic (schizophrenic) patients.

Task

Each subject wrote a story of his life, and 2,800 words of this was used.

Dats

(1) Extensive analysis of the type token ratio (TTR) (number of different words in the sample divided by the number of total words) for normals and schizophrenics on: (a) different segments of the passages (each successive 100 words), (b) males and females, and (c) types of words (parts of speech).

(2) Listing of the 100 most common words for normals and the 100 most common words for schizophrenics, with the following for each: (a) frequency for normals, (b) frequency for schizophrenics. and (c) part of speech. 


\section{8}

Marshall. G. R.. \& Cofer. C. N. Single-word free-association norms for 328 responses from the Connecticut cultural norms for verbal items in categories. In L. Postman and G. Keppel (Eds.). Norms of nond association. New York: Academic Press. 1970.

Stimulus Materials

328 responses from 21 of Cohen, Bousfield, and Witmarsh's (1957) 43 categories.

Sabjects

300 (Brooklyn College).

Tack

Each subject gave a single-word free association response to a third of the words used (either 109 or 110); in the presentation list. 2 responses from the same category were never presented contiguously.

Data

Listing of each of the 328 words. alphabetically within the appropriate conceptual categories. with every response (in decending order of frequency) and its frequency listed with the stimulus word.

\section{9}

Mayzner, M. S., \& Tresselt, M. E. Tables of single-letter and digram frequency counts for various word-length and letter-position combinations. Psychonomic Monograph Supplements. 1965. 1(Whole No. 2). 13-32.

Stimulus Materials

20.000 words of 3 to 7 letters in length. selected from 100 samples of 200 words each; Underwood and Schulz (1960) technique was employed. sampling nexispapers. magazines. fiction. nonfiction. etc.

Data

(1) Alphabetical listing of all single letters with the following for each: (a) frequency of occurrence at each of 25 possible positions: first letter of a 3-letter word (3/1). second letter of a 3-letter word (3 : 2), etc.; (b) total frequency across all possible positions; and (c) Underwood and Schulz frequency.

(2) Alphabetical listing of all bigrams found with the following for each: (a) frequency of occurrence at each of 20 possible positions: first and second letters of a 3-letter word (3/1-2), etc.; (b) total frequency across all possible positions: and (c) Underwood and Schulz frequency.

(3) Rank difference correlation between Underwood and Schulz and present study for single letters.

\section{0}

Mayzner. M. S., Tresselt. M. E.. \& Wolin, B. R. Tables of trigram frequency counts for various word-length and letterposition combinations. Psychonomic Monograph Supplements. 1965. 1(Whole No. 3), 33-78.

Stimulas Material

Same as Mavzner and Tresselt, 1965.

Data

(1) Alphabetical listing of all 3-letter combinations found, with the following for each: (a) frequency in each of 15 possible positions: all 3 letters of a 3 -letter word $(3 / 1-3)$. first 3 letters of a 4-letter word (4/1-3), etc.; and (b) total frequency across all positions.

(2) Total frequencies for each of the 15 positions (summed across all trigrams). plus overall total frequency.

\section{1}

Mayzner. M. S.. Tresselt. M. E.. \& Wolin. B. R. Tables of tetragram frequency counts for various word-length and letter-position combinations. Psychonomic Monograph Supplements. 1965. 1(Whole No. 4), 79-143.

Stimulos Materials

Same as Mayzner and Tresselt (1\%5). excluding all 3-letter words.
Data

(1) Alphabetical listing of all 4-letter combinations found, with the following for each: (a) frequency in each of 10 possible positions: all 4 letters in a 4 -letter word $(4 / 1-4)$. first 4 letters in a 5 -letter word (5/1.4), etc.; and (b) total frequency across all positions.

(2) Total frequencies for each of the $\mathbf{1 0}$ positions (summed across all trigrams). plus overall total frequency.

\section{2}

Mayzner. M. S., Tresselt. M. E.. \& Wolin, B. R. Tables of pentagram frequency counts for various word-length and letter position combinations. Psychonomic Monograph Supplements. 1955. I(Whole No. 5). 145-185.

\section{Stimulus Materials}

Same as Mayzner and Tresselt (1965). excluding all 3-letter and 4-letter words.

Data

Alphabetical listing of all 5-letter combinations found. with the following for each: (a) frequency in each of 6 possible positions: all 5 letters in a 5-letter word (5/1-5), first 5 letters in a 6-letter (6/1-5). etc.: and (b) total frequency across all positions.

103

McNulty. J. A. An analysis of recall and recognition processes in verbal learning. Joumal of Verbal Leaming and Verbal Behavior. 195. 4. 430-436.

\section{Stimalus Material}

96 8-letter sequences, 32 at each of 3 onders of approximation to English (first, third, and tert), using procedures described by Shannon (1948)

Data

(1) Listing of all 96 sequences. by order of approximation to English.

(2) Examination of effects of order of approximation on recall and recognition performance.

\section{4}

Mecherikoff. M.. \& Horton. D. L. Preferences for letters of the alphabet. Joumal of Applied Psychology, 1959. 43. 114-116.

\section{Stimulos Material}

7 letters (t. p. n. k. s. v, and g), chosen on the basis of 2 previous studies as being (a) neutral in rated looks and sound and (b) neutral in overall rated preference.

Sabjects

Task

82 (University of Minnesota)

Each subject selected the letter he preferred most in each of 21 pairs formed out of the 7 letters

Data

(1) Listing of all 7 letters in matrix form. with the proportion of time each letter was chosen over every other letter.

(2) Ratio of the number of times a letter was selected to the number of times it could be selected.

(3) Analysis of sex and position differences.

\section{5}

Mickelson. N. I. Meaningfulness $(m)$ indices for 120 nouns for children aged nine years. Joumal of Verbal Leaming and Verbal Behavior. 1969. 8. 80-82.

\section{Stimulus Material}

120 nouns randomly selected from Thomdike and Lorge (1944); 60 were $A$ frequency and 60 were AA frequency.

\section{Subjects}

135 9-year-old school children in Victoria. British Columbia. Canada.

Task

Each subject gave $60 \mathrm{sec}$ of continued free associations to each word, followine Noble's (1952) procedure. 
Data

(1) Listing of all 120 nouns. in decreasing order of meaningfulness $(m)$. with the $m$ values for each.

(2) Study evaluating the reliability of the results with 204 children using 48 of the nouns.

\section{6}

Miller, G. A., \& Selfridge, J. A. Verbal context and the recall of meaningful material. American Joumal of Psychology, 1950, 63, 176-185.

Stimulus Material

Word strings.

Subjects

The authors.

Task

Zero-arder approximation. The word strings were drawn at random from a dictionary. without regard to frequency of occurrence in the language (using Thorndike and Lorge, 1944).

First-order approximation. Scrambling of the words from the higher order series (frequency taken into account).

Second-order approximation. A common word was presented to a person and he put it into a sentence; the word following the critical one in the sentence he created was given to another person to put into another sentence. etc., until a chain of words of the desired length was formed.

Third-to seventh-order approximations. Same procedure as for the second order. except that 2 to 6 previous words were given to the subject to put in a sentence; then the new series-minus the first word and plus the last added one-would be given the next subject. Data

(1) 4 examples of 0.1 st. $2 \mathrm{nd}, 3 \mathrm{rd}$. 4th. 5 th. and 7 th orders of approximation, plus text, with one example of each of 4 lengths $(10$. 20. 30, and 50 words) at each order of approximation and text.

(2) Relationship of order'of approximation to learning.

\section{7}

Miller. G. A.. Bruner, J. S., \& Postman, L. Familiarity of letter sequences and tachistoscopic identification. Journal of General Psychology, 1954, 50, 129-139.

\section{Stimulus Material}

60 8.letter pseudowords. constructed according to the procedure discussed by Shannon (1948); the following are the types of pseudowords:

0 -order. Formed by selecting single letters from the alphabet randomly, with all letters having an equal probability of being chosen.

1-order. Formed by selecting single letters according to their frequency of occurrence in printed English.

2-order. Formed by selecting pairs of letters according to their frequency of occurrence in the written English language together; a letter was selected, then the letter following it on its next occurrence in text was written down; then the next occurrence of that new letter in the text was located and the letter following that was recorded, etc. (all final letters were ignored).

4-order. Formed by selecting letters according to the 3 letters preceding it; if the word began with "VER," the text would be searched until the next occurrence of "VER," then the next letter would be added to form "VERN"; then "ERN's" next occurrence would be sought to determine the next single letter in the series, etc. Data

(1) Listing of all 60 pseudowords formed on the basis of the above rules. with 15 in each of the 4 classes.

(2) Study comparing tachistoscopic perception of the pseudowords as a function of their order of structure.

\section{8}

Miller. G. A., Newman, E. B., \& Friedman, E. A. Lengthfrequency statistics for written English. Information and Control, 1958. 1. 370-389.

Stimulus Material

Content and function words from 4 sources: (1) Fries (1952)
(2) Bible. (3) article by William James, and (4) Atlantic Monthly magazine.

Data

(1) Listing of 363 function words, alphabetically within 13 word-length groups, with the frequency of occurrence of each.

(2) Extensive comparisons of content and function words looking at word length and frequency of occurrence.

109

Miller, K. M. Free-association responses of English and Australian students to 100 words from the Kent-Rosanoff word association test. In L. Postman \& G. Keppel (Fds.), Norms of word association. New York: Academic Press. 1970.

Stimulus Materiab

100 stimulus words from Kent and Rosanoff (1910).

Subjects

400 from 7 universities in England; 200 (Universities of Sydney and Tasmania).

Task

Each subject gave a single-word free association response to each of the 100 stimuli.

Data

(1) Listing of all 100 words, with the following information on the English subjects: (a) the 5 most frequent responses and their frequencies, and (b) total number of different responses.

(2) Listing of the 100 words, with the same 2 items on the Australian subjects.

\section{0}

Montagive, W. E., \& Kiess, H. O. The associability of CVC pairs. Joumal of Experimental Psychology Monograph Supplement, 1968. 78(No. 2), 1-38.

\section{Amociability I (AS-I)}

\section{Stimulus Material}

320 pairs of CVCs, 80 from each of the following 4 association value levels from Archer (1960): $2 \%$ to $13 \%, 38 \%$ to $47 \%, 66 \%$ to $67 \%$, and $99 \%$ to $100 \%$; within each level, 40 pairs were formed from the lowest $80 \mathrm{CVCs}$ of that level, and $\mathbf{4 0}$ from the highest level (to assure within-pair homogeneity of association value).

Subjects

Task

240 (University of Illinois).

Each subject looked at $90 \mathrm{CVC}$ pairs ( 20 from each level. plus 10 repeats) and wrote down the first associative device, if any, that a pair suggested to them; the device was to include both CVCs; if no association occurred, they were to leave it blank.

\section{Aseociability II (AS-II)}

\section{Stimulus Material}

320 pairs of CVCs, 80 from each of the association value classes of Archer as listed above; 10 from each class remained the same as in AS-I, and 70 were constructed to have minimum formal similarity.

Subjects

Task

240 (University of Illinois).

Same as in AS-I.

\section{Stimulus Materials}

\section{Anociability III (AS.II)}

(1) 40 CVC pairs from AS-I (10 from each level) (AS-1).

(2) 28 CVC pairs from Richardson and Erlebacher (1958) (RE).

(3) 80 CVC pairs from AS-I (20 from each level) with the order reversed from AS-I (RS).

(4) 60 CVC pairs high in stimulus association value (AV) from Archer $(96 \%$ to $100 \%)$ and low in response $A V(13 \%$ to $22 \%)$ (H-L).

(5) 59 CVC pairs of low stimulus AV (13\% to $22 \%)$ and high response $\mathrm{AV}(\% \%$ to $100 \%)(\mathrm{L}-\mathrm{H})$.

(6) 25 CVC pairs of high stimulus and response AV (H-H).

(7) 24 CVC pairs of low stimulus and response AVE (L-L).

\section{Subjects}

240 (University of Illinois). 
Task

Same as AS-I.

Data

(1) Correlations: (a) Archer $\mathrm{AV}$ and male's associative scaling (MAS) for each of $4 \mathrm{AV}$ levels (and overall). considering AS-I and AS-II separately; (b) Archer AV and female's associative scaling (FAS) for each of 4 AV levels (and overall). for AS-I and AS-I separately: and (c) FAS and MAS at each AV level (and overall). for AS-I and AS-II separately.

(2) Analysis of AS ratings for AS-I and AS-II considering sex and practice effects.

(3) Listing of 729 pairs of equal AV (320 from AS-I. 280 from AS-II, and 129 from AS-III), with the following for each: (a) study in which it was rated (AS-I. -II. or -III). (b) AV for the stmulus (SAV), (c) AV for the response (RAV), (d) MAS, (e) FAS. and (f) mean AS, across sezes.

(4) Listing of 118 pairs mixed on AV (59 H-L and $59 \mathrm{~L} \cdot \mathrm{H}$ ) from AS-III. with the following for each: (a) SAV, (b) RAV, (c) MAS and (d) FAS.

(5) Analysis of the data from AS-III.

(6) Reliability correlation on repeated pairs for each of the 3 studies.

(7) Intercorrelation of FAS and MAS in AS-III.

(8) Intercorrelation of pairs common to AS-I and AS-III, plus a statistical test.

(9) Intercorrelations of AS-I pairs with the same ones reversed in AS-III. separately by sex. plus a statistical test.

(10) Analysis on mixed pairs in AS-III.

(11) In AS-III. correlation of (a) AS and stimulus AV. and (b) $A S$ and response $A V$ in the mixed pairs (separately for $H \cdot L$ and L-H).

(12) Listing of the 28 pairs from Richardson and Erlebacher. with the following for each: (a) SAV. (b) RAV, (c) ease of learning value (EL) from Richardson and Erlebacher. (d) common meaning value (CM) from Richardson and Erlebacher, (e) MAS, and (f) FAS

(13) Correlations between FAS and EL, FAS and CM. MAS and EL. and MAS and CM.

(14) Relationship of AV and AS to learning in a series of experiments.

111

Newman. E. B., \& Gerstman, L. J. A new method for analyzing printed English. Joumal of Experimental Psychology. 1952. 44. $114-125$.

\section{Stimulos Materials}

10.000 letters sampled from the King James Bible (Isaiah 29 to 311 .

Data

(1) Alphabetical listing of all 26 letters plus "period" and "space." in matrix form. along with the frequency with which each of the 28 items followed it immediately.

(2) Same analysis as above, except for the items following it 9 letters later.

(3) Extensive analysis of a new system for analyzing printed English: the coefficient of constraint.

\section{2}

Noble, C. E. An analysis of meaning. Psychological Review, 1952. 59, 421-430.

\section{Stimalus Materials}

96 word and nonword disyllables; words (about $80 \%$ of the list) were selected from Thorndike and Lorge (1944) G count to represent (a) nearly all the alphabet in initial letters and (b) the extremes of usage frequency: nonwords (about $20 \%$ ) were chosen from Dunlap's (1933) list and created by author.

Subjects

119 (Human Resources Research Center).

\section{Tak}

Each subject gave continuous free association responses to each of the 96 words for $60 \mathrm{sec}$; the following instructions were given: "This is a test to see how many words you can think of and write down in a short time. You will be given a key word and you are to write down as many other words which the key word brings to mind as you can. These other words which you write down may be things. placed. ideas, events. or whatever you happen to think of when you see the key word.... Be sure to think back to the key word after each word you write down . .."; 2 practice words were given; 1 word was presented per page. with it being repeatedly written down the left side with a blank space next to each.

Data

(1) Listing of all 9 disyllables, in increasing order of meaningfulness $(m)$, with the following for each: (a) mean $m$ value, (b) standard deviation of $m$, (c) ranking, out of the 96 disyllables, and (d) order in the presentation list.

(2) Intergroup reliability coefficients for $\boldsymbol{m}$ scale, based on mean $m$ values for 4 groups of subjects.

\section{3}

Noble, C. E. The meaning-familiarity relationship. Psychological Review: 1953. 60, 89-98.

\section{Stimales Material}

96 disyllables used in Noble (1952).

Subject:

200 airmen undergoing routine classification testing at the Human Resources Research Center.

Tack

Each subject rated each disyllable on a 5-point scale relating to how many times he has experienced (see, heard, or used) the disyllable: 4 practice words given.

Data

(1) Listing of the 96 syllables. in order of increasing familiarity $(t)$, with the following for each: $f$ score. defined by the normal deviate transformation (score divided by the standard deviation, plus 1.34 ) of the ratings.

(2) Relative frequency distribution of graphic ratings in 5 categories of the Familiarity Schedule as a function of $f$ value derived from the method of graded dichotomies (from Attneave. 1949) for 12 disyllables.

(3) Cumulative proportions of ratings in 5 categories of the Familiarity Schedule for 12 disyllables.

(4) Relationships among median ordinal rating, mean ordinal rating. and graded dichotomies scale values derived from the Familiarity Schedule.

(5) Scattergram of the relationship between $f$ and meaning, or $\boldsymbol{m}$ (from Noble. 1952).

114

Noble. C. E. Tables of the $e$ and $m$ scales. Psychological Reports. 1958. 4. 590.

\section{Stimulus Materials}

9 disyllables from Noble (1952).

\section{Data}

Alphabetical listing of 96 disyllables, with the following for each:

(1) Mean rated emotionality (e). from Noble (1958).

(2) Median number of associations $(\mathrm{m})$. from Noble (1952).

\section{5}

Noble. C. E. Measurements of association value $(a)$. rated associations $\left(a^{\prime}\right)$. and scaled meaningfulness $\left(m^{\prime}\right)$ for the 2100 combinations of the English alphabet. Psychological Repons. 1961. 8. 487-521.

\section{Stimules Material}

$2.100 \mathrm{CVCs}$, including all possible ones with the following restrictions: (a) " $Y$ " is considered a consonant and (b) no letter repetitions within a CVC. 


\section{Subjects \\ 200 (Montana State University). \\ Task}

Each subject rated each CVC on the number of things or ideas it made him think of, on a S-point scale. using Noble. Stockwell. and Pryer's (1957) instructions (8 sec per CVC).

Data

(1) Alphabetical listing of all 2.100 CVCs. with the following for each: (a) Association value (a): percentage of responses which were not "NONE" in terms of rated number of associations. (b) Rated number of associations $\left(a^{\prime}\right)$ : weighting of the response frequencies in categories "NONE" through "VERY MANY" by the weights 1 through 5. respectively: these were then summed and divided by the total number. (c) Variance of $a\left(o^{2}\right)$.

(2) Reliability correlation on ratings, comparing 2 halves of the subjects on 100 randomly selected CVCs.

(3) Cross-cultural reliability correlations on these same $100 \mathrm{CVCs}$ (Louisiana vs. Montana).

(4) Correlation of $a$ with Krueger's (1934) $\mathrm{m}$. for 100 selected CVCs.

(5) $a^{2}$ plotted as a function of $a^{\prime}$ for 120 representative CVCs.

(6) Regression plot, correlation. and correlation ratio of $a$ vs. $a^{\prime}$ for these same 120 CVCs in (5).

(7) Listing of all $2.100 \mathrm{CVCs}$ in rank order of increasing scaled meaningfulness $\left(m^{\prime}\right)$, with the $m$ value for each (where $m^{\prime}$ is a median meaningfulness value).

(8) Relative frequencies of judgments in 5 categories for $21 \mathrm{CVCs}$ as a function of $m^{\prime}$.

(9) Nomographic plot of $a$ and $a$ as a function of $m$.

(10) Scatterplot and correlation between $m^{\prime}$ and Mandler's (1955) $m$ for 100 CVCs used by Mandler.

(11) Correlation between Archer's (1960) association values and a. $a^{\prime}$. and $m^{\prime}$ for $120 \mathrm{CVCs}$ in (5).

\section{6}

Noble. C. E. Meaningfulness and familiarity. In C. N. Cofer \& B. S. Musgrave (Eds.), Verbal behavior and learning: Problems and processes. New York: McGraw-Hill, 1963. Stimulus Materials

CVC production-see below.

Subjects

200 (Montana State University).

Task

Each subject generated a CVC by producing first any consonant. then any vowel, and then any consonant (except the consonant produced first).

Data

(1) Alphabetical listing of all 26 letters and their relative frequency of production at each position (first and third for consonants, and second for vowels).

(2) Correlation between single-letter frequency count of Underwood and Schulz (1960) and production frequency for each of the 3 positions $(C, V$, and $C)$ separately.

(3) Correlation between the relative production frequency for zonsonants at the tirst vs. the third position.

(4) Statistical test of whether first consonants occurred at chance level.

(5) Correlations: (a) $m^{\prime}$ values (Noble, 1961) and summed production frequency values for the CVCs: and (b) $m^{\prime}$ values and summed frequency of single letters from Underwood and Schulz, for the CVCs.

(6) Graphical comparison between CVC sum from present study ind the single-letter frequency CVC sum from Underwood and Schulz at each of 9 levels of $\boldsymbol{m}^{\prime}$.

117

VoBle, C. E. Comparative pronounceability ratings $(p)$ of
$100 \mathrm{CVCs}$ in two college populations. Psychonomic Science, $1967,8.433-434$

\section{Stimulus Materials}

100 CVCs repres:nting the full range of $2,100 \mathrm{CVCs}$ presented by Noble $(1 \% 1)$ in terms of $m^{\prime}$ values.

Subject:

100 (University of Montana): 100 (University of Georgia).

Task

Each subject rated each $\mathrm{CVC}$ on a 9-point pronounceability scale. using Underwood and Schulz's (1960) procedure.

Data

(1) Listing of all $100 \mathrm{CVCs}$, with the mean pronounceability ( $p$ ) value for each.

(2) Reliability correlations both within and between college samples.

(3) Regression of Montana norms on Georgia norms.

\section{8}

Noble. C. E., \& Parker, G. V. C. The Montana scale of meaningfulness (m). Psychological Reports, 1960, 7. 325-331.

Stimulus Materials

96 disyllables taken from Noble (1952).

Subjects

Task

00 (Montana State University).

Each subject gave $60 \mathrm{sec}$ of continued free associations to each disyllable, using Noble's (1952) procedure.

Date

(1) Alphabetical listing of all 96 disyllables, with the following for each: (a) mean meaningfulness $(\bar{m})$, and (b) median meaningfulness $(m)$.

(2) Comparison of present norms with previous norms (Noble. 1952).

(3) Correlation of verbal fluency (total number of associations) and verbal achievement (centile score on College Qualification Test).

(4) Reliability of scale: intergroup correlations for both $\bar{m}$ and m.

\section{9}

Noble, C. E., Stockwell, F. E., \& Pryer, M. W. Meaningfulness $\left(m^{\prime}\right)$ and association value $(a)$ in paired-associate syllable learning. Psychological Reports, 1957, 3, 441-452.

\section{Stimulw Material}

100 CVCs, randomly sampled from Hilgard (1951), excluding CVCs with "Y" as a vowel.

Subjects

200 (Louisiana State University).

\section{Task}

Each subject rated each CVC on the number of things or ideas it made him think of, on a 5-point scale; subjects were asked to spell and pronounce each $\mathrm{CVC}$ to themselves prior to rating it; 4 practice CVCs were given.

\section{Data}

(1) Alphabetical listing of all $100 \mathrm{CVCs}$, with the following for each: (a) Association value (a): percentage of responses which were not "NONE" in terms of rated number of associations. (b) Mean ratings $\left(a^{\prime}\right)$ : weighting of the response frequencies in categories "NONE" through "VERY MANY" by the weights 1 through 5, respectively; these were then summed and divided by the total number. (c) Scaled meaningfulness $\left(m^{\prime}\right)$ : median scale value.

(2) Relative frequency distributions of graphic ratings in the 5 categories of the Association Schedule for 10 representative syllables as a function of $\boldsymbol{m}^{\prime}$.

(3) Graphed relationship between $a^{\prime}$ and $m^{\prime}$.

(4) Intercorrelations of $a$ and association values reported by Glaze (1928), Hull (1933), and Krueger (1934).

(5) Correlation of Mandler's (1955) $m$ and Krueger's $a$.

(6) Effects of $m^{\prime}$ on paired-associate learning. 


\section{0}

Noble. C. E. Sutker, P. B., \& Jones, H. R. On the sigmoidal law relating association value $(a)$ and scaled meaningfulness $\left(m^{\prime}\right)$. Perceptual and Motor Skills, 1968, 26, 375-386.

Stimulus Materials

$500 \mathrm{CVCs}$ from Noble $(1 \% 1) ; 400$ were drawn from $m^{\prime}$ range of 3.0 to 4.8 and 100 were drawn from $m^{\prime}$ values less than 3.0 .

Subjects

219 (University of Georgia).

Task

Each subject rated every CVC on a 5-point scale of number of associations which the CVC brought to mind; $8 \mathrm{sec}$ were allowed to rate each CVC.

Date

(1) Alphabetical listing of all 500 CVCs with the following for each: (a) Association value (a): relative frequency of responses exceeding the "NONE" category (see Noble. 1961). (b) Rated number of associations $\left(a^{\prime}\right)$ : weighting of the category ratings to produce an adjusted total score (see Noble, 1\%1). (c) Scaled meaningfulness $\left(m^{\prime}\right)$ : median scale score transformation (see Noble, 1961).

(2) Cross-cultural comparisons on the various measures, comparing Montana and Georgia.

(3) Comparison of the relationship between $a$ and $\mathbf{m}^{\prime}$.

\section{1}

NOdINE, C. F., \& HARDT, J. V. Generated meaningfulness of single letters as a function of position in CVC trigrams. Psychonomic Science, 1968, 10.129-130.

Stimulus Materials

All 2.480 CVCs in the Archer (1960) norms.

\section{Dat}

(1) Listing of all 26 letters of the alphabet, with the mean and standard deviation of generated meaningfulness (GM) values for both first and third position for each consonant and for the middle position for each vowel. Calculation of GM: for each initial consonant, all trigrams with that initial letter were summed and meaningfulness values were averaged to come up with a $G M$ value for that consonant in that position; the same was done for each letter in each position; CVCs where a consonant was repeated were excluded; " $Y$ " was considered only as a consonant.

(2) Correlation of GM and single-letter frequencies (total, initial, and terminal letter frequencies).

\section{2}

Nodine, C. F., \& Hardt, J. V. A measure of pronunciability of CVC trigrams. Behavior Research Methods and Instrumentation, 1969. 1, 210-216.

\section{Stimulus Materials}

2,100 CVCs; all possible CVCs with the exception of (a) those containing duplication of consonants in initial and terminal positions and (b) those containing " $Y$ " as a vowel.

Subjects

40 (Camegie-Mellon University).

\section{Tack}

Each subject pronounced 525 CVCs, with 3 sec given for each; list was presented twice in succession.

Data

(1) Listing of each of 2.100 CVCs under its appropriate mean pronunciation latency (from stimulus onset to the start of pronunciation) class: 30 classes were used, from 0.53 to $1.73 \mathrm{sec}$, in $0.04-\mathrm{sec}$ intervals.

(2) Comparison of overall mean latencies with latencies from Gorfein (1967) and correlation of latencies for the 144 common CVCs.

(3) Examination of practice effects.

(4) Comparison of latencies between repetitions.

(5) Rank-order correlations on latencies for 4 forms of the items to check for equivalence of latency distributions.
(6) Correlation between pronunciation latency and Archer's (1960) $\mathrm{m}$.

(7) Plot of the average pronunciation latency for CVCs in each of 10 ranges of Archer's $m: 0 \%$ to $10 \%, 11 \%$ to $20 \%, \ldots 91 \%$ to $100 \%$.

123

O'Connor, J. Born that way. Baltimore: Williams \& Wilkins. 1928.

Stimulus Materiah

100 stimulus words from Kent and Rosanoff (1910). Subjects

Task

... one thousand adult men largely from industry."

Each subject gave a single-word free association to each stimulus (presented in same order as in Kent and Rosanoff).

Data

Listing of all 100 stimulus words, in order of presentation, with the following for each:

(1) Alphabetical listing of all responses having a probability of occurrence of $10 \%$ or more for either Kent and Rosanoff or the present study, with the following for each response: (a) Kent and Rosanoff frequency, (b) present study frequency, and (c) overall frequency (both studies combined).

(2) Miscellaneous response class (including those responses with less than $10 \%$ in both studies), with the following: (a) Kent and Rosanoff frequency, (b) present study frequency, and (c) overall frequency (both studies combined).

\section{4}

Orson. R.. \& Scewartz, R. Single and multiple solution five-letter words. Psychonomic Monograph Supplements. 1967. 2(Whole No. 24). 105-152.

\section{Stimulus Material}

Every 5-letter word from Webster's Third International Dictionary (1\%1). except hyphenated words; including apostrophied words. proper nouns. inflected forms of 2-, 3-, and 4-letter roots that attain 5 letters.

Data

(1) Source list. Alphabetical listing of all groups of 5 letters which can be rearranged to form at least 2 , or more. different 5-letter words. along with all possible solution words; each 5-letter set is listed first as an alphabetical arrangement of those letters (with asterisk). followed by all words which can be made from it. in alphabetical order (i.e.. *EHORS HOERS HORSE SHOER SHORE).

(2) Single solution list. Alphabetical listing of all 5-letter words which have only 1 word (themselves) as a possible anagram solution.

(3) Multiple solution list. Alphabetical listing of all 5-letter words having multiple solutions (i.e.. other words may be made from the same letter combination).

\section{5}

OsGood. C. E. Semantic differential technique in the comparative study of cultures. American Anthropologist. 1964. 66. $171-200$.

\section{Stimulus Materiak}

100 nouns.

Subjects

20 (college not specified; all males).

Task

Each subject gave a single-word free association response to each word.

Data

Listing of all 100 nouns. with $\mathrm{H}$-rank value for each $(\mathrm{H}$ rank = the degree to which the subjects gave the same response to the stimulus word) (NOTE: low $\mathrm{H}$ rank = culturally stereotyped word. while high $\mathrm{H}$ rank = culturally amorphous word). 
126

The Oxford English Dictionary. Oxford, England: Clarendon Press. 1961.

Data

Alphabetical listing of all English words, along with the date and actual quotation of the first recorded use of that word in written form.

\section{7}

Paivio, A. Latency of verbal associations and imagery to noun stimuli as a function of abstractness and generality. Canadiun Journal of Psychology. 1966. 20. 378-387.

\section{Stimulus Material}

96 nouns. 48 concrete and 48 abstract; 40 were previously classitied by Gorman (1961) and 56 by the author; within each type. 24 were judged as general (abstract general = emotion, concrete general $=$ mammal) and 24 as specific (abstract specific $=$ grief, concrete specific $=$ whale) by author plus a graduate assistant; an attempt was made to equate the Thorndike and Lorge (1944) frequencies of the 4 word classes generated.

Subjects

Task

116 (University of Western Ontario).

Imagery ratings $(\mathrm{N}=35)$. Each subject rated each noun on a 7-point scale of directness of sensory .reference, using procedure described by Paivio (195).

Meaningfulness ratings $(\mathrm{N}=81)$. Each subject produced continued free associations for $60 \mathrm{sec}$ to each of 24 of the nouns, following the procedure described by Noble (1952).

Data

(1) Listing of all 96 nouns in one of 4 groups (concrete-general. concrete-specific, etc.) with the following for each: (a) mean imagery rating (I), and (b) mean meaningfulness rating $(m)$.

(2) Overall mean $I$ and $m$ for eacil of the 4 word types.

(3) Relationship of imaginal and verbal reaction times to concrete-abstract and general-specific dimensions.

(4) Intercorrelations of verbal reaction time, imaginal reaction time. $m$. I, and associative variety.

(5) Partial correlation of $m$ and imaginal reaction time with I held constant.

(6) Partial correlation of I and imaginal reaction time with $m$ held constant.

\section{8}

Paivio, A. Imagery and deep structure in the recall of English nominalizations. Joumal of Verbal Learning and Verbal Behavior, 1971, 10. 1-12.

\section{Stimulns Material.}

180 subject and 180 object nominalizations; 160 ( 80 of each) came from Rohrman (1968) and 200 were created by taking 100 nouns from Paivio. Yuille, and Madigan (1968) ( 50 concrete and 50 abstract) and putting each into 2 different sentence frames designed to yield subject ("The trees are ing") and object ("Someone is ing trees") nominalizations, after which 22 subjects were given the subject and 22 subjects the object nominalizations to complete; from this, a common adjective and verb were chosen for the following study.

\section{Subjects}

Task

99 (University of Western Ontario).

Each subject rated 90 subject and 90 object nominalizations on a 7-point imagery, or directness of sensory reference, scale, using procedure of Paivio, Yuille, and Madigan; 4 practice nominalizations were given.

Data

(1) Listing of 70 subject and 70 object nominalizations with mean imagery values for each.

(2) Extensive comparisons of learning as function of (a) rated imagery and (b) type of nominalization.
129

Paivio, A.. Yuille. J. C.. \& Madigan, S. A. Concreteness, imagery, and meaningfulness values for 925 nouns. Journal of Experimental Psychology Monograph Supplement. 1968, 76(No. 1. Pt. 2). 1.25.

Stimulus Materials

925 words, which were relatively unambiguously classitiable as nouns; 325 had been previously scaled for imagery and meaningfulness (Paivio, 1965, 1966; Paivio, Yuille, \& Smythe, 1960); 272 words were from high (A or AA), 295 from medium (10-49 per million), and 358 from low (less than 10 per million) frequency levels. from Thorndike and Lorge (1944).

Subjects

560 (University of Western Ontario).

Task

Imagery rating $(\mathrm{I})(\mathrm{N}=30)$. Each subject judged all words (in 2 sessions; on how readily each aroused a nonverbal image, using a 7-point scale.

Concreteness rating $(C)(N=28)$. Each subject judged all words (in 2 sessions) on how directly the word refers to a sensory experience, using a 7-point scale.

Meaningfulness rating $(m)(\mathrm{N}=502)$. Noble's (1952) production method was used; each subject was allowed $30 \mathrm{sec}$ to give single-word responses to each word.

Data

(1) Alphabetical listing of all 925 words, with the following for each: (a) mean I rating, (b) mean $C$ rating, (c) mean $m$ rating, and (d) Thorndike and Lorge (1944) frequency.

(2) Reliability of I and C scores; correlations with previous scalings of these attributes.

(3) Reliability of $m$ values for certain selected words

(4) Intercorrelations of the attributes (I, C. and $m$ ).

(5) Words for which $C, I$, and $m$ values are most clearly differentiated.

130

Palermo, D. S., \& Jenkins. J. J. Superordinates. "maturity" and logical analyses of language. Psychological Reports, 192, 10. 437-438.

\section{Stimulus Material}

200 words: 100 were stimulus words from Kent and Rosanoff (1910) and 100 were words (a) systematically sampled from different word classes (verbs, nouns, adjectives, etc.) and (b) of $A$ or AA frequency in the G count of Thorndike and Lorge (1944) (except 1 word).

Subjects

867 (University of Minnesota); 2384 th, 3255 th, 3536 th, 379 7th. 3128 th, 411 10th, and 42512 th grade children.

Task

Each subject gave a single-word free association response to each of the $\mathbf{2 0 0}$ words; all Kent and Rosanoff words were presented first as a group, followed by the remainder as a group.

Data

(1) Listing of 39 Kent and Rosanoff stimuli evoking superordinates as responses, with the following for each: (a) superordinate response, (b) frequency of that response among 4th graders, (c) frequency of that response among college students,

(d) percentage of that response among 4th graders, and (e) percentage of that response among college students.

(2) Comparison (and statistical test) of the number of stimuli where children gave a higher percent of superordinates than adults.

\section{1}

PAlermo, D. S., \& Jenkins, J. J. Word association norms: Grade school through college. Minneapolis: University of Minnesota Press, 1964.

\section{Stimulus Material}

Same as Palermo and Jenkins (1962). 


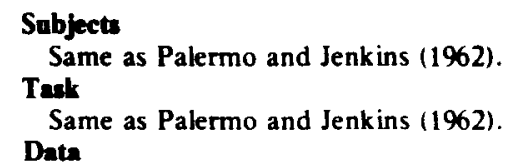

(1) Alphabetical listing of all stimulus words (200) with an alphabetical listing of all responses having a frequency of 2 or greater in at least 1 of the 16 sex-age subgroups, along with the frequencies for each of the 16 sex-age subgroups for each response to each stimulus.

(2) Alphabetical listing of all stimulus words with an alphabetical listing of all idiosyncratic responses. that is those which did not have a frequency greater than 1 in any sex-age subgroup.

132

Palermo. D. S., \& Jenkins, J. J. Sex differences in word associations. Journal of General Psychologg, 1965. 72. 77.84.

Stimulus Materials

Same as Palermo and Jenkins (1962).

Subjects

College students from Palermo and Jenkins (1962).

Task

Same as Palermo and Jenkins (1962).

Date

(1) Listing of the mean frequency and percent frequency for each of the 5 most frequent responses. separately for males and females within each of 3 classes: (a) 100 Kent and Rosanoff (1910) words. (b) 100 additional words. and (c) all 200 words combined.

(2) Statistical tests of the male-female differences for each of the top 5 response ranks.

(3) Tally of the frequency of congruence of the most frequent response for each of the 5 positions for males and females. separately for the 3 word classes.

(4) Mean and standard deviation of frequency of (a) the primary responses where males and females agreed and (b) those primaries where they did not agree.

(5) Listing of 32 (of the 200) words where the male and female primaries do not agree, with the following for each: (a) female primary response, (b) male primary response, (c) female frequency of female primary response. (d) male frequency of female primary response. (e) female frequency of male primary response. and (f) male frequency of male primary response.

(6) Correlations of male vs. female primary frequencies (a) on all words. (b) on $\mathbf{1 6 8}$ words where the primaries were the same, and (c) on 32 words where the primaries were different.

(7) Frequency of primary response being the same part of speech as the stimulus. separately for males and females.

(8) Mean frequency of superordinate responses to 39 Kent and Rosanoff (where one was possible). separately for males and females. plus a statistical test.

\section{3}

Postman, L. The California norms: Association as a function of word frequency. In L. Postman and G. Keppel (Eds.). Norms of word association. New York: Academic Press. 1970.

\section{Stimulus Materials}

96 2-syllable nouns: 24 from each of 4 Thorndike and Lorge (1944) frequency ranges ( $\mathrm{L}$ count) -1 to 3,10 to 33,100 to 333 , 1.000 to 3.333 (each representing a half-step increase on a log scale).

Subjects

\section{Dharde Amociation Teet}

Task

1.000 (University of California at Berkeley).

Each subject give a single-word free association response to each word. following the Russell and Jenkins (1954) procedure.

Data

(1) Listing of all 96 words. alphabetically within each of the 4 frequency classes. with listing of all responses for each word (in decreasing order of frequency) with the following for each response: (a) total frequency, (b) male frequency. (d) female frequency, (d) frequency for 500 of the subjects who were enrolled in an English course for students who failed to achieve a minimum score on the English placement test (low language group), and (e) frequency of 500 subjects who passed the course or who were exempted from it (high language group).

(2) Mean and standard deviation of the total number of different responses in each frequency range, and a statistical analysis.

(3) Mean and median percentages of occurrence for responses occupying each of the first 5 normative ranks, for each word frequency group.

(4) Word frequency (from Thorndike and Lorge L count) of responses for ranks 1 through 5 for each frequency range (entires are antilogs of mean $\log$ frequencies of responses at each rank).

$$
\text { Conthued Amociation Tew }
$$

\section{Subject:}

96 (University of California at Berkeley).

\section{Task}

Each subject gave 50 sec of continued free association responses to each word, following procedure of Noble (1952).

Data

(1) Listing of all 96 words, alphabetically within each of 4 frequency levels, with listing of all responses for each word (in decreasing order of frequedncy) with the frequency value for each response.

(2) Listing of all 96 words, in same format as above, with the following for each: (a) mean number of different responses per stimulus $(m)$. (b) standard ertor of $m\left(S E_{m}\right)$, and (c) number of different first responses.

(3) Mean and median percentage of occurrence of responses occupying each of the first 5 normative ranks, for each frequency group.

(4) Word frequency (from Thorndike and Lorge $L$ count) of responses for ranks 1 through 5 for each frequency range (entries are antilogs of mean $\log$ frequencies of responses at each rank).

\section{Data (comparing the 2 methoda)}

(1) Number of words where primary discrete response was also the most frequent in the continued test (for each frequency class separately).

(2) Correlations of percent occurrence of shared primaries (common to discrete and continued tests) for each frequency class

(3) Mean percent occurrence of shared and divergent primary responses separately for discrte and continued tests. for each frequency level.

(4) Mean percent of responses which occurred in the continued norms but did not occur in the discrete norms. separately for each frequency level. plus a statistical test.

\section{4}

Reed, H. B., \& Dick, R. D. The learning and generalization of abstract and concrete concepts. Joumal of Verbal Leaming and Verbal Behavior. 1968, 7. 486-490.

Stimulas Materials

Abstract and concrete concepts (words). Subjects

Task

Each subject rated either a set of 223 words $(N=89), 14$ words $(N=40)$, or 275 words $(N=125)$ on a 3-point scale of familiarity of meaning $(A=$ not familiar. $B=$ familiar. and $C=$ very familiar).

Data

(1) Listing of 108 of the words. under one of 8 concept classes (emotion, food. etc.). with the percent of subjects giving the word a " $\mathrm{C}$ " rating listed for each.

(2) Study on the effects of the abstract-concrete dimension on learning and generalization. 
135

Richardson, J., \& Erlebacher, A, Associative connection between paired verbal items. Journal of Experimental Psychology, 1958, 56. 62-69.

\section{Stimulus Material}

223 pairs of items, about $1 / 3$ from each of the following sources (1) adjectives from Thorndike and Lorge (1944)-high $=35$ per million or more, low $=15$ per 4 million or less; (2) CVCs from Glaze $(1928)-$ high $=80 \%$ association value or greater. low $=$ $27 \%$ association value or less; and (3) CCCs from Witmer $(1935)$-high $=71 \%$ association value or greater, low $=21 \%$ association value or less. Within each pair class, approximately $1 / 4$ were of each of the following types: high-high $(\mathrm{H}-\mathrm{H})$, high-low (H-L). low-high (L-H), and low-low (L-L).

Subjects

Number not specified (Northwestern University).

Task

Meaningfulness rating (half of subjects). Each subject rated each pair on a 15-point scale as to how meaningful the pair was; that is, the degree to which the items of the pair denoted the same or similar objects. actions, or conditions.

Ease of learning rating (half of subject). Each subject rated each pair on a 15-point scale as to how fast he thought he could learn it, in a paired-associate task with an anticipation format (be able to give the second member when presented the first).

Six practice pairs were given to each group. Data

(1) Mean and median ratings for pairs in each of the 12 categories ( 3 sources and 4 types within each) separately for each instructional group.

(2) Correlations between ratings of two instruction groups for each of the 3 word classes. plus overall.

(3) Listing of all 223 pairs, grouped into one of the 12 categories, with the following for each: (a) frequency or association value of the stimulus; (b) frequency or association value of the response; (c) learning rating: number of subjects rating it; (d) learning rating: mean rating; (e) learning rating: standard deviation of rating; (f) meaningfulness rating: number of subjects rating it; (g) meaningfulness rating: mean rating; and (h) meaningfulness rating: standard deviation of rating.

\section{6}

Rosanoff, A. J. Free association test. New York: Wiley, 1927.

\section{Stimulus Material}

100 stimuli from Kent and Rosanoff (1910). Subjects

1.000 normal adults.: 247 insane adults; 253 defective children over 9 years old; 125 normal white children 11 to 15 years old; 175 normal white children 4 to 10 years old; 125 normal Negro children 11 to 15 years old; 175 normal Negro children 4 to 10 years old. Task

Each subject gave a single-word free association response to each word. following the Kent and Rosanoff instructions. Data

(1) Listing of all 100 words, in order presented, with all responses (in alphabetical order) under each stimulus word, plus response frequency (based on the 1,000 normal adult subjects).

(2) Comparison of percent of responses falling in each of the following response classes for each of the 7 types of subjects listed above: (a) common: specific, (b) common: nonspecific (general descriptive terms), (c) doubtful, (d) idiosyncratic, and (e) failure to respond.

(3) Comparison of percent of responses falling in each of the following response classes, separately for normal adults. white children, and black children: (a) normal, (b) derivatives of the stimulus word. (c) partial dissociation. (d) perseveration, (e) neologisms, and (f) unclassified.

(4) Comparison of white and black children within each of 12 age levels (4 through 15) separately by response types listed under (2) above.
(5) Listing of all 100 stimulus words, in presentation order, and an alphabetical listing of all responses with a frequency over $0.1 \%$ from the Woodrow and Lowell (1916) norms (exact frequencies for the responses are not listed).

137

Rosanoff, A. J., Martin, H. E., \& Rosanoff, I. R. A higher scale of mental measurement and its application to cases of insanity. Psychological Monographs, 1918. 25(No. 109).

\section{Stimulus Materials}

100 technical words from various school subjects (literature. geometry. chemistry. etc.) which are not likely to be acquired except in a course of "systematic" education.

Subjects

1.000 college ed ucated persons; 100 "high-standard" persons (all appearing in Cattell's American Men of Science).

Task

Each subject gave a single-word free association response to each stimulus word: if the subject failed to respond, or gave a multiple word response, the word was repeated again at the end of the list. Data

(1) Listing of all 100 stimulus words, with the following for each: (a) individual frequency: number of idiosyncratic responses; (b) failure frequency: number of subjects who could think of no response; and (c) alphabetical listing of all responses, with separate frequencies for each of the 2 subject groups.

(2) Overall comparison of responses of 25 subjects in each of 12 grade levels $(5,6,7$ and 8 in grade school; 4 levels of high school; 4 levels of college) in terms of average common reactions, individual reactions, doubtful reactions, failures, etc.

(3) Comparison of responses of 4 clinical groups (dementia praecox, manic depressive, paranoic, and epiliptic) to normals.

\section{8}

Rothkopf, E. Z.. \& Coke, E. U. Intralist association data for 99 words of the Kent-Rosanoff word list. Psychological Reports, $1961,8,463-474$

\section{Stimulus Materiak}

99 stimulus words from Kent and Rosanoff (1910) ("cheese" was not included).

\section{Data}

Alphabetical listing of the 99 stimulus words, with the following for each:

(1) Number of other Kent and Rosanoff words which evoked that word as a response, considering only responses with a frequency of 11 or more or which were among the top 10 associates to a given stimulus (whichever yielded the greatest number of responses) (W).

(2) Actual Kent and Rosanoff words which evoked that word as a response (S)

(3) Total number of Kent and Rosanoff words which were common association responses to $S$, including $W$ (SAN).

(4) Frequency from Minnesota norms (Russell \& Jenkins, 1954) with which $W$ is evoked as an association response by $S$ (AsF).

(5) AsF divided by the sum of association frequencies of all Kent and Rosanoff word responses to $S$ (AsF/T).

(6) Associative frequency rank of $W$ among all Kent and Rosanoff word responses to $S$ (WRnk).

(7) Magnitude of associative frequency of $W$ relative to the median of association frequencies for Kent and Rosanoff responses to $S(M d n<; M d n>$ ).

(8) Other common association responses to $S$, of those listed in the Kent and Rosanoff list presented (word number in the present list plus its frequency, are presented) (OAs).

\section{9}

SALTZ, E. Thorndike-Lorge frequency and $m$ of stimuli as separate factors in paired-associates learning. Joumal of Experimental Psychology. 1967, 73, 473-478.

\section{Stimulus Materials}

100 nouns, randomly selected from 5 Thorndike and Lorge 
(1944) frequency categories (L count): 1 to 4 (20 words), 30 to 40 (20 words), 100 to 200 ( 21 words), 399 to 750 (19 words), and 1,000 to 2,000 ( 20 words) occurrences per $4 \frac{1}{2}$ million words. Subjects

Task

87 (Wayne State University).

Each subject gave $60 \mathrm{sec}$ of continued free associations to each noun, following the procedure of Noble (1952).

Data

(1) Listing of all 100 nouns, in decreasing order of meaningfulness $(m)$, within each of the 5 frequency levels, with exact $m$ values for each word.

(2) Mean $m$ value for words in each frequency level.

(3) Study examining relationship between frequency, $m$, and paired-associate learning.

140

SAPorta, S. Frequency of consonant clusters. Language, 1955, 31, 25-30.

\section{Stimulus Materialh}

19 English consonant phonemes.

Tank

Determine the difference between each possible pair of phonemes, in terms of the number of distinctive features (distinctive features include the following dimensions: vocalicnonvocalic, consonantal-nonconsonantal, compect-diffuse, graveacute, nasal-oral, tense-lax, constituant-interrupted, stridentmellow).

Data

(1) Matrix listing all possible pair combinations of the 19 phonemes, with the number of units difference between them (in terms of distinctive features).

(2) Same information as in (1) for 14 Spanish phonemes.

(3) Frequency distribution of the number of theoretically possible clusters (phoneme pairs), the obtained number of clusters, and the average number of clusters for each of 10 distinctive feature difference classes (0 through 9 ).

(4) Same information as in (3) for Spanish phonemes.

(5) A second frequency distribution, in the same form as (3), with the number of phonemes reduced to 17 (distinctive feature range being reduced to 0 through 8 ).

\section{1}

Schaud, G. R., \& Lindley, R. H. Effects of subject-generated recoding cues on short-term memory. Journal of Experimental Psychology, 1964, 68, 171-175.

Stindin Maverial

36. low-meaningfulness (LM) CVCs from Archer (1960), with 2 randomly selected from each percent between 3 and 20; and 36 high-meaningfulness (HM) CVCs from Archer, with 2 randomly selected from each percent between 80 and 97 .

Sebjects

$$
\text { Tack }
$$

20 (Trinity University)

Each subject gave a coding response to each of the CVCs, in the following manner: "I am going to spell 3 letters out loud. When I spell the last letter of the trigram, I shall start this electric timer. I want you to think of some thing that would help you remember or learn the trigram I spell"; 60 sec were given for each CVC. Data

(1) Listing of $24 \mathrm{HM}$ CVCs with the shortest median latencies and 24 LM CVCs with the longest median latencies, with the following for each: (a) common recoding cue: the most frequent response (for 15 of the 24 LM CVCs, a cue was generated by the authors because no single response had a frequency above 1); and (b) uncommon recoding cue: randomly selected response from among the pool of single-word responses occurring only once.

(2) Average association latencies for HM and $L M$, plus a statistical comparison.

(3) Percent of single, double, and triple (or more) associations to HM and LM CVCs.

(4) Relation of HM and LM to a short-term memory task.
142

Scott, D., \& BAddeley, A. D. Acoustic confusability values for 1172 CCC trigrams. Psychonomic Science, 1969, 14, 189-190, 192.

\section{Stimolom Material.}

1,172 CCCs chosen at random from Witmer (1935). Data

Zisting of all 1,172 CCCs, within its appropriate association value level ( 25 in all) in ascending order of acoustic confusability (AC) within each level, along with probability of AC for each [AC = an application of Clarke's (1957) constant ratio ruk to Conrad's (1964) acoustic confusion matrix, for each $\mathrm{CCC}$.

\section{3}

Scott, S. M., \& Harms, C. B. Association values of CVC trigrams in a prison population. Psychobgical Reports, 1968, 22, 797-801.

\section{Stinde Matertale}

300 CVCs from Archer (1960), 100 in each of the following association value (AV) classes: $1 \%$ to $8 \%, 47 \%$ to $53 \%$, and $93 \%$ to $100 \%$; only CVCs were selected which also appeared in Glaze (1928) and Krueger (1934).

Subjects

100 prison inmates.

Task

Each subject responded either "yes" or "no" to each CVC: "yes" if he though it (a) was a word, (b) sounded like a word, or (c) could be used in a sentence, and "no" if none of the above were true; 57 subjects were retested 1 week later on all CVCs.

Data

(1) Listing of all CVCs in increasing frequency of "yes" response, with the following for each: (a) frequency value in present study, (b) Glave AV, (c) Krueger AV, and (d) Archer AV.

(2) Range of present frequency values for CVCs in each of Archer's 3 classes.

(3) Test-retest correlations: overall, as well as separately for each of Archer's 3 CVC classes.

(4) Intercorrelations of the 4 association measures (present study, Glaze, Krueger, and Archer) separately for items in each of Archer's 3 AV classes, as well as overall.

(5) Mean association value for each of 4 associative measures in (4), separately for CVCs at each of Archer's 3 AV classes, as well as overall.

144

Shapiro, S. I., \& Palermo, D. S. An atlas of normative free association data. Psychonomic Monograph Supplements, 1968 , 2(Whole No. 28), 219-250.

Data

Alphabetical listing of stimulus words collected from 20 normative studies (4 published and 16 not published) with the following for each word:

(1) Thorndike and Lorge (1944) frequency (G count) of the stimulus.

(2) Primary response.

(3) Associative probability of the primary response.

(4) Thorndike and Lorge frequency of the primary response.

(5) Investigation(s) which generated data on the word (if more than one investigation was involved, that word was multiply listed).

NOTE: All studies involved single-word free associations using college subjects.

\section{5}

Shapino, S. I., \& Palermo, D. S. Conceptual organization and class membership: Normative data for representatives of 100 categories. Psychonomic Monograph Supplements, 1970. 3(Whole No. 43), 107-127.

\section{Stimulus Materiale}

100 conceptual categories, generated using the following criteria: (1) did not appear in the Connecticut category norms of Bousfield, Cohen, and Witmarsh (1957); (2) could be represented by at least 4 members which were single words. nouns, and specific in character; 
(3) range of kinds of categories should be maxumal: (4) some categories shouid contain very few members: (5) categories should be unambiguous: (6) difficulty of providing appropriate members should vary: (7) overlap between kinds of categories should be minimal: (8) categories excluded where an obvious major response would be unique to subjects in a particular population (i.e.. state name): and (9) categon names should be relatively brief.

Subjects

400 (Pennsvisania State University).

Task

Each subject gave 4 single-word noun responses to each of 50 categories: 3 practice categories were given.

Data

Listing of all 100 categories. with all responses listed under each. in decreasing order of frequency, in the following manner:

11) Responses with a frequency of 10 or greater were listed individualls. with the following 3 frequencies for each: male. temale and total.

(2) Responses with a frequency of 9 or less were listed in alphabetical order within the appropriate frequency class (no separate breakdown for males and females).

13) Numbers of omission and illegible responses were presented for each category: if any illegible or omission frequencies exceeded 4 . a breakdown by sex was made in parentheses beside the total frequenc:

\section{6}

ShAPIRo. S. S. Meaningfulness values for 52 CVCs for gradeschool-aged children. Psychonomic Science, 1964, 1. 127-128.

Stimulus Materials

52 word CVCs from Noble's (1961) norms of $m^{\prime}$ range from 2.64 to 4.78 on $m^{\prime}$ scale.

Subjects

t00 children. 200 in each of grades 4, 6. and 8

Task

Each subject gave as many written free associations to each CVC as thes could, up to 5: they were given up to $18 \mathrm{sec}$ per stimulus. Data

(1) Alphabetical listing of 26 high $m^{\prime}$ words (3.82 to 4.78) with mean meaningfulness $(m)$ values for each of the 6 grade-sex groups from the present study for each word.

(2) Alphabetical listing of 26 low $m^{\prime}$ words (2.64 to 3.81 ) with $m$ values for each grade-sex group for each word.

(3) Analysis on $m$ data considering the variables of grade. sex. and Noble's $m^{\prime}$ levels.

(4) Rank-order correlations of Noble's $m^{\prime}$ vs. present $m$ values for each grade-sex level.

(5) Intercorrelations among all grade-sex levels on $\boldsymbol{m}$.

\section{7}

Shapiro. S. S. Word associations and meaningfulness values for grade-school-aged children. Psychological Reports, 1964. 15. 447.455 .

\section{Stinclos Materinh}

(1) 52 word CVCs from Noble's (1961) norms; (2) 13 words varying in length from 1 to 4 letters.

\section{Sabjects}

Task

600 children, 200 in each of grades 4,6 , and 8 .

Each subject gave as many written free associations to each word as they could. up to 5; they were given up to $18 \mathrm{sec}$ per word. Date

(1) Listing of 36 stimulus words where either (a) the most common initial response $\left(R_{1}\right)$ and/or (b) the most common overall response (P) (pooling the first 3 responses only) were the same across all 6 sex-grade groups. with the particular response word presented for each.

(2) Comparison of primary responses of $R_{1}$ and $P$ varieties across grade and sex groupings.
(3) Comparison of present study values with Noble (1961): (a) mean. standard iteviation, and range of $m$ values for a group of 26 high $m^{\prime}$ ' and 26 low $m^{\prime}$ words (from Noble) separately for each sex-grade group: and (b) correlation of $m$ and $m^{\prime}$ within and between each sex-grade group.

\section{8}

Silverstein. A.. d Diensibier. R. A. Rated pleasantness and association value of 101 English nouns. Journal of Verbal Leaming and Verbal Behavior. 1968. 7. 81-86.

\section{Stimulus Materiat}

101 nouns: 95 were randomls selected 2-svllable nouns from Thorndike and Lorge (1944), and 6 additional words were added to increase the aftective range of the word list.

Subjects

400 (L'niversity of Rhode Island).

Task

Association value rating $\left(a^{\prime}\right)(\mathrm{N}=200)$. Each subject rated each noun as to how many associations the word produced for them, on a 5 -point scale. using Noble's $(1 \% 1)$ procedure.

Pleasantness rating ( $P L)(N=200)$. Each subject pronounced each word first. and then rated its pleasantness on a 7 -point scale Data

(1) Listing of all 101 words. with the following for each: (a) Thorndike and Lorge frequency. (b) mean $a^{\prime}$ rating, and (c) mean PL rating.

(2) Intercorrelations among these 3 measures. for men and women separately.

(3) Median and standard deviation of the ratings for $a^{\prime}$ and PL scales.

149

Smith. O. W.. Badia. P.. \& Rosenberg. B. G. Pronounceability ratings of some CVCs: Their reliability and relationship to $m^{\prime}$. Psychological Reports, 1968. 23.691-694.

\section{Stimulus Material}

100 CVCs taken from Badia. Rosenberg. and Langer (1965) (which varied in Noble's (1961) $\mathrm{m}^{\prime}$ and were rated on pronounceability, or $p^{\prime}$.

Subjects

51 (Bow.ling Green State University).

Task

Each subject rated each of the $100 \mathrm{CVCs}$ on a 9-point scale of pronounceability, using the procedure of Underwood and Schulz (1960): they were all tested again 1 week later on same material and procedure.

Data

(1) Alphabetical listing of 95 CVCs $(5$ lost due to clerical Error) with the following for each: (a) mean pronounceability $\left(p^{\prime}\right)$ value for the present study; (b) standard deviation of $p^{\prime}$ for the present study: (c) mean $p^{\prime}$ for Badia et al.; and (d) standard deviation of $p^{\prime}$ for Badia et al.

(2) Test-retest correlation foverall, as well as median value when done separately for each subject).

(3) Correlation between present study and Badia et al.'s $p$ values.

(4) Overall mean and standard deviation of scale values of $p^{\prime}$ for present study as well as Badia et al.

(5) Correlation between Badia et al.'s $p^{\prime}$ and $m^{\prime}$ (from Noble).

(6) Correlation between present study's $p^{\prime}$ and $m^{\prime}$.

\section{0}

Smith, O. W.. Badia. P.. \& Rosenberg, B. G. Are pronounceability and effort ratings psychologically equivalent? Psychological Reports. 1969. 24. 95.99.

Stimules Materials

95 CVCs selected from Noble (1961) and varying in rated meaningfulness $\left(m^{\prime}\right)$ 


\section{Subjects \\ 102 (Bowling Green State University).}

Task

Each subject rated all $95 \mathrm{CVCs}$ on each of the 2 dimensions listed below (1 week separated the 2 ratings):

Pronounceability $\left(p^{\prime}\right)$. A 9-point scale was used, following Underwood and Schulz's (1960) procedure.

Effort $\left(e^{\prime}\right)$. A 9-point scale was used, with the subjects rating the difficulty or effort involved in the use of the lips and tongue in saving the CVC to themselses.

Data

(1) Alphabetical listing of all 95 CVCs, with the following for each: (a) mean $p^{\prime}$ value. (b) standard deviation of $p^{\prime}$, (c) mean $e^{\prime}$ value, and (d) standard deviation of $e^{\prime}$.

(2) Overall means and standard deviations of ratings for each scale at each of the 2 sessions, as well as for both combined

(3) Intercorrelations of the scale values.

(4) Correlations between Noble's $m$ with $p^{\prime}$ and with $e^{\prime}$.

(5) Correlations between Badia. Rosenberg. and Langer's (1965) $p^{\prime}$ with the present $p^{\prime}$ and with $e^{\prime}$.

(6) Subjective judgments of the similarity of the $p^{\prime}$ and $e^{\prime}$ scales.

\section{1}

Solarz. A. K. Perceived activity in semantic atlas words as indicated by a tapping response. Perceptual and Motor Skills. 1963. 16. 91.94.

Stimulus Materials

$3^{-}$words from Jenkins (1\%60), representative of the distribution on the activity factor of the semantic differential.

Subjects

28 (University of California. Davis)

Task

First session. Each subject rated each wond in the following manner: " . . decide just how slow or fast a word seems to you ....

Then on the command 'tap' record your rate of motion by tapping on the page $“: 8 \mathrm{sec}$ of tapping was allowed for each word.

Second session. Subjects either retapped the same words again (Group I) or rated the same words on the activity dimension of the semantic differential (Group II).

Data

(1) Listing of the 37 words with the average standard score of tapping for each (standard scores computed separately for each subject).

(2) Correlation between activity value from Jenkins and standard tapping scores.

(3) Correlation between Group II's tapping and rating scores

(4) Reliability correlation between Group I's tapping rate in the 2 sessions

\section{2}

Solso, R. L. Meaningfulness of colors. Psychonomic Science. 1971. 23. 301-302.

\section{Stimulns Materiak}

\section{Measurement 1}

Names of 10 colors (black. blue, brown. green. orange. pink purple. red. white. and vellow) which were the 10 highest frequency color names according to Thorndike and Lorge (1944).

\section{Subjects}

Task

46 (Moorhead State College)

Each subject responded in 2 ways to each of the 10 color names (1) Give as many responses as you can to each. (2) Rate the number of associations each word produces on a 5-point scale. The 2 tasks uere performed separately.

\section{Measurement 2}

\section{Stimulus Materials}

10 actual colors used. plus black and white. with the best example of each being chosen by 5 judges from the entire set of Munsell colors.

\author{
Subjects \\ 146 (Moorhead State College). \\ Task \\ Identical to Measurement 1. except that color samples instead of \\ color names were used. \\ Data
}

(1) Listing of all colors, with the following for each: (a) mean meaningfulness $(m)$ and standard deviation of $m$ for color words: (b) mean $\boldsymbol{m}$ and standard deviation of $\boldsymbol{m}$ for actual colors.

(2) Listing of all colors. with the following for each: (a) mean rated meaningfulness $\left(a^{\prime}\right)$ and standard deviation of $a^{\prime}$ for color words; and (b) mean $a^{\prime}$ and standard deviation of $a^{\prime}$ for actual colors.

(3) Rank-order correlations among the following: (a) color word $m$. (b) color word $a^{\prime}$, (c) color $m$, and (d) color $a^{\prime}$.

(4) Alphabetical listing of each color with the following for each: (a) 5 most frequent responses to the word. in descending order of frequenc:; (b) percent of subjects giving each response; (c) 5 most frequency responses to the color, in descending order of frequency; and (d) percent of subjects giving each response.

\section{3}

SPREen. O.. \& Schulz. R. W. Parameters of abstraction. meaningfulness. and pronunciability for 329 nouns. Joumal of Verbal Learning and Verbal Behavior. 1966. 5. 459-468.

Stimulus Materials

All nouns (329) with Thorndike and Lorge (1944) frequency of 50 to $100(\mathrm{~A})$ and 3 or less svllables (eliminating all words with frequent nonnoun usage).

Subjects

143 (University of Iowa).

Task

Specificin rating $(\mathrm{S})(\mathrm{N}=23)$. Each subject rated each noun on how specifically it referred to persons. places. or things. using a 7.point scale (i.e., animal $=$ low. monkey $=$ high)

Concreteness rating $(C)(N=22)$. Each subject rated each noun on how directly it referred to a sensory experience. using a 7 -point scale.

Pronounceabilin rating (PR) $(\mathrm{N}=40)$. Each subject rared each noun on ease of pronunciation, using a 7-point scale (based on the Underwood and Schulz. 1900, technique).

Meaningfulness rating $(m)(\mathbf{N}=58)$. Each subject produced single-word free associations for $30 \mathrm{sec}$ to each word following the Noble (1952) procedure: 3 sessions were used with about $1 / 3$ of the words presented at each session (separated by 1-week intervaks)

Date

(1) Alphabetical listing of all 329 nouns. with the following for each: (a) mean $S$ rating, (b) mean $C$ rating, and (c) mean $m$ rating.

(2) Means, standard deviations, and quartiles of the ratings of $S$.

C. PR, and $m$.

(3) Reliability of ratings for each scale

(4) Intercorrelations among PR. C. S, $m$, and word length (L).

(5) Partial correlations among S. C. L, and $m$.

154

Stants. A. W., \& Stants, C, K. Meaning and $m$ : Correlated but separate. Psychological Review, 1959. 66. 136-144.

\section{Stimulus Materials}

10 words which were (a) distributed along the entire range of the ' good-bad dimension in Jenkins. Russell. and Suci (1958). and (b) had $m$ values available on them from Russell and Jenkins (1954).

\section{Sabjects \\ 46 (Arizona State University). \\ Task}

First rating. Each subject rated 50 words ( 10 critical plus 40 filler words) on a 7 -point good-bad scale.

Second rating. 3 weeks later. the same subjects rated the 20 most frequent responses to each of the 10 critical words 1172 total. 
because of some response duplication) on the same 7-point good-bad scale.

Data

(1) Listing of all 10 critical words. with the following for each: (a) mean rating from Jenkins et al.. (b) mean rating from the present study and (c) mean rating across all of the 20 associates for that word.

(2) Rank-order correlation between Jenkins et al. and the present study on the ratings.

(3) Rank-order correlation between ranking of the critical word and the ranking of their associate words.

\section{5}

Stratton. R. P.. Jacoeus. K. A., \& Bewingy, B. Age-ofacquisition, imagery, familiarity and meaningfulness norms for 543 words. Behavior Research Merhods and Instrumentation. 1975. 7. 1-6.

Stincles Materiah

543 words ( 4716 letters long and 735 letters long) from Thorndike and Lorge (1944). most of which conformed to all the following: (1) occurred at least once per million words. (2) began with a consonant. (3) had no repeated letters. and (4) was the only word which could be formed from that combination of letters (for purposes of anagram construction).

Sabjects

879 (University of Kentucky) for 6-letter words; 204 (University of Kentucky) for 5-ktter words.

Talk

Age of acquisition rating ( $N=$ at least 50 for 6- and at least 40 for 5-letter words). Each subject rated each word on a 9-point scale reflecting estimated age of acquisition. where 1 was age 2 and 9 was age 13 and older, following the procedure used by Carroll and White (1973).

Imageny rating (N = at least $\mathbf{5 0}$ for 6- and at least $\mathbf{4 0}$ for 5-letter words). Each subject rated each word on a 5-point scale of ease, or speed. with which the word aroused a sensory image $11=$ very difficult: 5 = very easy). following the procedure used by Paivio. Yuille. and Madigan (1968).

Familiariny rating ( $N=$ at kast 50 for 6 - and at least $\mathbf{4 0}$ for 5-letter words). Each subject rated each word on a 5-point scale of contemporany usage $(1=$ never used; $5=$ used every day), following the procedure used by Noble (1953).

Meaningfubness (N $=$ at least 30 per word for both sets). Each subject gave continuous free associations for $30 \mathrm{sec}$ to each of 25 words. following the procedure used by Noble (1952).

Date

(1) Alphabetical listing of all 573 with the mean and SD for each of the following dimensions: (a) age of acquisition rating. (b) imagery rating. (c) familiarity rating, and (d) meaningfulness production (number of word associations given).

(2) Intergroup reliability correlations (by randomly halving the groups).

(3) Test-retest reliability of 50 6-letter words which were put into the 5-letter group during testing.

(4) Intercorrelations among the 4 scales.

(5) Overall mean, SD, and range of each scale.

(6) Correlation of present study and Paivio et al. on the imagery and meaningfulness scales.

\section{5}

TAYron, J. D., \& Kmone, G. A. The association value of 320 selected words and paralogs. Journal of Verbal Learning and Verbal Behavior, 1967, 6, 744-752.

\section{Sol}

320 CVCVCs. composed of 303 nouns and 17 paralogs; the stim. uli were selected such that (a) they produce a rectangular distribution of familiarity ratings (done ahead of time by 9 judges), and (b) they produce a rectangular distribution of initial letters and letter combinations.

Sobjem

100 (Duke University).
Takk

Each subject gave a single-word free association response to each CVCVC. following the procedure used by Glaze (1928); 7 practice words were given.

Date

(1) Listing of the 303 word CVCVCs. with the following for each: (a) most frequent response. (b) number of subjects giving this response (F). (c) number of other responses given (C). (d) mean response latency for all responses $(M)$. and $(e)$ percent of subjects responding in less than $2.5 \mathrm{sec}(P)$.

(2) Intercorrelations among the above response measures.

(3) Study comparing the learning speed for items in 6 levels of $P$. as derived from the study.

157

Thorvdike, E. L. The association of certain sounds with pleasant and unpleasant meanings. Psychological Revien: 1945. 52. 143-149.

\section{Stimulus Materiah}

Selection of pleasant $(P)$ and unpleasant $(U)$ words from each of 6 different languages (English. German. Russian. Greek. Finnish. and Hungarian). P-word examples: strength, skill. beauty; $U$-word examples: veakness. clumsiness. ugliness.

Date

(1) Listing of $\mathbf{4 3}$ sounds of the International Phoenetic Alphabet (IPA) with the following for each (considering only English words): (a) example of what the sound is (sample word); (b) total number of occurrences: (c) percent of occurrences which were in $P$ words; and (d) chance probability of the sound occurring in $\mathbf{P}$ words.

(2) Total number of phonemes occurring in $P$ and $U$ words. separately for each of the 6 languages.

(3) Listing of 46 IPA sounds. with the following for each: (a) example of what the sound is (sample word); and (b) percent of the total occurrences which were in $P$ words, separately for each of the 6 languages.

\section{8}

Thorndike, E. L., \& LoRge, I. The teacher's word book of 30.000 nords. New York: Bureau of Publications. Columbia University. 1944

Stimules Material

30.000 words.

\section{Dath}

(1) Alphabetical listing of 19.440 words which occurred more than 1 time in 1.000.000 words. with the following for each: (a) number of occurrences per million (G count): 1 to 49 listed separately. $A=50$ to 99 . $A A=100$ or more: (b) number of occurrences per $41 / 2$ million ( $T$ count); (c) number of occurrences in a million words from various magazines ( $L$ count): (d) number of occurrences in $4 \frac{1}{2}$ million words from 120 juvenile books ( $\mathrm{J}$ count); and (e) number of occurrences in the Lorge-Thorndike semantic count of 5 million words.

(2) Alphabetical listing of (a) 9,202 words occurring less than once per million but more than 4 times in 18 million and (b) 1.358 words occurring 4 times in 18 million words. plus frequencies of each

(3) Alphabetical listing of those words occurring 1.000 or more times in either the $L$ or $S$ count, with the frequencies for each in both counts.

(4) Alphabetical listing of the 500 most frequent words (across al counts).

(5) Alphabetical listing of the 500 second most frequent words (actoss all counts).

(6) Alphabetical listing of $\mathbf{5 0 0}$ most frequent words from the $T$ count.

(7) Alphabetical listing of 500 second most frequent words from the T count.

(8) Alphabetical listing of words which were in the most frequent 1.000 words overall. but which did not appear in the 100 most frequent from the $T$ count. 
159

Trapp. E. P.. \& Kausler, D. H. A revision of Hull's table of associative values for 320 selected nonsense syllables. American Journal of Psychology. 1959, 72, 423-428.

Stimulus Materials

320 CVCs used by Hull (1933).

Subjects

353 (University of Arkansas).

Task

Each subject looked at each CVC for 1 or $2 \mathrm{sec}$, and if it made them think of "anything in particular" they were to write it down; "Please do not in. particularly, to think of associations for the various syllables, but if you do think of one, be sure to write it down."

Data

Listing of all 320 CVCs, with the following for each:

(1) Association value (percent of subjects giving an association) for male subjects

(2) Association value for female subjects.

(3) Association value for all subjects.

(4) Association value from Hull's norms.

\section{0}

TREsSelt, M. E., \& LeEds, D. S. The Kent-Rosanoff word association: I. New frequencies for ages $18-21$ and a comparison with Kent-Rosanoff frequencies. Joumal of Genetic Psychology. 1955, 87. 145-148.

Stimulus Materials

100 stimulus words from Kent and Rosanoff (1910)

Subjects

Task

105 subjects from ages 18 to 21 (from 5 different states)

Each subject gave a single-word oral free association response to each stimulus (orally presented).

Data

Listing of all 100 words, along with the following for each:

(1) Most frequent response from Rosanoff (1927).

(2) Frequency of that response from Rosanoff

(3) Frequency of that response from the present study.

(4) Critical ratio ( $t$ ratio) comparing the 2 frequencies $[(2)$ and (3)\}.

161

Tresselt, M. E., Leeds, D. S., \& Mayzner, M. S: The Kent-Rosanoff word association: II. A comparison of sex differences in response frequencies. Journal of Genetic Psychology. 1955. 87, 149-153.

Stimulus Materiabs

100 stimulus words from Kent and Rosanoff (1910).

Subjects

229 subjects. of which 105 were from Tresselt and Leeds (1955)

and 124 were new (from 12 different states, in all).

Task

Each subject gave a single-word oral free association response to each stimulus (orally presented).

Data

Listing of all 100 words, with 1 or more responses listed under each (no rationale given for why some have 1 and some have more than 1), with the following for each response:

(1) Male frequency.

(2) Female frequency.

(3) Value of the critical ratio (t ratio) comparing male and female frequencies, it it exceeds 3.00 .

\section{2}

Tryk. H. E. Subjective scaling of word frequency. American Journal of Psychology, 1968, 81, 170-177.

Stimulus Materials

100 words from Thorndike and Lorge (1944), which were all of the following: (1) nouns (by at least one definition); (2) from all frequency levels; (3) controlled for word length, across frequency levels; and (4) not proper nouns, abbreviations, or foreign words. Subjects

Task 50 college students.

Each subject gave the following ratings for all 100 words (NOTE: all words were rated at each session):

Cultural frequency (C). "Your task is to estimate how often the average American uses each of the following words in his conversation."

Private frequency $(\mathrm{P})$. Same as above, but pertaining to personal use.

The subjects wrote a frequency beside each word in the following manner: 5 times a day $=5:$ day, once every 2 years $=1:: 2$ years. etc.; $C$ ratings were done on weeks 1 and 4 , while $P$ ratings were done on weeks 2 and 5 .

Data

(1) Alphabetical listing of all 100 words, with the following for each: (a) Thorndike and Lorge frequency, (b) geometric mean of 20-year usage for $C$, and (c) geometric mean of 20-year usage for $P$.

(2) Reliability correlations for both $P$ and $C$.

(3) Intercorrelations of $P, C$, and Thorndike and Lorge frequency, with meaningfulness $(\bar{m})$ and goodness $(G)$ ratings done in a subsequent study.

\section{3}

Tulving, E., McNulty, J. A., \& Ozier, M. Vividness of words and learning to learn in fre-tecall learning. Canadian Journal of Psychology. 1965, 19, 242-252.

\section{Stimulus Materials}

82 2-syllable nouns, 5 to 7 letters long, with frequencies between 15 and 19 per million (from Thorndike \& Lorge, 1944).

Subjects

200 (University of Toronto).

Task

Vividness rating $(\mathrm{V})(\mathrm{N}=100)$. Each subject rated each noun on the "ease with which you can picture something in your mind," using a 7 -point scale.

Meaningfulness rating $(\mathrm{M})(\mathrm{N}=100)$. Each subject rated each noun on how meaningful it was to them, using a 7-point scale. Data

(1) Listing of 48 of the words by 3 groups of 16 each (high. medium, and low $V$ ). with the following for each: (a) mean $V$ rating. and (b) mean $M$ rating.

(2) Mean $M$ and $V$ ratings for each of the 3 groups in (1).

(3) Comparison of the ratings of 2 subgroups of subjects used (undergraduate psychology majors vs. premed students).

(4) Comparison of means and variances of $M$ and $V$ ratings.

(5) Study involving effects of $V$ and $M$ in learning-to-learn free recall lists.

\section{4}

UNDERWOOD, B. J., \& RichaRDSON, J. Some verbal materials for the study of concept formation. Psychological Bulletin. 1956. 53. 84-95.

\section{Stimulus Material}

213 nouns, selected on the basis that they would each elicit 1 sense impression fairly consistently.

\section{Subjects}

153 (Northwestern University)

\section{Task}

Each subject gave a single sense impression association to each noun; subjects were thoroughly instructed ahead of time about sense impressions, and that they were the only responses allowed; subjects were given $6 \mathrm{sec}$ per word, and presented 20 practice words.

Data

(1) Alphabetical listing of all 213 nouns, with the following for each: (a) listing of each category (by number) which accounted for $5 \%$ or more of the responses to the word. along with the actual 
percent: if $5 \%$ or more sense impressions were given to a word. but tht class of impressions was not among the numbered 40 . then that sense impression was written out along with its percent; (b) percent of miscellaneous responses (those less than $5 \%$, plus nonsense impression responses): and (c) Thorndike and Lorge (1944) frequency.

(2) Study comparing the speed of learning as related to the dominance level of the concept (percent association level).

\section{5}

UNDERW OOD. B. J.. \& SCrulz. R. W. Meaningfulness and verbul leaming. Philadelphia: Lippincott. 1960.

\section{Semang of Previogs Stadies}

Data

(1) Alphabetical listing of 1.937 CVCs common to Glaze (1928) and Krueger (1934). with meaningfulness values for each study separately.

(2) Listing of 4.524 CCCs from Witmer (1935) by association value group. with association value for each.

(3) Listing of 96 disyllables from Noble (1952) in decreasing order of $m$. with $m$ values for each.

\section{Objective Frequency Coont}

Date

(1) Alphabetical listing of bigrams. with the following information for each: (a) T-L value: total number of occurrences of the bigram in 2.080 words sampled from the 19.440 most frequent in Thorndike and Lorge (1944) by selecting the top 5 words in each column (excluding contractions, abbreviations. repetitions. letters after a hyphen in a hyphenated word. and words lacking a G.count frequency); whenever a word was excluded. the next word in the column was selected. (b) $U$ value: total number of occurrences in 15.000 words of written material (150 passages of 100 words each) with all words included (count done by authors). (c) Total value: both samples combined.

(2) Alphabetical listing of trigrams. with the following for each: (a) T-L value (taken in same manner as bigram value): (b) $\mathrm{U}$ value (taken in same manner as bigram value): (c) frequency from Pratt (1939) sample based on 20.000 words: and (d) total value, combining frequencies from the 3 samples.

(3) Alphabetical listing of all single letters. with total frequency from the $U$ count in addition to frequency of occurrence ranks for the following 5 word counts: (a) $U$ count. (b) $T-L$ count. (c) Encyclopedia Americana (1956). (d) Lysing (1936). and (e) Attneave (1953).

(4) Rank-order correlations for frequency of single-letter occurrence in the 5 samples listed above.

(5) Frequency distribution of bigrams for T.L and U counts separately.

(6) Rank-order correlations for frequency of bigrams for $T \cdot L$ and $\mathrm{U}$ counts. separately. considering only those beginning with the following letters: A, G. M. N. S, W, and X.

(7) Comparison of frequency distribution of trigrams for $T \cdot L$ and $\mathrm{U}$ counts.

(8) Comparison of frequency distribution of trigrams for $U$ and Pratt counts.

(9) Correlation between $T-L$ and $U$ counts on frequency of 13 sets of systematically sampled trigrams.

(10) Correlation between $U$ and Pratt counts on frequency of 13 sets of systematically sampled trigrams.

111) Count of the overlap in trigram occurrence among 3 counts. with frequencies and percents for each of the following: (a) $T-L$ count only, (b) $U$ count only, (c) Pratt count only, (d) T-L and $U$ counts. (e) T-L and Pratt counts. (f) $U$ and Pratt counts, and (g) all 3 counts.

(12) Rank-order correlation between frequency of consonant in CVCs is. written English. for 3 association value levels of CVCs (from Glaze).

113) Rank-order correlation between frequency of consonant in CCCs is. wirten English. for 3 association value levels of CCCs Ifrom Witmeri.
(14) Studies on the effects of objective frequency, rated frequency. meaningfulness. and pronounceability on learning.

\section{Stimulus Material}

$$
\text { Pronounceablity Ratings - Study } 1
$$

178 CCCs and CVCs

\section{Subjects}

181 (Northuestern Liniersity)

\section{Taak}

Each subject rated each trigram "... as to the relative ease or relative difficulty of pronouncing it" on a 9-point scale.

\section{Stinulas Material}

$$
\text { Pronounceablity Rateog - Study } 2
$$

95 CCCs and CVCs. 34 from Study 1 and 61 new ones. Subjects

70 (Northwestern University).

\section{Task}

Standard instructions $(\mathbf{N}=35)$. Same as in Study 1.

Special instructions $(N=35)$. Same as in Study 1 plus the subjects were warned to avoid rating pronounceability on the basis of frequency or familiarity dimension.

Data

(1) Rank-order correlation of mean scale values for the 2 instruction groups of Study 2.

(2) Alphabetical listing of 239 trigrams used in both studies. along with mean pronunciation ratings (NOTE: where the trigram was from Study 2 only, just the data from subjects in the standard instruction group were included).

\section{Stimalus Materials}

\section{Letter Sequence Amociations - Study 1}

26 lents of the alphabet: 676 bigrams (all possible 2-letter combinations).

Subjects

273 (Northwestern University).

Task

Each subject gave a single-letter association to each of the 702 stimuli (single letters and bigrams). purting down "... the letter which to you seems to follow. as quickly as you can."

Date

(1) Alphabetical listing of each letter of the alphabet along with the frequency with which every other letter was given as a response to it.

(2) Alphabetical listing of each 2-letter stimulus with the frequency with which every letter was given as a response to it.

(3) Reliability comparisons between 2 subgroups of subjects.

\section{Stimulas Material}

$$
\text { Letter Sequence Amocintions - Study } 2
$$

26 single letters of the alphabet: 119 bigrams. representative of those in Study 1.

Sabjects

Terk

67 (University of California at Berkeley).

Regular instructions (UC-R) ( $N=84)$. Same as letter sequence associations-Study 1 .

Language instructions (UC.L) $(N=83)$. Each subject was asked to imagine the letter(s) as beginning a word and to fill in the letter most likely to follow in the word (without actually imagining any specific words).

\section{Data: Single-Letter Data}

(1) Alphabetical listing of all single letters and the percent of time which each single letter occurred as a response to single-letter stimuli. separately for the Study 1 (NU). UC.R, and UC.L groups.

(2) Rank-order correlations among NU, UC.R, and UC-L on the single-letter responses to single-letter stimuli.

(3) Alphabetical listing of all contiguous alphabetical pairs (i.e. A-B. B-C. C-D. etc.) with the frequency of each pair's occurrence (as stimulus and response) for single-letter stimuli, separately for UC.R and UC.L.

(4) Rank-order correlation: frequency of a response to all single-letter stimuli with the cotal frequency in the language (from U count). separately for NU. UC-R. and UC.L. 
(5) Rank-order correlation: frequency of a response to all single-letter stimuli with the frequency of that letter as the second letter in a word (as derived from the original data of the $U$ count), separately for NU, UC-R, and UC-L.

(6) Plot of frequency with which each letter occurred in the language and the frequency with which each letter occurred as a response to single-letter stimuli.

(7) Percent of the time that vowels and consonants were given as responses to single-letter vowels and consonants, in each of 4 cases: (a) NU sample, (b) UC-R sample, (c) UC-L sample, and (d) words (from U count).

(8) Rank-order correlation: frequency of specific letter response when the single-letter stimulus was a vowel, comparing NU, UC-R, and UC-L.

(9) Rank-order correlation: same as above, except using consonant single-letter stimuli.

(10) Relationship between 4 predictor variables and response frequency of each letter to each of 10 single-letter stimuli.

\section{Data: Blgram Stimuli}

(1) Alphabetical listing of all single letters with the following for each: (a) percent of the time it was a response to bigrams; and (b) percent of the time it was the maximal frequency response in the NU sample.

(2) Rank-order correlation between the 2 measures in (1).

(3) Response frequencies to bigrams completing initials of 23 well-known institutions.

(4) Percent of time in the language with which a vowel (V) or consonant $(\mathrm{C})$ follows $\mathrm{VV}, \mathrm{VC}, \mathrm{CV}$, and $\mathrm{CC}$, considering both instances where (a) the 2 letters were first in a word, and (b) all letter sequences in the language are considered.

(5) Rank-order correlations: frequency of individual letters given to each of the following (comparing NU, UC-R, UC-L, and words, in each case): (a) 5 selected VVs, (b) 5 selected VCs. (c) 7 selected CVs. and (d) 6 selected CCs.

(6) Mean maximal frequency of response to bigram stimuli as a function of number of different letters which follow the bigram sequences in words.

(7) Mean frequency of first. second, and third most frequently given letter when (a) 19 or more letters follow the bigram sequence in words and (b) no letters follow the sequence in words.

(8) Actual association value compared with generated association value (obtained by summing the frequencies of the number of times the second letter was given as a response to the first and the third given as a response to the first 2 , from the norms) for several association levels from Witmer and Glaze.

(9) Mean number of subjects responding with the second letter of a 3-letter word when the first was the stimulus and with the third letter when the first 2 were the stimuli and the overall total, as a function of the frequency of the word according to Thorndike and Lorge ( 6 frequency levels represented).

(10) Series of experiments on the relationship of letter association and learning.

\section{6}

W Allenhorst, $R$. Some relations between reaction time and choice of response in word association. Psychological Reports, $1965,17,619-626$

Stimulus Materials

100 words (from 5 published studies).

\section{Subjects}

50 (Canisius College); 50 (D'Youville College)

Task

Each subject gave a single-word oral free association response to each stimulus, presented orally.

Data

(1) Listing of all 100 words, in increasing order of mean associative reaction time (RT), with the following for each: (a) position in the presentation list, (b) mean RT, and (c) standard deviation of the RT.

(2) Overall mean, median, and range of RTs.
(3) Correlations: (a) fastest RT with mean RT (for each subject), and (b) slowest RT with mean RT (for each subject).

(4) Comparisons of male and female RTs.

(5) Examination of frequency difference (according to Thorndike and Lorge, 1944, norms) as a factor in RT.

(6) Examination of each of the following factors concerning response type: (a) communality, (b) idiosyncracy, (c) systematic perseveration, and (d) associative disturbances.

\section{7}

WeSt, M. A general service list of English words. London: Longmans, Green, 1953.

Stimulus Materials

2.000 "general service" words, considered suitable as the basis of vocabulary for learning English as a foreign language.

Task

Summing frequency of occurrence of each meaning of each word in a pool of 5 million written words ( 2 counts of $2 \frac{1 / 2}{2}$ million words were combined).

Data

Alphabetical listing of 2,000 words, with the following for each:

(1) Part(s) of speech.

(2) Frequency of occurrence in 5 million words (NOTE: an " $e$ " after the number means it was based on only $2 \frac{1}{2}$ million; an asterisk after the number means it was based on an indeterminant number).

(3) A listing of all the different meanings of the word and the percent of its total occurrences where that meaning was employed (NOTE: on single-meaning words, the percent is sometimes omitted, indicating $100 \%$ ).

\section{8}

Whitney, W. D. Oriental and linguistic studies. New York: Scribner's, 1974

\section{Stimulus Materials}

5 poetry passages and 5 prose passages, all from classical literature (Shakespeare, Milton, Bible. etc.).

Data

(1) Listing of 44 basic sounds, in decreasing order of frequency, with the following for each: (a) whether they were vowels or consonants; (b) percent of the total number of sound occurrences which they comprised; (c) listing of the passage(s) where the greatest percent occurrence was, along with the actual percent; and (d) listing of the passage(s) where the smallest percent occurrence was, along with the actual percent.

(2) Listing of different classes of consonants and vowels, along with the percent of occurrences under each.

(3) Average number of syllables per word, sounds per word, and consonants per syllable.

\section{9}

Williams, J. E. Connotations of color names among Negroes and Caucasians. Perceptual and Motor Skills, 1964, 18, 721-731.

\section{Stimulus Material}

10 different colors: 5 race related (white, black, brown, yellow, and red) and 5 control (blue. green, purple, orange, and gray).

Subjects

116 Caucasians (Wake Forest College); 70 Caucasians (Washburn University); 110 Negroes (Winston-Salem State University).

Task

Each subject rated each color using 12 different 7-point semantic differential scales.

Data

(1) Listing of all 10 colors (by group), with mean ratings for each semantic differential factor (evaluation, potency, and activity) separately for each group of subjects.

(2) Comparisons within white race (contrasting 2 subject samples). 
(3) Comparisons between race separatcly for race-related and control colors (separate examinations of evaluation, potency. and activity scores within each color class).

\section{0}

Witmer. L. R. The association value of three place consonant syllables. Joumal of Genetic Psychology, 1935, 47, 337-360.

\section{Stimulas Material}

4.534 CCCs; all possible combinations with " $Y$ " and " $V$ " excluded. and the additional restrictions that (a) the same letter is not used twice in one CCC. and (b) 2 letters which occur next to each other in the alphabet not occur adjacently in the CCC.

Subjects Task

24 (Yale College and Sheffiedd Scientific School).

Each subject responded to each $\mathrm{CCC}$ by (a) saying a word or a phrase which described what the CCC meant. or (b) saying "yes" if the meaning was too long for the $4 \mathrm{sec}$ allowed, or if it was unrecallable at the moment, or (c) saying nothing if it had no meaning. CCCs were presented one every 4 sec on a memory drum, and the subjects responded orally to each; 61 -h sessions were needed (on 6 separate days); 15 practice trigrams were given (common abbreviations).

Data

(1) Listing of all 4,534 CCCs, alphabetically within one of 25 association value categories (depending on how many of the 24 subjects gave a response to it).

(2) Graphical comparison of the number of syllables at each association value which evoked a response based on 2 of its letters vs. 3 of its letters (inferred by author).

(3) Comparisons of present study with Glaze (1928) in terms of the distribution of association values across the range.

(4) Correlation of total number of responses with both

(a) intelligence and (b) vocabulary size of the subject.

(5) Critical ratios of the difference between all possible pairs of association values.

\section{1}

WoOdrow, H., \& Lowell, F. Children's association frequency tables. Psychological Monographs, 1916, 22(Whole No. 97).

Stimulus Materials

100 words: 90 from Kent and Rosanoff (1910) plus 10 new ones. Subjects

2.000 child ren from 9 to 12 years old, inclusive, from 20 different Minneapolis schools (grades 4 and 5 only).

Task

Written test $(\mathrm{N}=1,000)$. Each subject was given each of the 100 words orally, to which they made a single-word free association response in writing.

Oral test $(\mathrm{N}=1,000)$. Each subject was given each of 9 words orally. to which they made a single-word oral free association response.

Data

(1) Listing of all 100 words, with an alphabetical listing of all responses given, as well as the frequency of each, for the written group: for the first 9 words, the frequency for the oral group was also given

(2) Listing of all 100 words, with the number of failures to respond for each, for written group (and oral group, where applicable).

(3) Listing of all 100 words, with the 3 most popular responses at each of 4 age levels.

(4) Extensive comparisons of adult and child associations as broken down into 22 types of associations (i.e.. supercrdination. contrast, cause-effect, etc.).

(5) Listing of all 100 words, with the preferred responses (4 to 6 per stimulus) of adults listed in decreasing order of frequency, with both child and adult frequencies for each response.

(6) Listing of all 100 words, with the number of idiosyncratic responses for both adults and children.
(7) Listing of all 100 words. with the total number of different responses to each for adults and children.

(8) Comparison of written and oral responses for 9 words in terms of (a) association types [see (4)], (b) 3 most frequent responses, (c) number of idiosyncratic responses, and (d) total number of different responses.

172

ZechMeIster, E. B. Orthographic distinctiveness. Journal of Verbal Learning and Verbal Behavior, 1969, 8, 754-761.

\section{Stimulus Materials}

150 5-letter words chosen from Thorndike and Lorge (1944) which occurred 12 or less times in 18 million.

Subjects

294 (Northwestern University).

Task

Orthographic group $(\mathrm{N}=138)$. Each subject rated each word on the relative distinctiveness which it evidenced, among the other words, on a 9-point scale.

Pronounce group $(\mathrm{N}=156)$. Each subject rated each word on a 9-point pronounceability scale, using the Underwood and Schulz (1960) technique.

Data

(1) Alphabetical listing of all 150 words, with the following for each: (a) mean and standard deviation of orthographic rating; (b) mean and standard deviation of pronunciation rating; and (c) total bigram frequency count, from Underwood and Schulz.

(2) Reliabilities of both types of ratings.

(3) Correlation between both types of ratings.

(4) Extensive analysis of the contribution of bigram frequency to the ratings of orthographic distinctiveness.

(5) Examination of the contribution of "type font" to the ratings of orthographic distinctiveness.

\section{REFERENCES}

ANDERson, N. S. Associations to various things. Paper read at Psychonomic Sockty. New York. September 1961.

Atrneave, F. A method of graded dichotomies for the scaling of judgments. Psychological Review, 1949. 56, 334-340.

Badia, P., Rosenberg, B. G., \& Langer, J. Representational value, meaningfulness, and pronounceability in serial learning. Psychological Reports, 1965, 16, 997-1000.

Battig, W. F. Paired-associate learning under simultaneous repetition and nonrepetition conditions. Joumal of Experimental Psychology, 1962. 64. 87.93.

Battig, W. F., \& BRACKett, H. R. Comparison of anticipation and recall methods in paired-associate learning. Psychological Reports, 1961, 9. 59.65.

Bousfield, W. A., Cohen, B. H., \& Witmarsh, G. A Cultural norms for verbal items in 43 categories. Technical Report No. 22, ONR Contract Nonr-631. University of Connecticut. 1957.

Brown, W. P. Emotional indicators in word association. British Journal of Psychology, 1965, 56, 401-412.

Brown, W. P., \& OGLE, W. C. Latencies in single word and continuous association. Psychological Reports, 1966, 19. 172.

Carroll, J. B., \& White, M. N. Word frequency and age of acquisition as determiners of picture-naming latency. Quarterly Journal of Experimental Psychology, 1973, 25, 85-95.

Carroll, J. B., Davies, P.. \& Richman, B. The American heritage word frequency book. Boston: Houghton Mifflin, 1971.

ClaRke, F. R. Constant ratio rule for confusion matrices in speech communication. Joumal of the Acoustical Society of America, 1957, 29. 715-720.

Cohen, B. H., Bousfield, W. A. \& Witmarsh, G. A. Cultural norms for verbal items in 43 categories. Technical Report No. 22, 1957, University of Connecticut, Contract No. Nonr 631 (00), Oftice of Naval Research.

ConRad, R. Acoustic confusions in immediate memory. British Journal of Psychology, 1964, 55. 75-84. 
DUNLAP. K. List of 43,200 dissyllable words and paralogs. Washington, D.C: National Research Council, 1933.

Fallows, F. R. A complete dictionary of synonyms and antonyms. New York: Fleming $\mathrm{H}$. Revell, 1898.

Fillenbaum. S., \& Jones, L. V. Grammatical contingencies in word association. Journal of Verbal Learning and Verbal Behavior, 1965, 4, 248-255.

FitTs, P. M.. \& SWITZER, G. Cognitive aspects of information processing. Journal of Experimental Psychology, 1962, 63 321-329.

Fries, C. C. The structure of English. New York: Harcourt Brace, 1952.

GorfeIN, D. S. Measurement of the pronounciability of CVC syllables. Psychological Reports, 1967, 21, 879-880.

Gulliksen, H. Theory of mental tests. New York: Wiley, 1959.

Jones, L. V., \& Fillenbaum, S. Grammatically classified word associations. Research memo, No. 15, Psychology Laboratory. University of North Carolina, 1964.

Jones, L. V., Goodman, M. F., \& Wepman, J. M. The classification of parts of speech for the characterization of aphasia. Language and Speech, 1963, 6, 94-107.

Keller, K. C.. \& SAPorta. S. The frequency of consonant clusters in Chontal. International Journal of American Linguistics, 1957, 23, 28-35.

JunG, C. G. The association method. American Journal of Psychology, 1910, 21, 219-269.

Lysing, H. Secret writing: An introduction to cryptograms. cipher, and codes. New York: Kemp, 1936.

Noble, C. E. Emotionality $(e)$ and meaningfulness $(m)$. Psychological Reports, 1958, 4, 16.

Osgood. C. E., Archer, W. K., \& Miron, M. S. The crosscultural generality of meaning systems. Mimeo report. Institute of Communication Research, University of Illinois, 1962.

Palvio, A. Abstractness, imagery, and meaningfulness in pairedassociate learning. Journal of Verbal Learning and Verbal Behavior, 1965, 4, 32-38.
Paivio, A., Yuille, J. C., \& Smythe, P. C. Stimulus and response abstractness, imagery, and meaningfulness, and reported mediators in paired-associate learning. Canadian Journal of Psychology, 1966, 20, 362-377.

PRATT, F. Secret and urgent. Indianapolis: Bobbs-Merrill, 1939.

RaPaport, D., Gill, M., \& Schafer, R. Diagnostic psychological testing (Vol. 2). Chicago: Year Book Publishers, 1946.

Rohrman, N. L. The role of syntactic structure in the recall of English nomalizations. Journal of Verbal Learning and Verbal Behavior, 1968, 7, 904-912.

Russell, W. A., \& Jenkins, J. J. Associative frequencies for Kent-Rosanoff stimuli and responses under various conditions. Unpublished mimeo, 1953.

Russell, W. A., \& Jenkins, J. J. The complete Minnesota norms for responses to 100 words from the Kent-Rosanoff word association test. Technical Report No. 11, University of Minnesota, Contract N8-ONR-66216, 1954.

Shannon, C. E. A mathematical theory of communication. Bell System Technical Journal, 1948, 27, 379-423.

SHAPIRO, B. J. The subjective estimation of relative word frequency. Journal of Verbal Learning and Verbal Behavior. 1969. 8, 248-251.

Smith, M. G., \& Harleston, B. W. Stimulus abstractness and emotionality as determinants of behavioral and physiological responses in a word-association task. Journal of Verbal Learning and Verbal Behavior, 1966, 5, 309-313.

SMITH, W. W. The measurement of emotion. London: Kegan Paul. 1922.

TAYLOR, J. Meaningfulness of 320 words and paralogs. Unpublished doctoral dissertation, Duke University, 1959.

Thorndike, E. L. The teacher's word book. New York: Columbia University, 1921.

(Received for publication January 29, 1975; accepted March 7, 1975.) 